\title{
Recent advances in carbon capture storage and utilisation technologies: a review
}

\author{
Ahmed I. Osman ${ }^{1}$ (1) $\cdot$ Mahmoud Hefny ${ }^{2,3} \cdot$ M. I. A. Abdel Maksoud ${ }^{4} \cdot$ Ahmed M. Elgarahy $^{5,6} \cdot$ David W. Rooney $^{1}$
}

Received: 3 October 2020 / Accepted: 30 October 2020 / Published online: 22 November 2020

(c) The Author(s) 2020

\begin{abstract}
Human activities have led to a massive increase in $\mathrm{CO}_{2}$ emissions as a primary greenhouse gas that is contributing to climate change with higher than $1{ }^{\circ} \mathrm{C}$ global warming than that of the pre-industrial level. We evaluate the three major technologies that are utilised for carbon capture: pre-combustion, post-combustion and oxyfuel combustion. We review the advances in carbon capture, storage and utilisation. We compare carbon uptake technologies with techniques of carbon dioxide separation. Monoethanolamine is the most common carbon sorbent; yet it requires a high regeneration energy of $3.5 \mathrm{GJ}$ per tonne of $\mathrm{CO}_{2}$. Alternatively, recent advances in sorbent technology reveal novel solvents such as a modulated amine blend with lower regeneration energy of $2.17 \mathrm{GJ}$ per tonne of $\mathrm{CO}_{2}$. Graphene-type materials show $\mathrm{CO}_{2}$ adsorption capacity of $0.07 \mathrm{~mol} / \mathrm{g}$, which is 10 times higher than that of specific types of activated carbon, zeolites and metal-organic frameworks. $\mathrm{CO}_{2}$ geosequestration provides an efficient and long-term strategy for storing the captured $\mathrm{CO}_{2}$ in geological formations with a global storage capacity factor at a Gt-scale within operational timescales. Regarding the utilisation route, currently, the gross global utilisation of $\mathrm{CO}_{2}$ is lower than 200 million tonnes per year, which is roughly negligible compared with the extent of global anthropogenic $\mathrm{CO}_{2}$ emissions, which is higher than 32,000 million tonnes per year. Herein, we review different $\mathrm{CO}_{2}$ utilisation methods such as direct routes, i.e. beverage carbonation, food packaging and oil recovery, chemical industries and fuels. Moreover, we investigated additional $\mathrm{CO}_{2}$ utilisation for base-load power generation, seasonal energy storage, and district cooling and cryogenic direct air $\mathrm{CO}_{2}$ capture using geothermal energy. Through bibliometric mapping, we identified the research gap in the literature within this field which requires future investigations, for instance, designing new and stable ionic liquids, pore size and selectivity of metal-organic frameworks and enhancing the adsorption capacity of novel solvents. Moreover, areas such as techno-economic evaluation of novel solvents, process design and dynamic simulation require further effort as well as research and development before pilot- and commercial-scale trials.
\end{abstract}

Keywords Carbon capture and storage $\cdot \mathrm{CCUS} \cdot \mathrm{CO}_{2}$ capture $\cdot$ Geothermal energy $\cdot$ Energy storage $\cdot$ Pre-combustion . Oxyfuel combustion $\cdot$ Post-combustion $\cdot$ Hydrogen $\cdot$ Ionic liquids $\cdot$ Metal-organic frameworks $\cdot$ Geosequestration

Ahmed I. Osman

aosmanahmed01@qub.ac.uk

1 School of Chemistry and Chemical Engineering, Queen's University Belfast, Belfast BT9 5AG, Northern Ireland, UK

2 Geothermal Energy and Geofluids, Department of Earth Sciences, ETH Zurich, Zurich, Switzerland

3 Geology Department, South Valley University, Qena, Egypt

4 Materials Science Laboratory, Radiation Physics Department, National Center for Radiation Research and Technology (NCRRT), Egyptian Atomic Energy Authority, Cairo, Egypt

5 Egyptian propylene and polypropylene company (EPPC), Port-Said, Egypt

6 Environmental Science Department, Faculty of Science, Port-Said University, Port-Said, Egypt

$\begin{array}{ll}\text { Abbreviations } \\ \text { BECCS } & \text { Bioenergy carbon capture and storage } \\ \text { CMSMs } & \text { Carbon molecular sieve membranes } \\ \text { CAMD } & \text { Computer-aided molecular design } \\ \text { IGCC } & \text { Integrated gasification combined cycle } \\ \text { IAST } & \text { large ideal adsorption solution theory } \\ \text { TRL } & \text { Technology readiness level } \\ \mathrm{MOFs} & \text { Metal-organic frameworks } \\ \mathrm{MAB} & \text { Modulated amine blend } \\ \mathrm{CH}_{4} & \text { Methane } \\ \mathrm{Mt} & \text { Million tons } \\ \mathrm{NO} x & \text { Nitrogen oxide gas emissions } \\ \mathrm{CO}_{2} & \text { Carbon dioxide } \\ \mathrm{K}_{2} \mathrm{CO}_{3} & \text { Potassium carbonate } \\ \mathrm{WGSR} & \text { Water-gas shift reaction }\end{array}$

Abbreviations

BECCS Bioenergy carbon capture and storage

CMSMs Carbon molecular sieve membranes

CAMD Computer-aided molecular design

IGCC Integrated gasification combined cycle

IAST large ideal adsorption solution theory

TRL Technology readiness level

MOFs Metal-organic frameworks

MAB Modulated amine blend

$\mathrm{CH}_{4} \quad$ Methane

Mt Million tons

NOx Nitrogen oxide gas emissions

$\mathrm{CO}_{2} \quad$ Carbon dioxide

$\begin{array}{ll}\mathrm{K}_{2} \mathrm{CO}_{3} & \text { Potassium carbonate } \\ \text { WGSR } & \text { Water-gas shift reaction }\end{array}$ 
CPGs $\quad \mathrm{CO}_{2}$-Plume geothermal system

MIEC Mixed ionic-electronic conducting membrane

\section{Introduction}

Renewable energy technologies have been dramatically progressing over the past decade. The levelised cost of electricity for wind and solar energy technologies has been reduced by 66 and $85 \%$, respectively. This means that the levelised cost of energy for solar was approximately six times higher only a decade ago (Lazard 2018). Despite this speed of maturity in renewable technologies, we still rely on fossil-based fuels to generate the global energy demand. The energy demand globally is expected to be nearly met by from fossil-based fuel (coal, natural gas and oil), which constitutes $78 \%$ by 2040 (Cao et al. 2020). While waiting for renewable energy technologies to fully mature enough and replace fossil-based fuel, carbon capture storage and utilisation of fossil-based emissions are crucial as a transition state (Zhang et al. 2016, 2020a). For instance, integrated gasification combined cycle (IGCC) is a common approach coupled with carbon capture and storage in clean coal power plants. In a country such as India, transportation and electricity generation contribute to $45 \%$ of the country's total greenhouse gas emissions (Ashkanani et al. 2020).

Furthermore, coal is considered the current and the future fuel in India, where there are total reserves of approximately 150 gigatons. Thus, the IGCC process along with carbon capture looks crucial. In terms of coal reserves, India comes third globally after the USA and Russia as first and second (Ashkanani et al. 2020). Globally, coal is the largest energy source for electricity generation and the second-largest feedstock source of primary energy (Wei et al. 2020). However, with the current rate of $\mathrm{CO}_{2}$ emissions globally and with a $\mathrm{CO}_{2}$ level in the atmosphere higher than 409 ppm, anthropogenic activities have caused more than $1{ }^{\circ} \mathrm{C}$ global warming than that of the pre-industrial level, of which higher than $0.3{ }^{\circ} \mathrm{C}$ was due to coal-burning (Wei et al. 2020; Osman et al. 2020a). In 2015 the Paris agreement was developed which aims to limit global warming to $2^{\circ} \mathrm{C}$ by 2100 , while attempting to limit the increase to $1.5^{\circ} \mathrm{C}$ (Fawzy et al. 2020). Thus, investigating carbon capture technologies is of great importance as it is considered the only solution to mitigate $\mathrm{CO}_{2}$ emissions from industrial-scale power generation plants, which could lower those emissions by $50 \%$ by 2050 (Wei et al. 2020; Wienchol et al. 2020; International Energy Agency 2008). It is worth noting that the cost of reducing $\mathrm{CO}_{2}$ emissions will dramatically increase by $140 \%$ if carbon capture and storage technologies are not considered (GCCSI 2017).

Three main technologies are being utilised in carbon capture: pre-combustion, post-combustion and oxyfuel combustion routes. Here, the first two routes represent $96.6 \%$ of the literature work until 2018 , while oxy-reforming technology showed only $3.4 \%$ of the total publications (Omoregbe et al. 2020). The utilisation of liquid solvents in pre- and post-combustion technologies is usually done in an absorber packed-bed in a counter-current directions, where the fuel gas (pre-combustion) or the exhausted flue gas (post-combustion) is pumped from the bottom of the reactor to the top, while simultaneously, the flow of the chemical or physical solvent flows from top to bottom. Temperature or a pressure swing is then applied to release the majority of absorbed $\mathrm{CO}_{2}$ from the $\mathrm{CO}_{2}$-rich physical or chemical solvent, while the $\mathrm{CO}_{2}$ lean chemical or physical solvent is sent back to the absorber reactor. Finally, the captured $\mathrm{CO}_{2}$ is compressed and utilised in gas recovery, oil recovery, agriculture, soda ash manufacturing, food industry and production of value-added chemicals and fuels or stored in geological reservoirs or saline aquifers (Ashkanani et al. 2020; Miranda-Barbosa et al. 2017; Tarkowski and UliaszMisiak 2019).

Globally, there are 22 demo projects for carbon capture and storage based on power generation with the majority share of pre- and post-combustion projects, nearly equalling 10 and 9 , respectively. There are only three demo projects based on oxyfuel combustion projects (Vega et al. 2020). In terms of countries that invest in carbon capture and storage, the USA is leading the world with seven projects, and China comes second with five demo projects. For carbon capture technologies to become economic feasible, having adequate carbon pricing is crucial either in carbon tax or carbon allowances. By 2019, carbon tax significantly varied from one country to another, with values ranging from a few dollars to one hundred \$/tonne of $\mathrm{CO}_{2}$. At the same time, pricing for carbon allowances was approximately $\$ 35.4$ per tonne of $\mathrm{CO}_{2}$ equivalent within the European Union Emission Trading Scheme by July 2019 (Kárászová et al. 2020). This value of carbon allowance started at $\$ 5.17 /$ tonne $\mathrm{CO}_{2}$ equivalent in May 2017 and is expected to reach $\$ 47.25 /$ tonne $\mathrm{CO}_{2}$ equivalent by 2023 (Kárászová et al. 2020). Comparing the net present value of various types of power plants integrated with carbon capture technology, pulverised coal was the cheaper option under low carbon prices. Simultaneously, the IGCC power plants were desirable only when the carbon price was high (Huang et al. 2020; Bohm et al. 2007). Thus, the carbon pricing is considered as one of the most effective ways to encourage the deployment of carbon capture and storage technologies.

This review offers the most up-to-date advancements in carbon capture, storage and utilisation technologies to help mitigate climate change. It outlines the advantages and disadvantages of each route with its readiness for commercialisation to decarbonise the industrial sector. Moreover, the review suggests steps and future guidelines from gaps 
in the literature using bibliometric analysis. Overall, this critical review aims to benefit the academics working in the decarbonisation field alongside the policies of carbon capture, storage and utilisation technologies and will focus on themes that face the development and potentially face the commercialisation of capture, storage and utilisation technologies and their future.

\section{$\mathrm{CO}_{2}$ capture technologies}

In carbon capture storage and utilisation, there are mainly three technologies that are being utilised: pre-combustion, oxyfuel combustion and post-combustion technologies.

\section{Pre-combustion}

In this decarbonisation route, traditional fuels (coal or natural gas) are reacting with air or $\mathrm{O}_{2}$ and with or without steam to produce mainly synthesis gas, which is a mixture of carbon monoxide $(\mathrm{CO})$ and hydrogen $\left(\mathrm{H}_{2}\right)$, also known as fuel gas or syngas as shown in Fig. 1. The main two processes for producing syngas are shown in Eqs. (1) and (2) for partial oxidation and steam reforming reactions, respectively (Jansen et al. 2015).

$\mathrm{C}_{\mathrm{n}} \mathrm{H}_{\mathrm{m}}+\frac{\mathrm{n}}{2} \mathrm{O}_{2} \rightarrow \mathrm{nCO}+\left(\frac{\mathrm{m}}{2}\right) \mathrm{H}_{2} \quad \Delta \mathrm{H}_{\mathrm{CH}_{4}}=-36 \mathrm{~kJ} \mathrm{~mol}^{-1}$

$\mathrm{C}_{\mathrm{n}} \mathrm{H}_{\mathrm{m}}+\mathrm{n} \mathrm{H}_{2} \mathrm{O} \rightarrow \mathrm{nCO}+\left(\frac{\mathrm{n}+\mathrm{m}}{2}\right) \mathrm{H}_{2} \quad \Delta \mathrm{H}_{\mathrm{CH}_{4}}=206 \mathrm{~kJ} \mathrm{~mol}^{-1}$
In the case of using steam reforming, the typical reformer products are $43 \% \mathrm{H}_{2}, 11 \% \mathrm{CO}, 21 \% \mathrm{H}_{2} \mathrm{O}$ and $6 \% \mathrm{CO}_{2}$ (Osman et al. 2018a). When the partial oxidation and steam reforming are deployed in pre-combustion simultaneously, the process is called auto-thermal reforming, where the heat released from the exothermic nature of the partial oxidation can drive the endothermic steam reforming reaction. The syngas mixture is then cooled down and cleaned up from impurities such as hydrogen sulphide, hydrochloric acid, mercury and carbonyl sulphide (Cao et al. 2020). The purified syngas is then subjected to the water-gas shift reaction (WGSR) by reacting the $\mathrm{CO}$ with steam $\left(\mathrm{H}_{2} \mathrm{O}\right)$ as shown in Eq. (3), to increase the $\% \mathrm{CO}_{2}$ and facilitate the $\mathrm{CO}_{2}$ separation in later stages along with the production of $\mathrm{H}_{2}$ fuel as decarbonised fuel, which only produces $\mathrm{H}_{2} \mathrm{O}$ when combusted.

$\mathrm{CO}+\mathrm{H}_{2} \mathrm{O} \rightarrow \mathrm{CO}_{2}+\mathrm{H}_{2} \quad \Delta \mathrm{H}=-41 \mathrm{~kJ} \mathrm{~mol}^{-1}$

Finally, $\mathrm{CO}_{2}$ is separated through various physical and chemical absorption processes for either storage or utilisation (Kumar et al. 2018; Li et al. 2019a). In the chemical industry, the pre-combustion approach is mature and has been utilised for $\mathrm{CO}_{2}$ capture for nearly a century (higher than 95 years). For power generation purposes, the $\mathrm{H}_{2}$-rich fuel can be used in a Rankine + Brayton combine cycle plant. Although $\mathrm{CO}_{2}$ separation herein is much easier and requires lower energy than other techniques such as postcombustion, it still needs energy for reforming, air separation and improvements in the efficiency of energy recovery within the process. Additionally, further purification stages

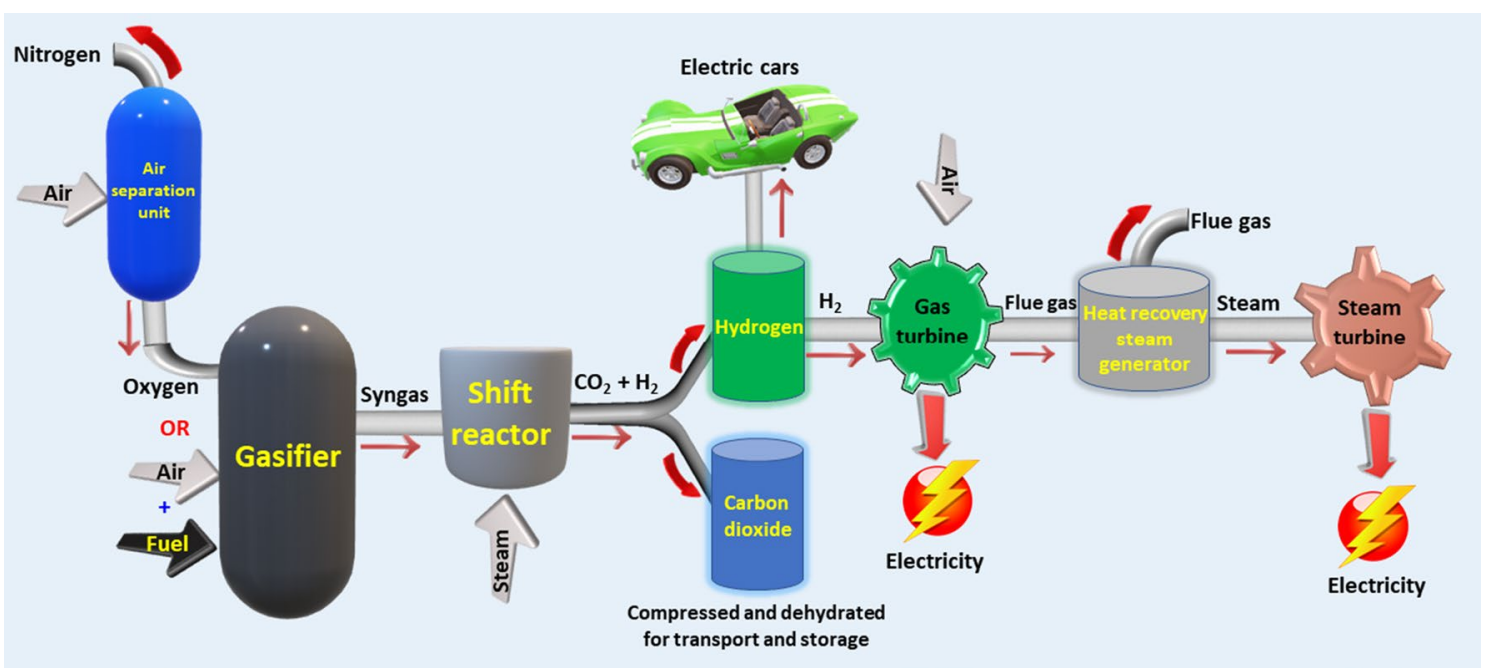

Fig. 1 Pre-combustion technology consists of an air separation unit for oxygen separation (not mandatory). Then the fuel is reacting with air or $\mathrm{O}_{2}$ to produce mainly synthesis gas, which is then sent to the shift reactor unit to produce hydrogen and $\mathrm{CO}_{2}$. The produced hydro- gen can be used to fuel electric cars or to produce electricity through a gas turbine, while the flue gas is sent to the heat recovery and steam generation unit for electricity production. Finally, the $\mathrm{CO}_{2}$ is compressed and dehydrated for transport and storage purposes 
are required when oil or coal is utilised to eliminate impurities, ash and sulphur-containing compounds. In the first generation of the integrated gasification combined cycle (IGCC), the main cause for efficiency loss was the WGSR step, which was responsible for $44 \%$ of the total efficiency loss. This was due to the energy required for steam generation along with the heat released within the WGSR process as it is an equilibrium limited and exothermic process.

On the other hand, $\mathrm{CO}_{2}$ produced through the pre-combustion process is characterised by high pressure. $\mathrm{CO}_{2}$ is then undergoing compression and liquefication for storage or transportation purposes at low power requirements. Moreover, it promotes the production of $\mathrm{H}_{2}$ as a fuel that can be used in fuel cells (after further purification), transportation or as a building block in the production of value-added chemicals (Osman et al. 2020a). Another big benefit of the pre-combustion route is the flexibility of the outputs where $\mathrm{H}_{2}$ production or power generation can easily be switched according to the demand.

The separation of the $\mathrm{H}_{2}$ and $\mathrm{CO}_{2}$ mixture in the precombustion route can be done using physical or chemical absorption techniques via syngas scrubbing using a liquid solvent selective to carbon dioxide and hydrogen sulphide as acid compounds (Jansen et al. 2015). The main common chemical solvent is amine-based, and its absorption capacity is higher at lower partial pressure than that of physical solvents that require higher partial pressure. On the other hand, the physical solvents' loading relies on the partial pressure of the $\mathrm{CO}_{2}$, according to Henry's law. Generally, at low temperatures and high partial pressures, the physical solvents' performance is high as those conditions provide better sorption capacity. Physical solvents suffer from drawbacks such as low $\mathrm{CO}_{2}-\mathrm{H}_{2}$ selectivity, high solvent viscosity, thermal stability, corrosivity, toxicity and flammability (Ashkanani et al. 2020). Regarding low-temperature $\mathrm{CO}_{2}$ separation, many techniques are being deployed, such as cooling, compression, condensation, flashing along with cryogenic distillation that is commercially used in the food industry. However, it is mainly used for highly concentrated $\mathrm{CO}_{2}$ streams (higher than 90\%) and not adequate for dilute $\mathrm{CO}_{2}$ streams.

The purity of the produced hydrogen in the pre-combustion approach is not a priority, while the $\mathrm{CO}_{2}$ separation is . Thus, for high-purity $\mathrm{H}_{2}$ and $\mathrm{CO}_{2}$, advancement in separation technologies is crucial. Adsorptive reactors and membrane reactors are promising where the integration of reaction and separation occurs in a single unit to lower the energy requirement, as well as the formation of by-products, while increasing the overall efficiency of the process. In adsorptive reactor technology, a selective solid $\mathrm{CO}_{2}$ adsorbent is utilised to facilitate the removal of $\mathrm{CO}_{2}$ from the stream and hence, shift the equilibrium reaction towards $\mathrm{H}_{2}$ production. The characteristics for those adsorbents are high $\mathrm{CO}_{2}$ adsorption capacity, mechanically robust, fast sorption, selective and stable during multiple $\mathrm{CO}_{2}$ adsorption and regeneration cycles. For instance, due to the deteriorating $\mathrm{CO}_{2}$ adsorption capacity at elevated temperatures, adsorbents such as zeolites, metal-organic frameworks and activated carbons are not suitable. Various designed adsorbent systems have been utilised, such as promoted calcium carbonate, hydrotalcite and others in that approach. For membrane reactors, the palladium membrane or its alloy is the most commonly used. However, palladium is prone to sulphur poisoning and deactivation even at a lower reaction temperature (Osman et al. 2016), while the silica-based membrane is not, thus, superior in this perspective.

Nevertheless, silica membranes are not stable at high temperatures and pressures. Dense polymeric membranes are cheap materials; however, they are thermally unstable and not selective to hydrogen. In this perspective, the carbon molecular sieve membranes (CMSMs) showed good performance as they are resistant to sulphur poisoning and robust materials. Recently, Cao et al. (2020) integrated both adsorptive reactors and membrane reactors in multiple cycles for the pre-combustion route and showed good performance for 750 hours of syngas exposure and a temperature of $250{ }^{\circ} \mathrm{C}$ and pressure of 25 bar, with CMSMs as adsorptive reactors.

Overall, the pre-combustion technology is promising in carbon capture storage and utilisation, while there are many challenges to improving its overall efficiency. For instance, the solvent regeneration temperature needs to be conducted at a lower temperature than currently used to avoid any reduction in the solvent. Thus, ionic liquids are being utilised to overcome this issue, as they are characterised with their negligible volatility (Zhou et al. 2021; Krishnan et al. 2020; McDonald et al. 2014). On the other hand, selecting the appropriate ionic liquid is not an easy task due to the existence of possible structures from various anion and cation combinations which requires trial and error to find the best separation performance (Lu et al. 2019). For that purpose, computer-aided molecular design (CAMD) is recently being used to find out the best combinations to design ionic liquids structurally. (Zhou et al. 2021) have investigated 10116 solubility data along with 463 hydrogen solubility data from the literature of ionic liquids with modelling to find out the best ionic liquids for pre-combustion technology. They found out that the most promising ionic liquid solvents are hydroxyl $(\mathrm{OH})$-ammonium $\left(\mathrm{NH}_{3}\right)$ and hydroxyl-imidazolium $\left(\left[\mathrm{Tf}_{2} \mathrm{~N}\right]\right)$ bis (trifluoromethyl sulphonyl) amide at $40^{\circ} \mathrm{C}$ and 30 bars according to industrial pre-combustion conditions.

In theory, the pre-combustion route could offer a cheaper cost than that of post-combustion and oxyfuel combustion routes by $38-45$ and $21-24 \%$, respectively (Portillo et al. 2019). However, due to the retrofitting of current facilities, this added costing and complexity to the set-up process have limited its commercialisation. 


\section{Oxyfuel combustion}

In the oxyfuel combustion route, the carbon-based fuel is combusted in re-circulated flue gas and pure oxygen $\left(\mathrm{O}_{2}\right)$ stream, rather than air, hence limiting its commercialisation potential due to the high cost of $\mathrm{O}_{2}$ separation and production as shown in Fig. 2. However, the $\mathrm{CO}_{2}$ capture and separation are easy, and the oxyfuel combustion method is considered as the most promising energy-efficient route among the main three methods (pre-, post- and oxyfuel), with a low-efficiency penalty of $4 \%$ compared with $8-12 \%$ for the post-combustion route (Wienchol et al. 2020). The reduction in the volume of exhausted flue gas and nitrogen gas emissions (NOx) along with the increasing boiler efficiency can be achieved by applying the oxyfuel combustion route in power systems. One big challenge in such a route is the supply of pure oxygen as its separation is an energy-intensive and costly process in the air separation unit. For example, cryogenic distillation is the only proven technology for producing a large amount of $\mathrm{O}_{2}$ with high purity for large-scale utilisation (Chen et al. 2019). Thus, investigating new novel routes of air separation is quite important herein, such as ion-transport and oxygen-transport membranes along with chemical looping methods (Shin and Kang 2018; Martinez and Hesse 2016; Chen et al. 2018a; Shi et al. 2018). To resolve the problem associated with the energy needed for cryogenic air separation, oxygen-transport membranes were introduced, known as the mixed ionic-electronic conducting membrane (MIEC) (Portillo et al. 2019; Kotowicz and Balicki 2014). Carbo et al. reported that the inclusion of oxygen-transport membranes in oxyfuel combustion could reach an economic saving in the range of $19-50 \%$, compared to that of post-combustion technology (Carbo et al. 2009). There is recently a drastic increase in publications concerned with oxygen-transport membranes, where an average publications in 1985 were 30 publications compared to 200 in 2012 (Portillo et al. 2019).

Interestingly, the utilisation of the chemical looping method can enhance the net power plant efficiency by $3 \%$ when employed in oxyfired along with IGCC and instead of the air separation unit. Furthermore, capital costing of the power plant and electricity costing will decrease by $10-18$ and 7-12\%, respectively (Wienchol et al. 2020; Cormos 2020). One such advantage of using the oxyfuel combustion route is that it can be employed in current or new power plants along with utilisation of various types of fuels such as municipal solid waste or lignocellulosic biomass.

The integration between bioenergy and carbon capture and storage is called BioCCS or BECCS, leading to a negative carbon approach for climate change mitigation. It was reported that in oxyfuel combustion of lignocellulosic biomass, the accumulative emissions of $\mathrm{CO}_{2}$ of net electricity production was $-0.27 \mathrm{kgCO}_{2} \mathrm{MJel}^{-1}$ (Gładysz and Ziębik 2016). While the integration of carbon capture along with municipal solid waste incineration has led to emissions of $-0.70 \mathrm{kgCO}_{2}, \mathrm{eq} \mathrm{kg}^{-1}$ of wet waste feedstock (Pour et al. 2018). This, in turn, showed that BECCS could be an effective way of achieving decarbonisation and the negative carbon technology for climate change abatement along with oxyfuel combustion.

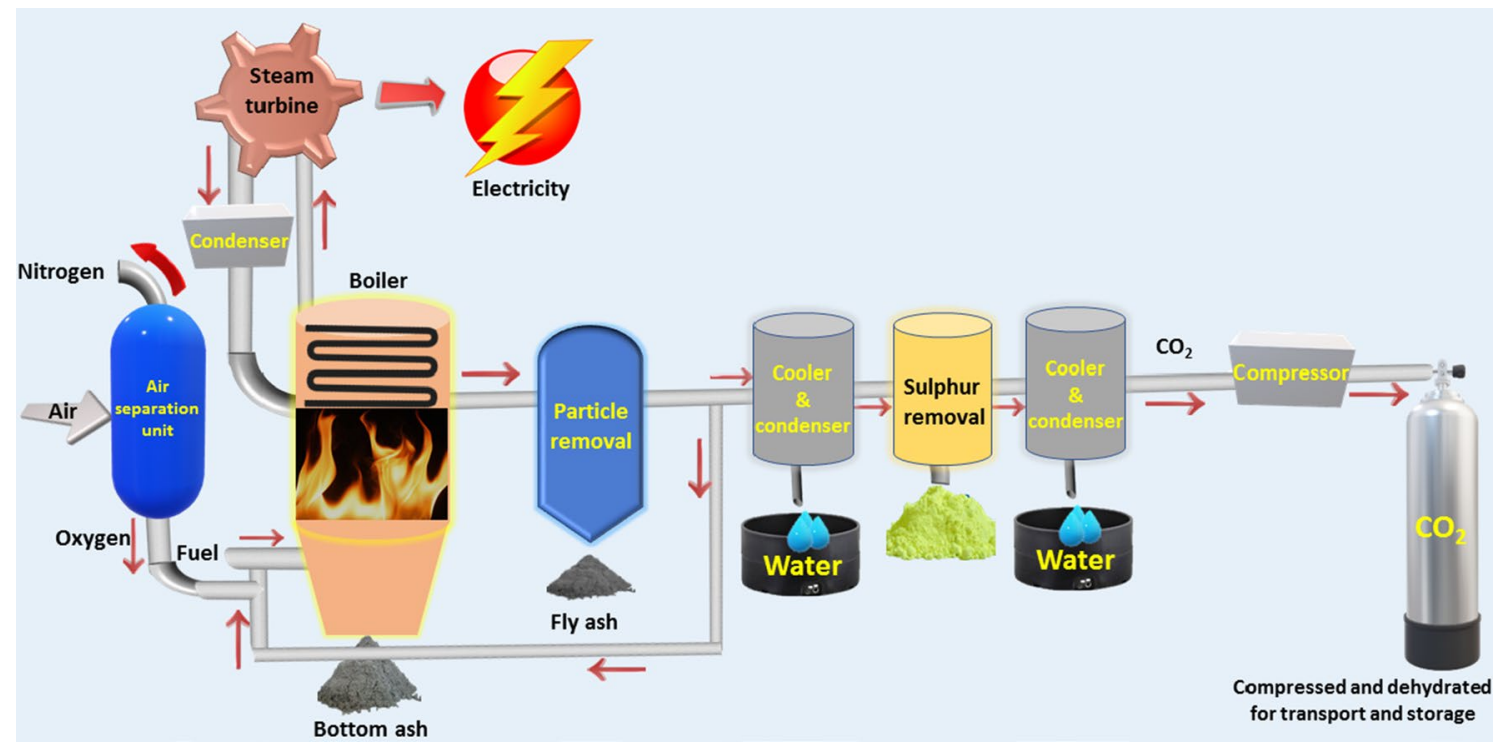

Fig. 2 Oxyfuel combustion technology consists of an air separation unit for oxygen separation (mandatory). Then the carbon-based fuel is combusted in the re-circulated flue gas and pure oxygen $\left(\mathrm{O}_{2}\right)$ stream in a boiler. Then the flue gas is sent to the particle removal unit, followed by the cooler and condenser unit to remove water and then to the sulphur removal unit before sending it again to the cooler and condenser unit. Finally, the $\mathrm{CO}_{2}$ is compressed and dehydrated for transport and storage purposes 
Interestingly, there are twenty BECCS projects globally that include waste-to-energy, ethanol production, combustion of biomass and co-firing, biomass gasification and biogas plants (Pour et al. 2017; Bui et al. 2018c). Nevertheless, still, there are challenges in the BECCS approach, such as the higher cost of biomass compared to fossil-based fuel, such as coal along with high levelised cost of electricity and lower efficiency. When including air separation and $\mathrm{CO}_{2}$ purification and compression units in the oxyfuel combustion system, the cycle efficiency decreases by $9-13 \%$ points as those are energy-intensive units. Thus, to make the overall process attractive for commercialisation, process and heat integrations are inevitable herein. For instance, the utilisation of heat generated from the compressor cooling systems in the units, as mentioned above, along with the steam cycle, showed that it is an effective method in this case (Chen et al. 2019). Moreover, the pressurised oxyfuel combustion cycle showed better performance than that of the traditional atmospheric cycle and could increase the efficiency by $3 \%$ points (Hong et al. 2010).

There is a growing global interest to prove the feasibility of the oxyfuel combustion technology with different demonstration projects and pilot-scale plants being deployed since the last decade; however, capacities are all lower than 100 MWth (Strömberg et al. 2009; Cook 2009). Wei et al. (2020) reported that the utilisation of biomass in oxyfuel combustion using the supercritical $\mathrm{CO}_{2}$ cycle showed a reduction of -3.7 megatonnes of $\mathrm{CO}_{2}$ per annum. Furthermore, BECCS technology will be more economically feasible than fossil-based fuel if the carbon tax is higher than $\$ 28.3$ per tonne of $\mathrm{CO}_{2}$.

\section{Post-combustion}

The capture and separation of dilute $\mathrm{CO}_{2}$ in an oxidant environment from the flue gas of a combustion system is called the post-combustion route (Zhang et al. 2020a, b). Before $\mathrm{CO}_{2}$ capture, the exhaust flue gas emissions go through denitrification and desulphurisation along with dust removal and cooling to prevent solvent degradation (Wu et al. 2020). Then the flue gas containing mainly $\mathrm{CO}_{2}, \mathrm{H}_{2} \mathrm{O}$ and $\mathrm{N}_{2}$, is then fed counter-currently to the absorber that contains the solvent, as shown in Fig. 3. The scrubbed gas is then washed with water, followed by $\mathrm{CO}_{2}$ regeneration. Usually, the captured $\mathrm{CO}_{2}$ is then compressed into supercritical fluid and then transported for storage in geological reservoirs or saline aquifers. As the flow rate of $\mathrm{CO}_{2}$ is high, and its concentration is low in flue gas streams, along with its inherently stable nature, an energy-intensive process is required for solvent regeneration.

Monoethanolamine absorption is considered as the most common and only commercialised method in the post-combustion approach, while other absorbents are used as well, such as 2-amino-2-methyl-1-propanol and $\mathrm{N}$-methyldiethanolamine and others (Karnwiboon et al. 2019; Ochedi et al. 2020). The adsorption route is also used in post-combustion in the form of either temperature swing or pressure swing adsorption processes along with calcium looping (Bui et al. 2018b). Amine solutions are the most common solvents due to their high $\mathrm{CO}_{2}$ absorption capacity and good selectivity towards acidic gases (Rochelle 2009). Nevertheless, they suffer from drawbacks such as the corrosivity of amines, high energy footprint during regeneration, degradation and hence, solvent loss and evaporation. Although the monoethanolamine chemisorption, as mentioned, is the only commercially available method, the capital along with the operating costing herein is expensive; thus, some projects based on that technology have been shut down (Schlissel 2018). To decrease the capital costing associated with the postcombustion technology, membrane separation could be a suitable technology as it requires a low energy need, low carbon footprint, low operational cost and easy retrofitting and scaling up with the current power plants (Vakharia et al. 2018). At the same time, there are many challenges associated with membrane separation, such as water condensation on the membrane, rapid diminution of selectivity and permeance after operation along with emissions (NOx and SOx) that pass through the membrane. Some membranes also suffer from difficult temperature adjustment and fluctuation in humidity that causes a drastic change in the transport characteristics of the membrane (Pfister et al. 2017).

For the adsorption route, metal-organic frameworks (MOFs) possess some interesting characteristics such as the functionalised pore morphology and tailored structures that could work properly in $\mathrm{CO}_{2}$ carbon capture. MOFs materials can exist in higher than 75,000 different structures, which help facilitate specific pore-structure materials for the carbon sequestration approach. Despite that, none of the MOFs materials has been deployed at the industrial scale due to the intense energy required for regeneration and their rapid structure instability (Qazvini and Telfer 2020). MOFs modification could be done through the functionalisation with polar groups or the loading of exposed metal sites within the MOFs structure (Zhou et al. 2019; Ding et al. 2019; Jiang et al. 2019). Furthermore, computational screening modelling strategies are a powerful tool for finding optimum performing materials among thousands of adsorbents, such as MOFs materials. Regarding the vacuum swing adsorption, there is a common relationship between pellet porosity and pellet size for all materials at the optimal adsorbent performance (Farmahini et al. 2020). Furthermore, computational simulations could be used for designing new photo-reactive MOFs materials with high adsorption and desorption capacities. One major drawback of using adsorbents such as MOFs in carbon capture and storage is the energy-intensive nature associated with the desorption process in the form of a large 


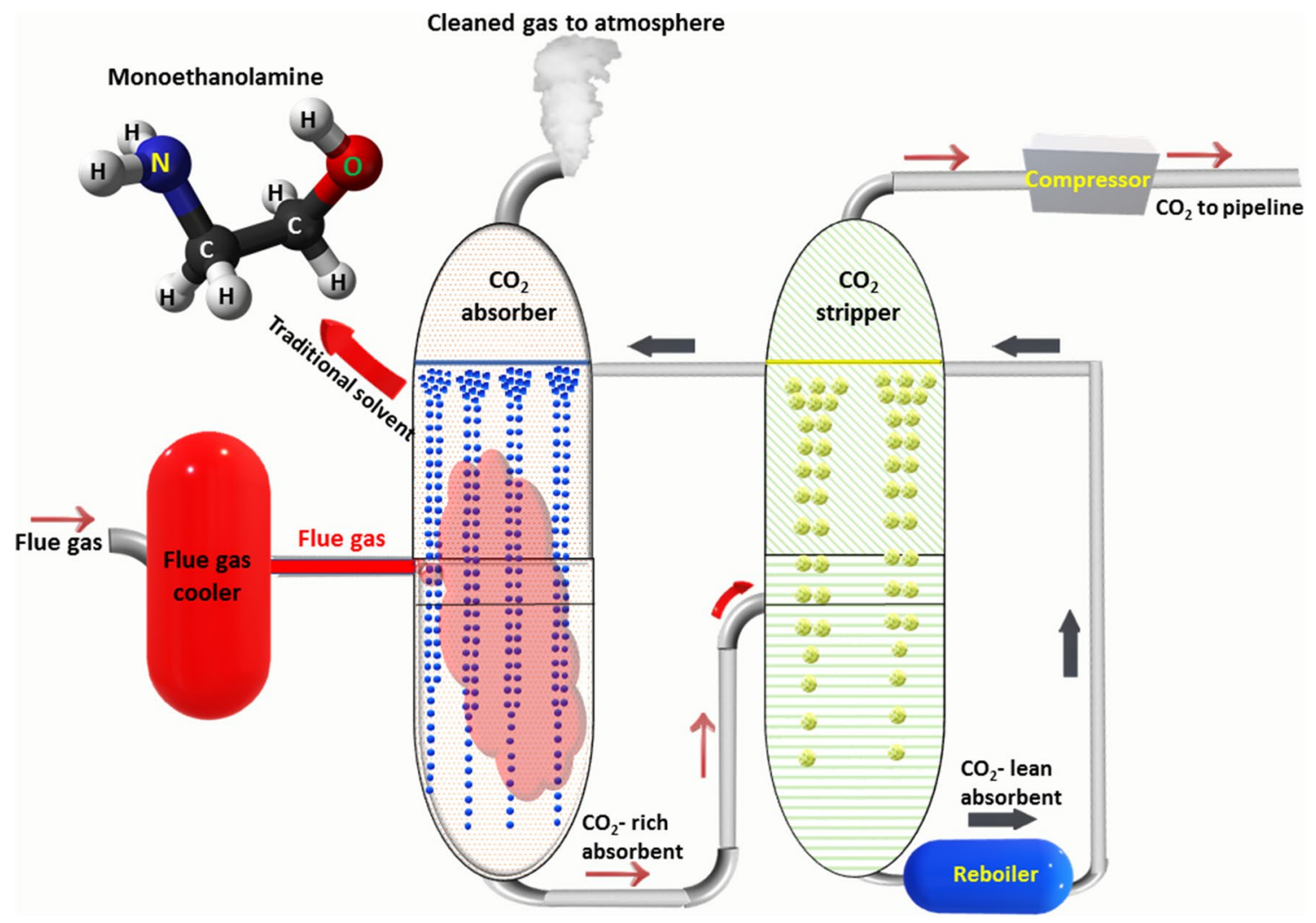

Fig. 3 Post-combustion technology, where the hot flue gas is cooled first and then sent to a $\mathrm{CO}_{2}$-absorber unit that usually contains monoethanolamine solvent as traditional sorbent. Then the $\mathrm{CO}_{2}$-rich absorbent is sent to the $\mathrm{CO}_{2}$-stripper unit to release the $\mathrm{CO}_{2}$ gas,

amount of pressure or temperature swing. Sunlight as an external stimulus can facilitate the desorption process with lower energy demand over photoresponsive MOFs materials such as diarylethene and azobenzene. Park et al. (2020), with the aid of computational modelling, synthesised $\mathrm{Mg}$ IRMOF-74-III (with azopyrdine attached to its unsaturated metal sites) material that showed a $\mathrm{CO}_{2}$ adsorption capacity of $89.6 \mathrm{~cm}^{3} \mathrm{~g}^{-1}$, that is the highest value within photoresponsive MOFs reported in the literature.

Although the pre-combustion technology offers higher efficiency than that of post-combustion technology, it is more expensive. To reduce the cost associated with the precombustion route, finding a superior absorption solvent is crucial. Currently, post-combustion technology is the most mature and widely used route among the three main routes of carbon capture and storage (Wienchol et al. 2020; Wang et al. 2011a). However, due to the dilution of $\mathrm{CO}_{2}$ comes from the flue gas by $\mathrm{N}_{2}$ from the air, this reduces the partial pressure of $\mathrm{CO}_{2}$ and increases the additional cost in the electricity generation by approximately $60-70 \%$ for the new infrastructure or 220-250\% for the retrofitting (Portillo et al. 2019). while the $\mathrm{CO}_{2}$-lean absorbent is sent back to the $\mathrm{CO}_{2}$-absorber unit. Finally, pure $\mathrm{CO}_{2}$ is compressed and dehydrated for transport in pipelines and storage purposes

As mentioned earlier, chemisorption using amine-based solvents is a ready technology for retrofitting of current power plants. Based on that technology, pilot-scale power plants that have been implemented showed a $\mathrm{CO}_{2}$ absorption capacity of 80 tonnes per day (Vega et al. 2020). It is projected that the first integrated commercial carbon capture and storage along with coal-fired power plants will be open by 2020-2025. Consequently, it will be utilised in the rest of the carbon-intensive commercial-scale processes afterward. Vega et al. (2020) compared traditional and novel technologies that are used in carbon capture and storage areas such as post-combustion (traditional) and partial oxy-combustion (novel). At the pilot-scale of the absorption route, novel along with blend solvents have been deployed to reduce the energy footprint of the overall process before demonstration-scale trials. There are desirable properties in novel solvents such as the high cyclic capacities, low production cost, low corrosiveness, lower degradation and thus lower by-products along with the environmental impact. Over the currently deployed pilot power plants, $\mathrm{CO}_{2}$ capacity was in the range of 0.1 to 1 tonne per day at a low capacity level, while the high capacity level showed values in the range of 10-80 tonnes per day (Vega et al. 2020). Shell company 
developed a new $\mathrm{CO}_{2}$ capture method (Shell Cansolv ${ }^{\mathrm{TM}}$ ) based on amine solvent technology (Stéphenne 2014). The proposed technology is appropriate for various industries such as refineries, energy production, mining and chemical industry processes. One such advantage of the CansolvTM solvent is that the required regeneration energy for capturing one tonne of $\mathrm{CO}_{2}$ is in the range of 2.5-2.9 GJ per tonne of $\mathrm{CO}_{2}$. Which is lower than the most common solvent, monoethanolamine, as it showed regeneration energy of 3.5 GJ per tonne of $\mathrm{CO}_{2}$ (Yun et al. 2020; Krishnamurthy 2017; James et al. 2019). Yun et al. investigated the technoeconomic feasibility of monoethanolamine as a traditional absorption solvent and modulated amine blend (MAB) as a novel solvent in the carbon capture and storage technology. The novel solvent has an advantage over the common solvent in the regeneration energy required for capturing one tonne of $\mathrm{CO}_{2}$, which was $2.17 \mathrm{GJ}$ per tonne of $\mathrm{CO}_{2}$, where monoethanolamine common solvent as mentioned earlier showed a value of $3.50 \mathrm{GJ}$ per tonne of $\mathrm{CO}_{2}$. The technoeconomic evaluation revealed that the cost for $\mathrm{CO}_{2}$ capture in the Republic of Korea for monoethanolamine and Modulated Amine Blend solvents were 35.50 and 25.70 per tonnes of $\mathrm{CO}_{2}$, respectively (Yun et al. 2020).

The decarbonisation of the industrial sector will require an assessment of the technology readiness level (TRL) of different carbon capture, storage and utilisation techniques. Pre-combustion (natural gas processing) is the only capture technology that has reached commercial scale (TRL9) (Bui et al. 2018a). Other capture technologies such as adsorption post-combustion, oxyfuel combustion (coal power plants), pre-combustion (IGCC), membrane polymeric (natural gas), BECCS technology and direct air capture are in the demonstration scale (TRL7), while, in pilot-scale (TRL6), there are membrane polymeric (power plants), post-combustion (biphasic solvents), chemical looping combustion as well as calcium carbonate looping technologies. The remaining capture technologies are ranging from laboratory-scale plant (TRL5) to proof of concept (TRL3) such as membrane dense inorganic, oxyfuel combustion (gas turbine), ionic liquid post-combustion and low-temperature separation precombustion technologies.

Regarding carbon storage technology, post-combustion (amine) in power plants, saline formations and $\mathrm{CO}_{2}$ -enhanced oil recovery are the only three technologies that have reached commercial scale (TRL9) (Campbell 2014; Singh and Stéphenne 2014). While other technologies such as $\mathrm{CO}_{2}$-enhanced gas recovery and depleted oil and gas fields are still in the demonstration level (TRL7), other storage technologies such as ocean storage and mineral storage are in infant stages of formulation (TRL2) and proof of concept in laboratory tests (TRL3), respectively. On the other hand, the transport technologies either onshore and offshore pipelines along with transport ships are both mature (TRL9) (Bui et al. 2018a). An important aspect during the early stages of CCUS deployment is the development of appropriate infrastructure, whereby the consolidation of multiple $\mathrm{CO}_{2}$ sources can provide an opportunity to take advantage of economies of scale in carbon capture.

\section{$\mathrm{CO}_{2}$ separation methods from flue gas in combustion capture process}

Numerous exceptional separation techniques are utilised through the combustion method for the $\mathrm{CO}_{2}$ separation of flue gas. These techniques are absorption, microalgae, membrane separation, adsorption and cryogenics (Fig. 4) (Osman et al. 2020a; Li et al. 2012a).

Absorption is an entrenched $\mathrm{CO}_{2}$ separation procedure utilised in the synthetic and petroleum area up to date. Absorption divides into two classifications: (1) physical, where it relies on both temperature and pressure (absorption happens at extraordinary pressures and low value of temperatures), and (2) chemical, where absorption of $\mathrm{CO}_{2}$ relies upon neutralising acid-base response ( $\mathrm{Li}$ et al. 2011c). Remarkable of the favoured solvents are amines (for example, monoethanolamine), solutions of ammonia, Selexol, Rectisol and fluorinated solvents. The common current addition is ionic liquids, which have shown incredible potential in the absorption of $\mathrm{CO}_{2}$ and are likewise eco-friendly (Hasib-ur Rahman et al. 2010).

Microalgae bio fixation is a suitable procedure for the expulsion of $\mathrm{CO}_{2}$ of flue gases. This procedure demands the utilisation of photosynthetic organisms (microalgae) for anthropogenic carbon capture and storage. Marine microalgae have been proposed to be of more prominent potential because they have more distinguished carbon stabilisation rates than land plants (Ben-Mansour et al. 2016). Microalgal culturing is very costly; however, the technique creates different composites of high worth that can be utilised for income production. Microalgal photosynthesis further commands to precipitation of calcium carbonate that can aid as an enduring sink for carbon (Nakamura and Senior 2005).

The separation based on membranes substances depends on the variances in the interactions that occurred within gases and the materials of the membrane, that adjusted to permit several pieces to transfer discriminatory into the membrane (Li et al. 2011c). Membranes have extraordinary merit in $\mathrm{CO}_{2}$ separation in pre-combustion capture and postcombustion $\mathrm{CO}_{2}$ separation. A broad category of diverse membrane materials and methods are obtainable, some of which now on the industrial field, and potentially related to $\mathrm{CO}_{2}$ separation. The enforcement and related cost of technologies based on membrane separation in extensive range $\mathrm{CO}_{2}$ capture principally rely totally on the membrane materials. 


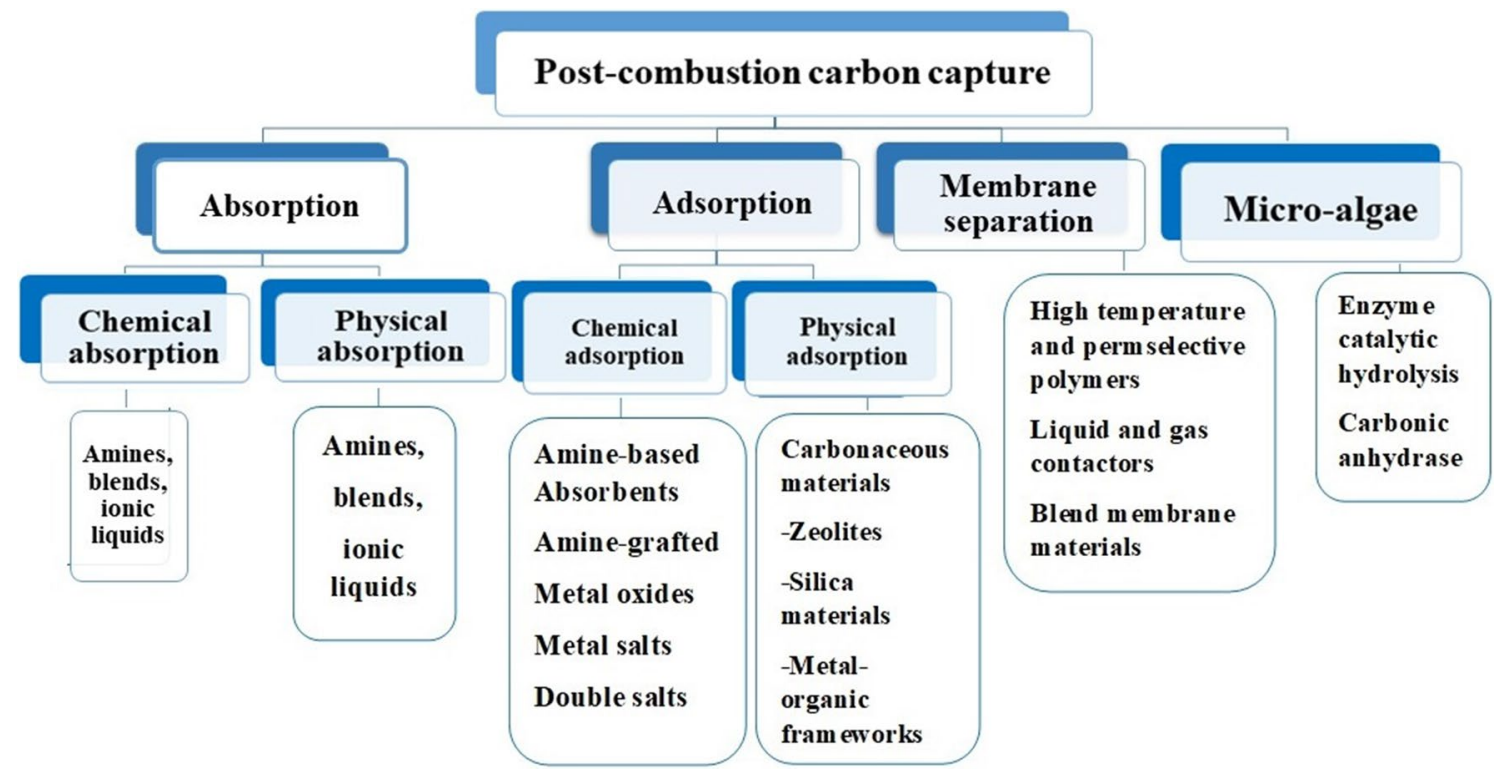

Fig. 4 Technologies and methods that are utilised regularly in $\mathrm{CO}_{2}$ separation. In post-combustion carbon capture technologies, there are many four routes: absorption, adsorption, membrane separation and microalgae

Adsorptive separation is a hybrid separating technique which operates on the principle of varieties in adsorption and desorption properties of the component of the hybrid (Li et al. 2012a). The cryogenic $\mathrm{CO}_{2}$ separation procedure utilises the basis of liquid case temperature and pressure variation in component gases of flue gas. In this procedure, cooling and condensation of $\mathrm{CO}_{2}$ occur, then extracted from the flue gases (Song et al. 2012).

\section{Absorbents and their performance}

Absorption is a technique of transporting the matters from their vapour state to the fluid phase as long as that the vapour is dissolvable in that fluid (Abdeen et al. 2016). In the state of $\mathrm{CO}_{2}$, the solubility of the gas is conditioned on the solvent's physical and chemical features. Contingent upon the solvent utilised, the gas parts can be easily dissolved physically or are bound chemically to the solvent designated as physical or chemical absorption or a hybrid of both processes (Koytsoumpa et al. 2018). If the particles of vaporous of $\mathrm{CO}_{2}$ are combined with liquid particles with inadequate intermolecular forces, the absorption is defined as physical absorption.

Thermal energy demands through chemical solvents are extremely more necessary than those for physical solvents that are attributed to the energy augmented through the reboiler of the stripper column (Koytsoumpa et al. 2018; Jansen et al. 2015). In the case of physical solvents, the loading limit of the solvents is in a practical direct reliance within the partial pressure of the parts to be separated and the solvent loading as indicated by Henry's law, deducting its recovery through pressure throttling. The destruction of $\mathrm{CO}_{2}$ in the physical fluid solution is ascribed to the Van der Waals or interactivity electrostatic and is typical at tremendous pressure and lowered value of temperature (Koytsoumpa et al. 2018; Theo et al. 2016).

The chemical or reactive absorbents comprise amines, blends, ionic liquids, aqueous solvents, ammonia, etc. The blends were then created to merge the positive features of diverse absorbents, and concurrently overcoming their negative features. The physical absorbents comprise solvents like Rectisol, Selexol, etc. To be applied as an absorbent, a solvent should possess the required features such as exceptional reactivity and absorptivity with $\mathrm{CO}_{2}$, great stability below elevated thermal and fixed chemical exposure, moderate vapour pressure, suitable renewability, low environmental impact and cost-effective to apply (Sreedhar et al. 2017a, b). Amines such as monoethanolamine and diethanolamine were the newest and the most usually applied absorbents attributed to their economical cost, excellent reactivity and a remarkable rate of absorption. Nevertheless, they undergo several obstacles like diminishing in the oxidative atmosphere, intense renewal energy demand, restricted $\mathrm{CO}_{2}$ storing potential and corrosive features by foaming and fouling components (van der Zwaan and Smekens 2009).

Gao et al. (2016) have revealed a trial of a $30 \mathrm{wt} \%$ monoethanolamine-methanol compared to aqueous $30 \mathrm{wt} \%$ monoethanolamine solvent in a pilot-plant testbed, which involves the whole absorption and desorption. The outcomes showed that monoethanolamine-methanol solvent possessed a more accelerated $\mathrm{CO}_{2}$ absorption rate and lowered regenerating energy-consuming compared to aqueous 
monoethanolamine solvent (Fig. 5). Recovery heat duty of monoethanolamine-methanol solvent at best-operating statuses was lower than that of aqueous monoethanolamine solvent which revealed that monoethanolamine-methanol possessed a potential to displace aqueous monoethanolamine solvent in manufacturing $\mathrm{CO}_{2}$ pilot plant.

Cyclic amine piperazine was applied as a promoter attributed to its prompt production of carbamates with carbon dioxide. Ma et al. (2016) have studied the influences of different additives of piperazine and $\mathrm{Ni}$ (II) ( were utilised as an absorbent in the bubbling reactor) on $\mathrm{CO}_{2}$ absorption performance and ammonia escape rate. Also, they compared the efficiency of the mixed additive in the extraction technique with that of pure ammonia solution (Fig. 6). The obtained performance for the absorption of $\mathrm{CO}_{2}$ was higher by $72 \%$ at the addition of $2 \mathrm{wt} \% \mathrm{NH}_{3}$ solution with piperazine $(25 \mathrm{mmol} / \mathrm{L})$ and $\mathrm{Ni}(\mathrm{II})(50 \mathrm{mmol} / \mathrm{L})$, as compared to that performed by $3 \mathrm{wt} \% \mathrm{NH}_{3}$ solution without any addition. Furthermore, the loss in of the $\mathrm{NH}_{3}$ amount was approximately
$1 / 3$ compared in the case of using a $3 \mathrm{wt} \%$ of $\mathrm{NH}_{3}$ solution without any addition.

2-Amino-2-methyl-1propanol was further reviewed in the literature due to its excellent absorption potential, special resistance for degradation and corrosion and more extraordinary selectivity (Sreedhar et al. 2017a; Kim et al. 2013). The blend of 2-amino-2-methyl-1propanol and piperazine is beneficial where it managed to lessen in regeneration energy with a $20 \%$ and reducing in the rate of circulation absorbent by ( $45 \%)$, away from a notable increment in thermal and oxidative decay resistances (Sreedhar et al. 2017a). Khan et al. (2016) have investigated reviews a post-combustion procedure of capture of $\mathrm{CO}_{2}$ of flue gas by utilising aqueous amine blend of 2-amino-2-methyl-1-propanol and piperazine. The specific rate of absorption for the blends ranged between $14.6 \times 10^{-6}$ and $26.8 \times 10^{-6} \mathrm{kmol} / \mathrm{m}^{2} \mathrm{~s}$. The measured highest rate of $\mathrm{CO}_{2}$ absorbed was (99.63\%) at the greatest content of piperazine $(10 \mathrm{wt} \%)$ in the blend. The most chief $\mathrm{CO}_{2}$ loading potential was $(0.978)$ to the greatest content of piperazine. The regeneration performance was

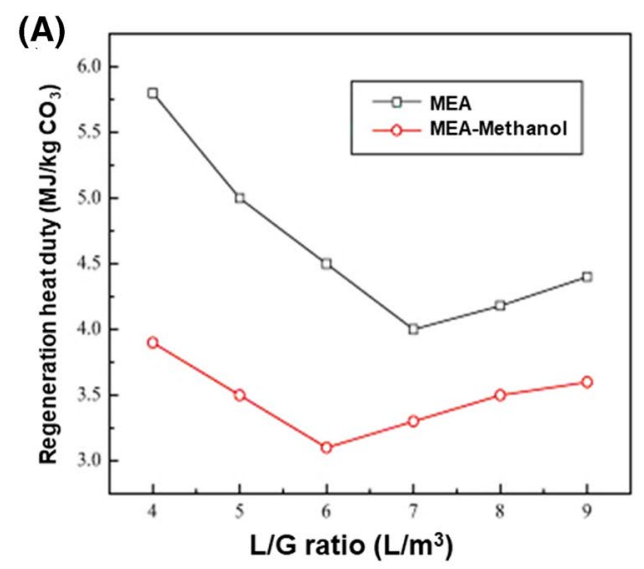

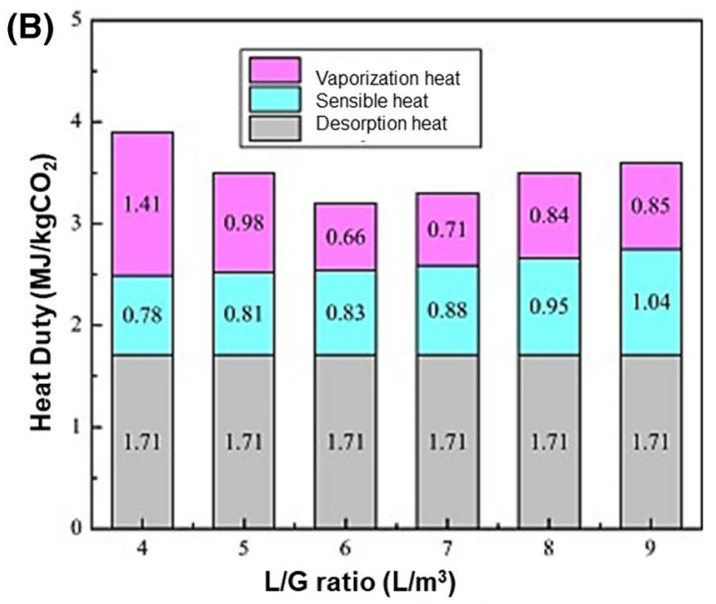

Fig. 5 a Regeneration heat duty for monoethanolamine (MEA) and monoethanolamine-methanol (MEA-methanol) solvent, b regeneration heat duty for monoethanolamine-methanol solvent $\mathbf{c}$ for

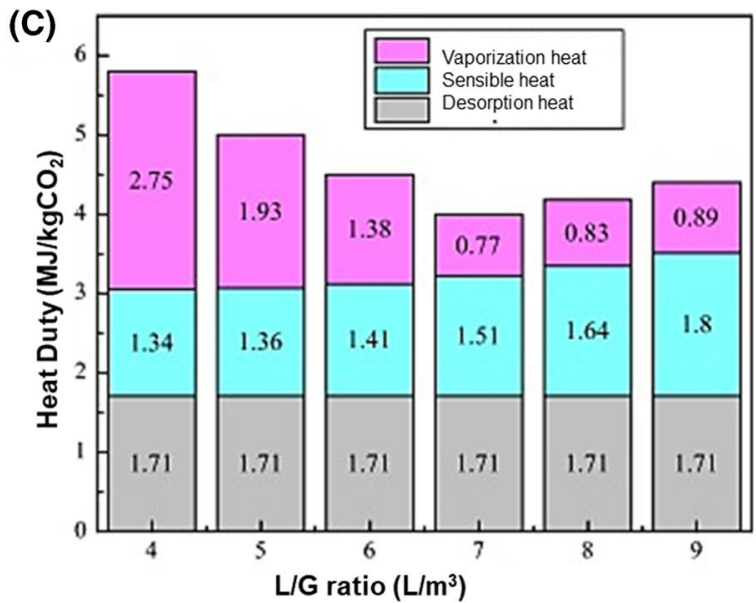

monoethanolamine solvent. Adapted with permission from Gao et al. (2016), Copyright 2020, Elsevier 
Fig. 6 Using $\mathrm{Ni}(\mathrm{II})$ and piperazine to decrease $\mathrm{NH}_{3}$ escape during $\mathrm{CO}_{2}$ capture by a $\mathrm{NH}_{3}$ solution. This can be utilised in post-combustion technology

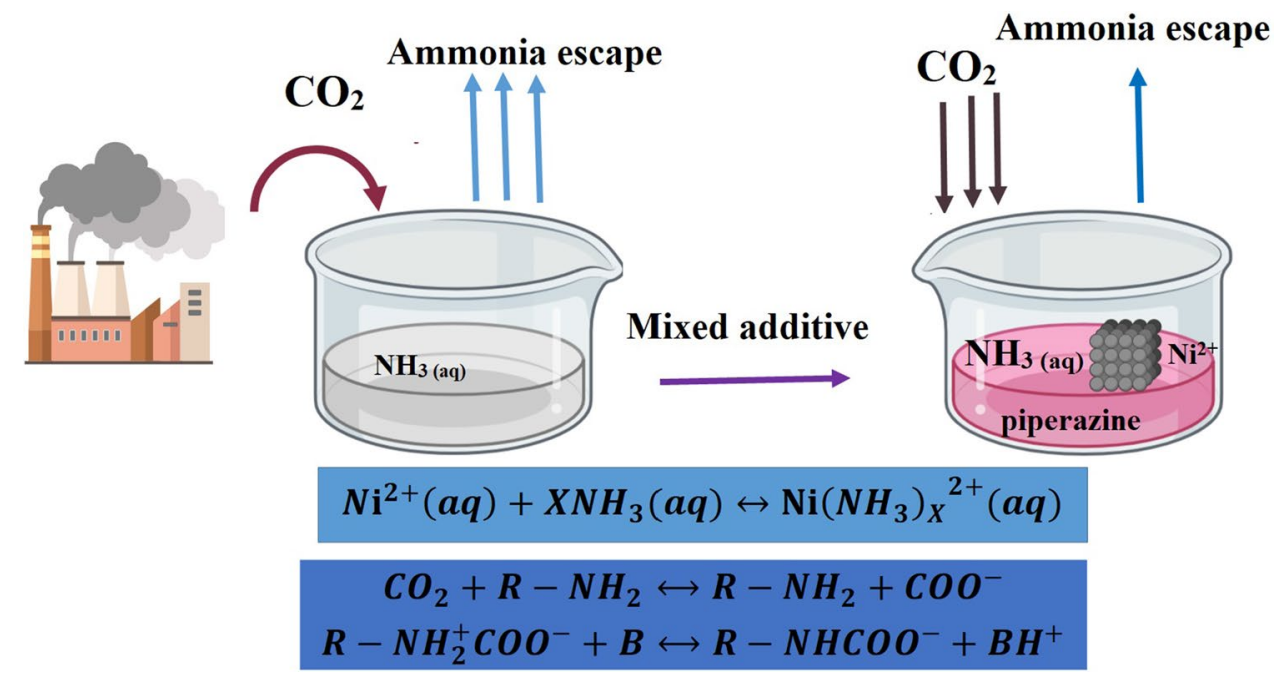

detected within the range of 90.93-98.93\% and the found best performance was $(98.93 \%)$ at using the greatest content of 2-amino-2-methyl-1 propanol (28 wt\%).

Diethylenetriamine possesses three amino groups (two principal and one secondary). In contrast to monoethanolamine, diethylenetriamine displayed more special reactivity (Salvi et al. 2014), lower heat of reaction although with sufficient $\mathrm{CO}_{2}$ absorbing potential (Kim et al. 2014), more elevated rate of mass transference (Fu et al. 2012) and smaller heat capacity for regeneration (Zhang et al. 2014). Sulpholane behaves like a physical additive within the chemical absorption system, attributed to its extraordinary stability and special resistance towards corrosion. The diethylenetriamine-pentamethyldiethylenetriamine mixedamine solvent was affirmed as a biphasic solvent. The pentamethyldiethylenetriamine duties as the proton acceptor, i.e. extracted the zwitterion and improved the $\mathrm{CO}_{2}$ absorption in diethylenetriamine, securing great $\mathrm{CO}_{2}$ capacity (Wang et al. 2020a). Wang et al. (2020a) have found that the sulpholane enhanced the rate of $\mathrm{CO}_{2}$ absorption via diethylenetriamine-pentamethyldiethylenetriamine-sulpholane solvent (1.3 times) compared to that diethylenetriamine-pentamethyldiethylenetriamine solvent. Figure 7 demonstrates the chemical structures and carbon atom label of the species in the diethylenetriamine-pentamethyldiethylenetriamine-sulpholane biphasic solvent. The $\mathrm{CO}_{2}$ was captured over diethylenetriamine corresponding to the zwitterionic mechanism and provided carbamate to the solvent. If more $\mathrm{CO}_{2}$ was absorbed in the solvent, the quantities of liberating diethylenetriamine and pentamethyldiethylenetriamine at the solution reduced, and a higher amount of diethylenetriamine and pentamethyldiethylenetriamine have owned a proton. Contrasted with untreated pentamethyldiethylenetriamine and sulpholane, the formed diethylenetriamine-carbamate,<smiles>CC(N)CCCC(C)N</smiles><smiles>CC(N)CNC(C)C[NH3+]</smiles><smiles>C[C@@H](CN(C)CCN(C)C)N(C)C</smiles><smiles>C[C@@H](C[NH+](C)C[C@@H](C)N(C)C)N(C)C</smiles>

\section{Diethylenetriamine/Diethylenetriamine $\mathrm{H}^{+}$Pentamethyldiethylenetriamine/Pentamethyldiethylenetriamine $\mathrm{H}^{+}$}

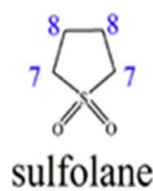<smiles>CNC(=O)ON(C)C(=O)O</smiles>

carbamate<smiles>O=C([O-])OOC(=O)[O-]</smiles>

Fig. 7 The chemical structures and carbon atom label of the diethylenetriamine-pentamethyldiethylenetriamine-sulpholane biphasic solvent. Adapted with permission from Wang et al. (2020a), Copyright 2020, Elsevier 
protonated diethylenetriamine and pentamethyldiethylenetriamine, bicarbonate was further hydrophilic and possessed large polarity, causing to a more durable ability to merge with water than untreated pentamethyldiethylenetriamine and sulpholane.

Hence, throughout $\mathrm{CO}_{2}$ absorption within the solvent, the uniform solution was split to hydrophilic and hydrophobic phases. Also, it is denoted that the hydrophobic sulpholane and untreated pentamethyldiethylenetriamine were dispersed off the higher layer, whereas the hydrophilic parts were dispersed off the below layer due to the density variation. Therefore, the hydrophobic sulpholane developed the hydrophilic-hydrophobic division within the $\mathrm{CO}_{2}$ stored solution, which improves the phase division, as presented in Fig. 8.

The influence of the addition of enzyme carbonic anhydrase was examined on monoethanolamine, methyldiethanolamine, 2-amino-2-methyl-1propanol and potassium carbonate $\left(\mathrm{K}_{2} \mathrm{CO}_{3}\right)$ (Gladis et al. 2017). The $\mathrm{K}_{2} \mathrm{CO}_{3}$ was tried as an absorbent due to its economic value, the moderate value of enthalpy demands, lowering toxicity, small solvent losses and extraordinary resistance for decomposition. To counterpoise the lowering rate of mass transfer, promoters, biological enzymes, organics and alkaline amino acids were stated to be utilised (Endo et al. 2011; Russo et al. 2013).

Wang et al. (2019) have synthesised spherical pellets of $\mathrm{K}_{2} \mathrm{CO}_{3}$ comprising varying amounts of $\mathrm{Al}_{2} \mathrm{O}_{3}$ for $\mathrm{CO}_{2}$ capture (Fig. 9). The activated alumina promoted sorbent pellets arranged with $50 \mathrm{wt} \%$ of $\mathrm{K}_{2} \mathrm{CO}_{3}$ hold the most chief $\mathrm{CO}_{2}$ adsorption potential $(0.0023 \mathrm{~mol} / \mathrm{g})$. Besides, the urea additive $(15 \mathrm{wt} \%)$ can also improve $\mathrm{CO}_{2}$ separation $\left(\sim 0.0031 \mathrm{~mol} \mathrm{CO}_{2} / \mathrm{g}\right)$ of the pellets filled with $50 \mathrm{wt} \%$ of $\mathrm{K}_{2} \mathrm{CO}_{3}$. The enriched $\mathrm{CO}_{2}$ capture is attributed to the notably improved sorbent pellets' porosity as a sequence of urea decay. Furthermore, the urea sorbent pellets keep the exceptional compressive strength (18.96 MPa) and excellent resistance towards corrosion (retain about $99.41 \%$ of its original weight after 4000 rotations).

Fig. 8 The suggested phase division mechanism in diethylenetriamine-pentamethyldiethylenetriamine-sulpholane biphasic solvent. This represents the single phase along with biphasic (hydropholic and hydrophobic)
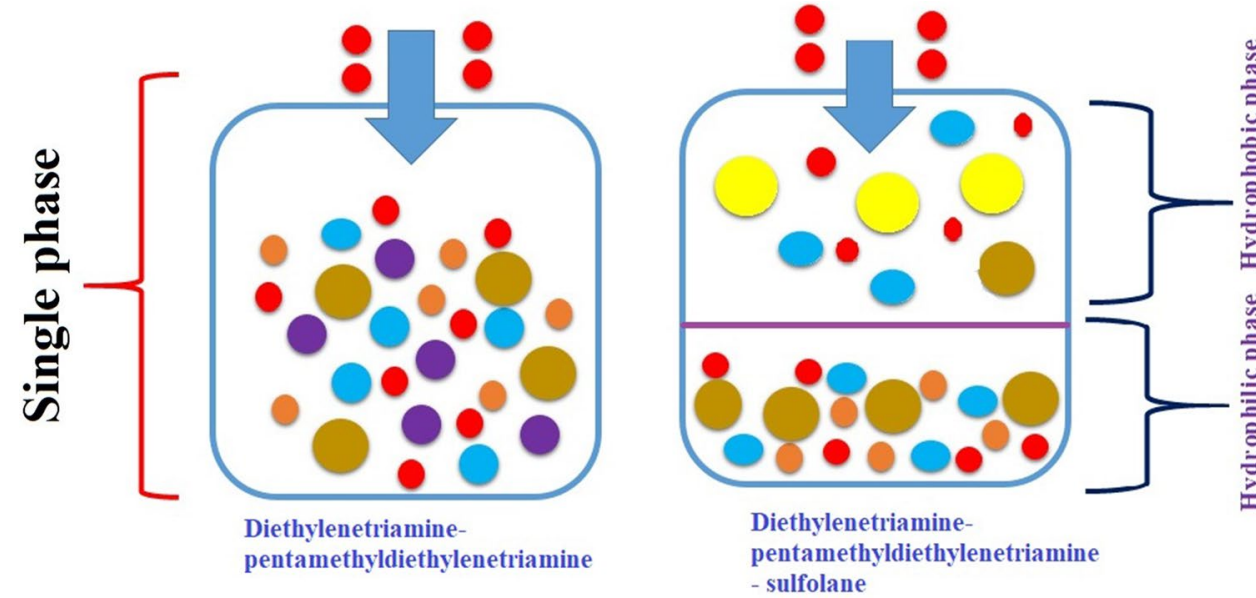

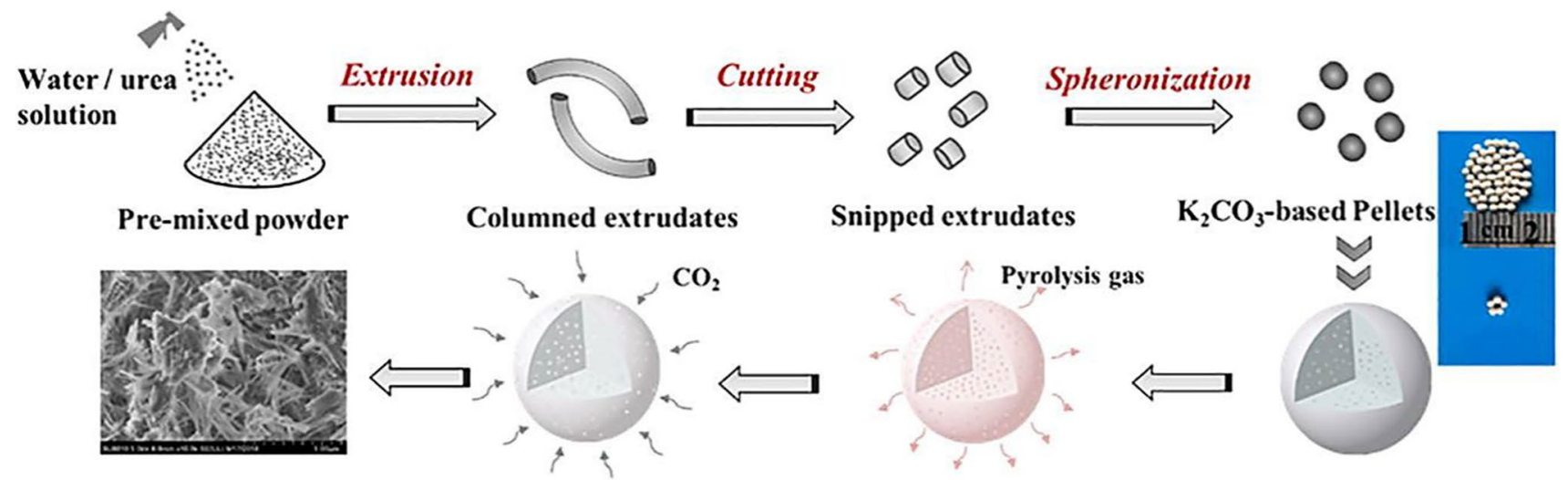

Morphology of pellet Structurally improved pellet High-temperature treatment Fresh modified pellet

Fig. 9 The synthesis process of $\mathrm{K}_{2} \mathrm{CO}_{3}$ pellets sorbents. Adapted with permission from Wang et al. (2019), Copyright 2020, Elsevier 


\section{Adsorption}

The concept of adsorption is interpreted as the emerging adhesion between atoms, ions or molecules, whether in a liquid or gaseous or solid state, and the surface. The ions, atoms or particles that adhere to create a film on the substance's surface in which they are bound and are termed as an adsorbate, while the substance on which they appended is named adsorbent. Adsorption is diverse from absorption due to, in absorption, the absorbate (fluid) is dissolved via an absorbent, whether solid or liquid. Adsorption forms on the outside surface, while absorption entails the whole material volume. Sorption is correlated to the couple manners, while desorption is considered as counter-reaction or reversed the adsorption process (Ben-Mansour et al. 2016; Abd et al. 2020).

Adsorption may begin physically; this requires ineffective Van der Waals forces (physisorption). Likewise, it might happen chemically, which demands covalent bonding (chemisorption), and it may happen attributed to the electrostatic attraction. The most prominent chemical adsorption and absorption systems, in $\mathrm{CO}_{2}$ capture techniques, include the interaction within chemicals that leads to the creation of molecular structures based on $\mathrm{CO}_{2}$, following which recovery of the uptake $\mathrm{CO}_{2}$ is achieved over an adequate rise in temperature via heat treatment. The regeneration method spends the greatest of the potential demand in $\mathrm{CO}_{2}$ capture. So, there is a necessity to promote energetic substances and methods for $\mathrm{CO}_{2}$ uptake that can considerably lessen operation expenditure via the decline in expenditure of regeneration (Ben-Mansour et al. 2016).

The physical adsorbents which used in $\mathrm{CO}_{2}$ adsorption whether carbonaceous and non-carbonaceous substances, as shown in Table 1, demands lowering value energy in the contrasting to that required in the case of using the chemical adsorbents. This can be explained that in the physical adsorbents, not new bonds are created between the carbon dioxide and the surface of the used adsorbent; hence, this ultimately results in reducing the energy demanded regeneration process (Abd et al. 2020).

\section{Carbonaceous materials adsorbents}

Carbonaceous materials typically were composited of carbon and additional linked material that can consider unique features like environmentally benign, extraordinary stability feature whether the thermal and chemical behaviour, exceptional conduction mechanism (heat and electrical characteristics) or surpassing strength. Besides, these materials have numerous merits such as low-cost, effective, simple composition from materials settled in nature, extraordinary distinct surface area, unique pore volume, and they are fine weight substances (Abd et al. 2020; Lozano-Castelló et al. 2002).
Activated carbon materials Over the ages, the porous carbon adsorbents have emerged as proper substances for $\mathrm{CO}_{2}$ uptake ascribed to the physical adsorption of $\mathrm{CO}_{2}$ on their surface, signifies the energy that demands the regeneration process was declined. Besides, the excellent $\mathrm{CO}_{2}$ adsorption will be performed ascribed to their porous feature. Also, these materials can be efficiently qualified to combine exceptional surface features and necessary beneficial groups that can assist in enhancing the resulting interaction between the adsorbent substances and $\mathrm{CO}_{2}$ which are crucial for providing an extraordinary $\mathrm{CO}_{2}$ adsorption potential ( $\mathrm{Li}$ et al. 2019b; Singh et al. 2019). The activated carbons were fabricated of carbonaceous substances through pyrolysis at high temperatures and special pressure in the activation furnace (Kosheleva et al. 2019). The resulting from this process is extraordinary surface area and heterogeneous pore structure. Besides, an inert gas (nitrogen or argon) was applied in the carbonisation step to eliminate any volatile parts to fabricate enriched carbon specimens. After that, the fabricated specimen was activated in the existence of the oxidising agent (oxygen, steam or carbon dioxide) at a wide range of elevated temperatures (Mahapatra et al. 2012).

The activation stage among the carbonaceous substances and the oxidising agents is an endothermic reaction, as explained in the following:

$\mathrm{C}+\mathrm{CO}_{2} \rightarrow 2 \mathrm{CO}, \quad \Delta \mathrm{H}=+173 \times 10^{3} \mathrm{~J} \mathrm{~mol}^{-1}$

$\mathrm{C}+\mathrm{H}_{2} \mathrm{O} \rightarrow \mathrm{CO}+\mathrm{H}_{2}, \quad \Delta \mathrm{H}=+132 \times 10^{3} \mathrm{~J} \mathrm{~mol}^{-1}$

The carbon dioxide was preferably utilised as an activation agent than steam ascribing to its capacity to produce particles that have tight micropores nature that satisfies the characteristics of molecules of carbon dioxide, while steam is beneficial to compose particles with mesopores feature (González et al. 2009; Román et al. 2008).

The influence of nitrogen incorporating with the activated carbon was estimated to behave that the carbon dioxide uptake performance is managed via porosity character and nitrogen ratio. Recently, He et al. (2021) have synthesised activated carbons via carbonisation and potassium hydroxide $\mathrm{KOH}$ activation employing rice husk as a raw material. The studied samples show remarkably surface area about $\approx 1496 \mathrm{~m}^{2} \mathrm{~g}^{-1}$, and micropore volume of $44.7 \times 10^{-2} \mathrm{~cm}^{3} \mathrm{~g}^{-1}$. Also, compared with the biochar to $\mathrm{KOH}$ as (1:5) ratio sample, chitosan modified (biochar/KOH as 1:5) sample displays remarkable $\mathrm{CO}_{2}$ uptake achievement $0.00583 \mathrm{~mol} \mathrm{~g}^{-1}$, which can be ascribed to the creation of the $\mathrm{CO}_{2}$-philic active sites on activated carbons surface via nitrogen species. The isosteric heat of $\mathrm{CO}_{2}$ uptake for chitosan modified (biochar $/ \mathrm{KOH}$ as 1:5) sample is extremely higher than that of the non-modified sample. The adsorption performance of the modified sample with chitosan can be suitably represented via the 
Freundlich model (Fig. 10). The large ideal adsorption solution theory (IAST) selectivity factor to the modified sample with chitosan designates their unique adsorption selectivity for $\mathrm{CO}_{2}$ over doping with nitrogen.

Activated carbons were prepared using two stages of activation steps from different types of waste and low-value lignocellulosic biomass such as potato peel waste, barley waste and miscanthus with surface areas $\left(\mathrm{m}^{2} / \mathrm{g}\right)$ of 833 (Osman et al. 2019), 692 (Osman et al. 2020c) and 1368 (Osman et al. 2020b), respectively. Singh et al. (2019) have presented the manufacture of activated porous carbon spheres for D-glucose carbonisation with a unique potassium acetate for carbon dioxide uptake. The obtained spheres shape activated porous carbon possesses a specific surface area of $\approx 1920 \mathrm{~m}^{2} / \mathrm{g}$, spherical shape for surface morphology and special pore volume of $\approx 0.9 \mathrm{~cm}^{3} / \mathrm{g}$. The activated porous carbon spheres display outstanding achievement, and manifest carbon dioxide uptakes ranged between 0.00196 to $0.00662 \mathrm{~mol} / \mathrm{g}$ at different operating conditions. Furthermore, the samples exhibit efficient carbon dioxide uptake achieved $0.02008 \mathrm{~mol} / \mathrm{g}$ at a temperature of $0{ }^{\circ} \mathrm{C}$ and pressure of $30 \mathrm{bar}$ and achieved $0.01408 \mathrm{~mol} / \mathrm{g}$ in the case the temperature raised to $25^{\circ} \mathrm{C}$ and pressure 30 bars (Fig. 11). This achievement could be ascribed to the extremely revealed porous construction of the studied materials.

To sum up, the activated carbon adsorbents exhibit remarkable merits such as low value for regeneration energy, simple to restore, low regeneration temperature, an abundance of raw materials and extraordinary thermal stability; mainly the uptake achievement improves if the applied pressure of carbon dioxide rises.

Carbon nanotube materials Carbon nanotube materials are being examined in $\mathrm{CO}_{2}$ uptake area ascribed to their attractive physical and chemical features such as great conduction behaviour whether thermal or electrical, besides the feasibility to develop their surfaces through attaching a chemical duty group, the exceptional yield for uptake storage potential. Further, the carbon nanotubes were achieved as a proper adsorbent for $\mathrm{CO}_{2}$ uptake (Abuilaiwi et al. 2010; Srivastava and et al. 2003). Recently, Ghosh and Ramaprabhu (2019) have studied transition metal (iron, cobalt and nickel) salt-encapsulated nitrogen-doped bamboo-like carbon nanotubes for $\mathrm{CO}_{2}$ uptake across a broad range of temperature and pressure (Fig. 12). The observed results reveal that the $\mathrm{CO}_{2}$ adsorption potential completely improves for all transition metals covered the nitrogen-doped bamboo-like carbon nanotubes in both the pressure range. Further, the adsorption potentials lessen with the increment in temperature to all the studied samples inferring that physical uptake is the principal adsorption mechanism. Also, the sample used the Fe as an encapsulating metal shows the most chief adsorption potential, whereas the sample used $\mathrm{Ni}$ as an encapsulating metal uptake was the least between the studied samples. Furthermore, the adsorption potentials of the Fe encapsulated

(A)

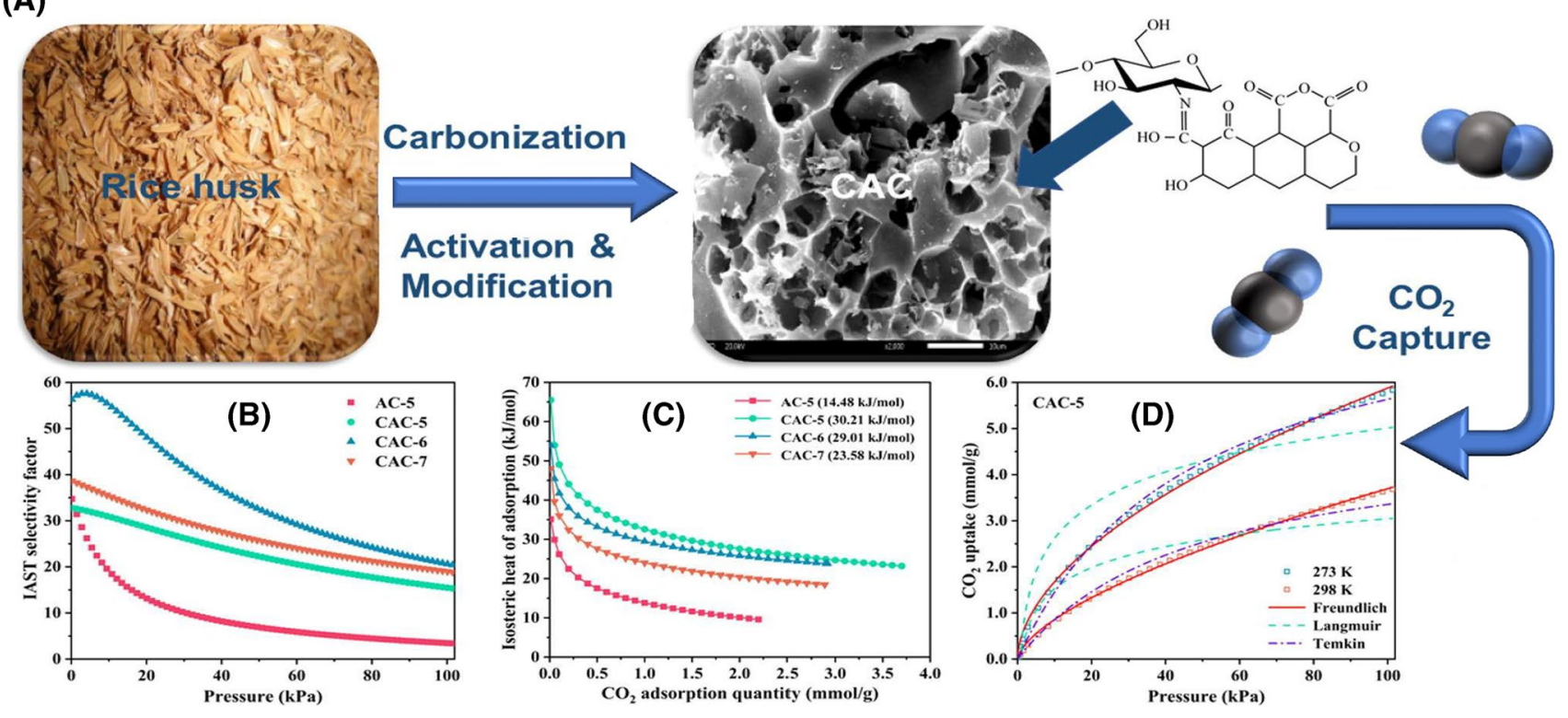

Fig. 10 A Activated carbon prepared by varying biochar and $\mathrm{KOH}$ mass ratios, B large ideal adsorption solution theory (IAST) selectivity factors of (a) biochar/KOH(1:5) (AC-5), (b) chitosan@ biochar/ $\mathrm{KOH}(1: 5)$ (CAC-5), (c) chitosan@biochar/KOH(1:6) (CAC-6) and (d) chitosan@biochar/KOH(1:7) (CAC-7) at $298 \mathrm{~K}, 0-101 \mathrm{kPa}$, $\mathrm{C}$ isosteric heat of $\mathrm{CO}_{2}$ uptake on (a) biochar/KOH (1:5) (AC-5), (b) chitosan@biochar/KOH(1:5) (CAC-5), (c) chitosan@biochar/ $\mathrm{KOH}(1: 6)$ (CAC-6) and (d) chitosan@ biochar/KOH (1:7) (CAC-7) estimated, and $\mathbf{D} \mathrm{CO}_{2}$ adsorption isotherms of (a) biochar/KOH(1:5) (AC-5) sample fitted to various isotherm models. Adapted with permission from He et al. (2021), Copyright 2020, Elsevier 
Fig. 11 A Activated porous carbon spheres fabricated from d-glucose, $\mathbf{B} \mathrm{CO}_{2}$ adsorption isotherms of (a) activated porous carbon spheres sample, (b) activated porous carbon spheres- $1 \mathrm{~g}$ of potassium acetate, (c) activated porous carbon spheres-2 $\mathrm{g}$ of potassium acetate, (d) activated porous carbon spheres-3g of potassium acetate, and (e) activated porous carbon spheres $-4 \mathrm{~g}$ of potassium acetate at $0{ }^{\circ} \mathrm{C}$, and $\mathrm{C} \mathrm{CO}_{2}$ adsorption isotherms of activated porous carbon spheres- $3 \mathrm{~g}$ of potassium acetate at (a) $0{ }^{\circ} \mathrm{C}$, (b) $10^{\circ} \mathrm{C}$ and (c) $25^{\circ} \mathrm{C}$. Adapted with permission from Singh et al. (2019), Copyright 2020, Elsevier
(A)

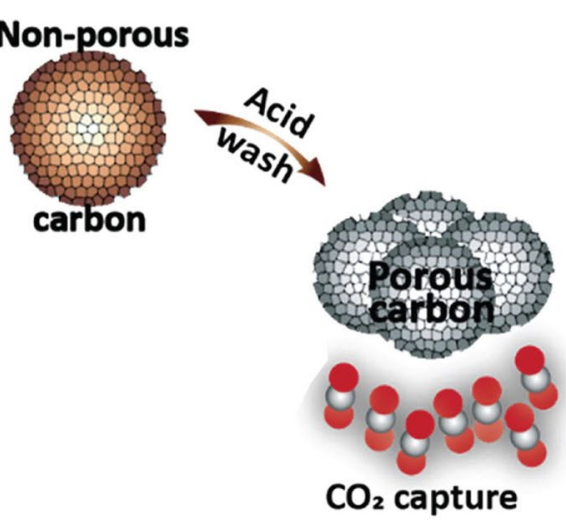

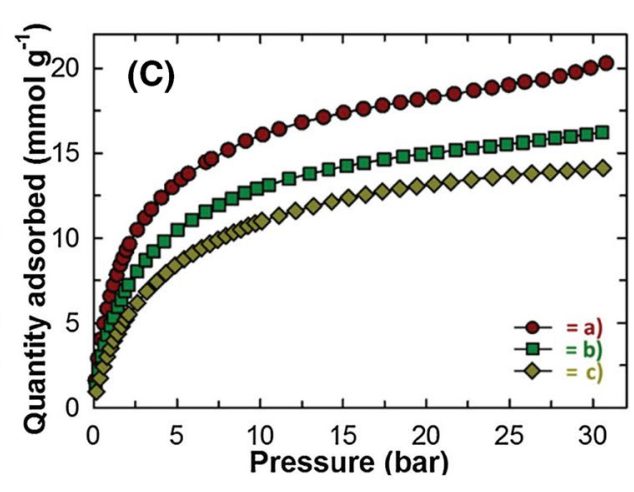

Fig. 12 Synthesis of transition metal (iron, cobalt and nickel) salt-encapsulated nitrogen-doped bamboo-like carbon nanotubes. Adapted with permission from Ghosh and Ramaprabhu (2019), Copyright 2020, Elsevier
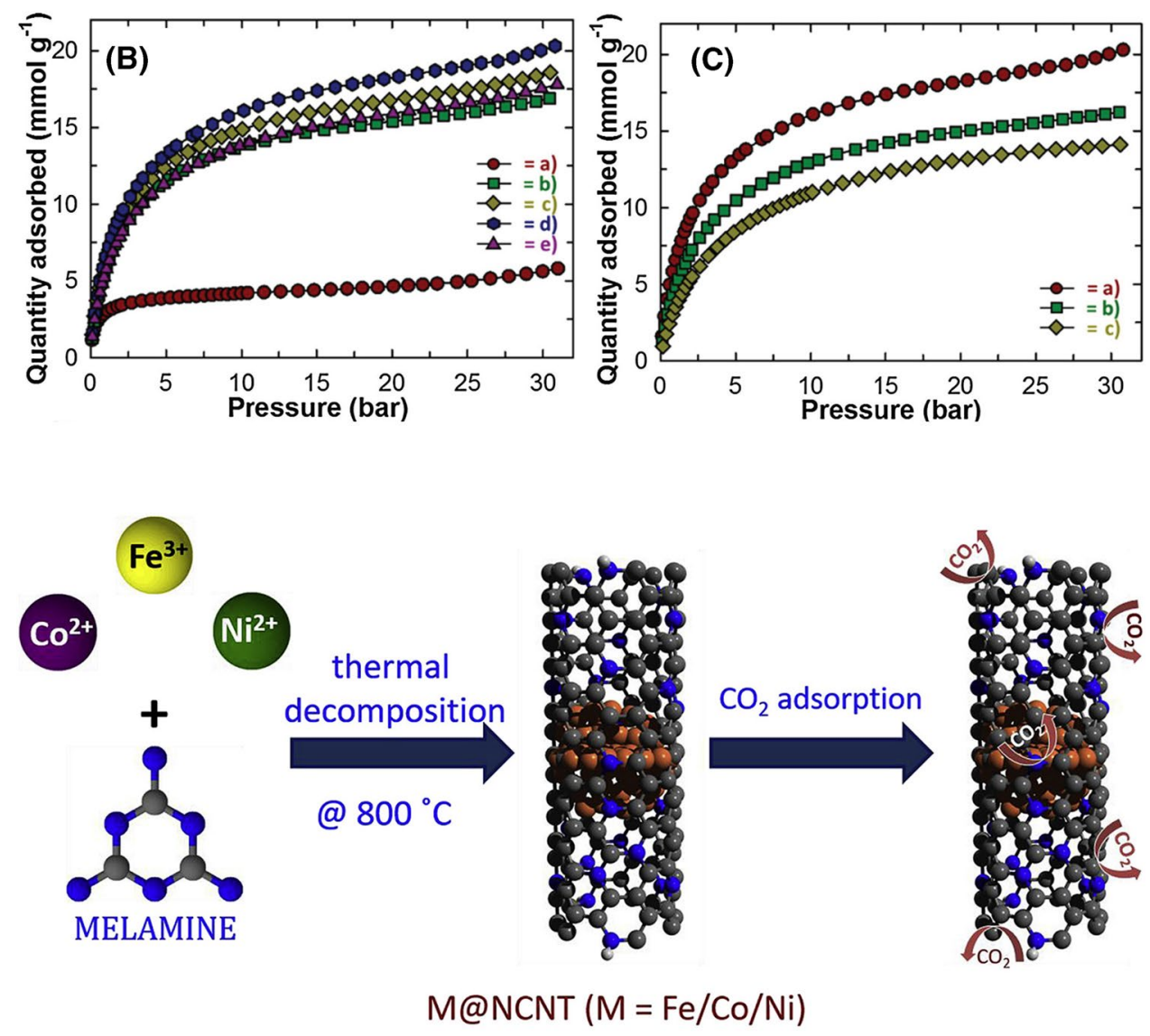

C N Metal nanoparticle $(\mathrm{Fe} / \mathrm{Co} / \mathrm{Ni})$

the nitrogen-doped bamboo-like carbon nanotubes is reached $0.0015 \mathrm{~mol} / \mathrm{g}$, whereas the Co covered the nitrogen-doped bamboo-like carbon nanotubes uptakes $0.00115 \mathrm{~mol} / \mathrm{g}$, and the Ni coated the nitrogen-doped bamboo-like carbon nanotubes uptakes $0.00098 \mathrm{~mol} / \mathrm{g}$ at $298 \mathrm{~K}$ which increment with the reduction in temperature.

Also, Su et al. (2011) have prepared multiwalled carbon nanotubes were functionalised with a large weight load of 3-aminopropyltriethoxysilane to examine their performances in the $\mathrm{CO}_{2}$ uptake. The adsorption potential of multiwalled carbon nanotubes@3-aminopropyltriethoxysilane was significantly impacted through the existence of vapour of water. Whereas raising the water amount, the uptake potential increased, which revealed that the uptake process is an exothermic reaction. Also, they observed that the uptake potential declined with increasing temperature. The $\mathrm{CO}_{2}$ uptake potential reached $0.0026 \mathrm{~mol} / \mathrm{g}$ at $293 \mathrm{~K}$ for multiwalled carbon nanotubes@3-aminopropyltriethoxysilane. The outcome implies that the solid multiwalled carbon 
nanotubes@3-aminopropyltriethoxysilane are a promising system for $\mathrm{CO}_{2}$ uptake.

Jena et al. (2019) have presented the synthesis of the nanohybrid (3-aminopropyl) triethoxysilane@zinc oxide@ multiwalled carbon nanotubes. The nanohybrid displays mesoporous features possessing a unique surface area $\left(\sim 27 \mathrm{~m}^{2} / \mathrm{g}\right)$ with a pore size of about $3.8 \mathrm{~nm}$. The multiwalled carbon nanotubes surface that is adjusted with the zinc oxide considerably enhances the $\mathrm{CO}_{2}$ uptake potential $(0.00132 \mathrm{~mol} / \mathrm{g})$. Furthermore, the increase in the $\mathrm{ZnO}$ density that is attached at the surface of multiwalled carbon nanotubes produced a tremendous affinity for the sake of $\mathrm{CO}_{2}$ uptake at low pressure.

Graphene Graphene is a unique category of carbonaceous substances with superior adsorption potential and lately got extensive consideration (Abdel Maksoud et al. 2020). Various investigations applied different strategies to qualify the surface of graphene and introduce an extraordinary surface area and acceptable pore volume (Kumar and Xavior 2014). Recently, Varghese et al. (2020) have progressed the graphene oxide foam via the ultraviolet irradiation and investigated for $\mathrm{CO}_{2}$ uptake potential (Fig. 13). They found that $\mathrm{CO}_{2}$ recover potential increased as the ultraviolet exposure increase. The $\mathrm{CO}_{2}$ recover potential reached about $90 \%$ for the graphene oxide foam exposed to 5 hours for ultraviolet irradiation and reached $91 \%$ as the exposed time for ultraviolet irradiation increased to ten hours in contrast to the untreated graphene oxide foam were recovered $65 \%$ of $\mathrm{CO}_{2}$.
Furthermore, with boosting the regeneration temperature, the $\mathrm{CO}_{2}$ recovery improved.

Hsan et al. (2019) have confirmed chitosan grafted graphene oxide aerogels for $\mathrm{CO}_{2}$ uptake. The result of the uptake potential of $\mathrm{CO}_{2}$ via the prepared grafted sample is around $0.26 \mathrm{mmol} / \mathrm{g}$ at the pressure $1 \mathrm{bar}$, which is notably greater in contrast to the uptake potential of pure chitosan sample. The outcomes affirm that this examination assists to decrease the cost-effectiveness of adsorbents where chitosan is abundant with a large amount in marine waste, and therefore, this research intends to decrease the cost of $\mathrm{CO}_{2}$ uptake with suitable temperature and pressure.

Wang et al. (2020c) have combined unique hierarchical porous $\mathrm{C}$ acquired from poly(p-phenylenediamine) with reduced graphene oxide for $\mathrm{CO}_{2}$ uptake technology. The obtained reduced graphene oxide on poly(p-phenylenediamine) sample has a surface area around $860 \mathrm{~m}^{2} / \mathrm{g}$ besides it displays superior $\mathrm{CO}_{2}$ uptake potential $(0.00465 \mathrm{~mol} / \mathrm{g}$ at a temperature of $298 \mathrm{~K}$ and pressure of $5 \mathrm{bar}$ ).

Meng and Park (2012) have declared that exfoliated nanoplate of graphene was a highly proper adsorbent for $\mathrm{CO}_{2}$ uptake. The graphene nanoplate was synthesised from graphene oxide through a low-temperature approach. The treated adsorbents performed an extraordinary $\mathrm{CO}_{2}$ removal of about $0.056 \mathrm{~mol} / \mathrm{g}$. Further, the remarkable adsorption potential of graphene nanoplates was ascribed to the larger inter-layer spacing and essential interior volume. The treated graphene nanoplates showed excellent capture uptake
(A)

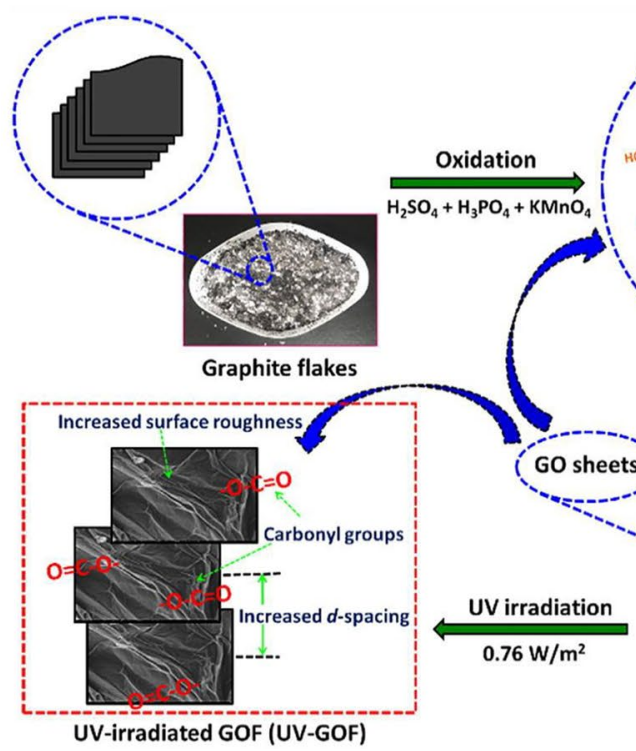

Fig. 13 a Synthetic stages of graphene oxide foam and ultraviolet irradiation (UV-GOF), b $\mathrm{CO}_{2}$ adsorption isotherms of untreated graphene oxide foam (GOF) and treated graphene oxide foam via ultraviolet irradiation (UV-GOF) adsorbents and $\mathbf{c} \mathrm{CO}_{2}$ and $\mathrm{N}_{2}$ adsorption
(B)

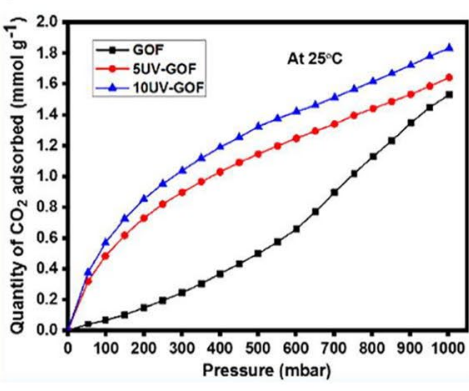

(C)

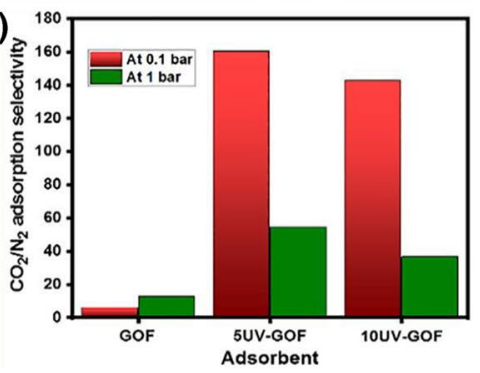

selectivity of untreated graphene oxide foam (GOF) and treated graphene oxide foam via ultraviolet irradiation (UV-GOF) adsorbents at different pressures. Adapted with permission from Varghese et al. (2020), Copyright 2020, Elsevier 
(248 wt\%) at the operating conditions. Also, Hong et al. (2013) have proposed progressing the basicity via improving the surface of graphite using 3-aminopropyl-triethoxysilane, which can increase the $\mathrm{CO}_{2}$ removal. The outcomes stated that amine adjustment enhances the $\mathrm{CO}_{2}$ uptake; hence, the increment of the basicity is the principal factor in advancing $\mathrm{CO}_{2}$ uptake which is agreeable with the adherent molecules of amine that attached into the graphite surface.

\section{Non-carbonaceous dry adsorbents}

Zeolites Zeolites are another category of physical adsorbents found in nature and can be manufactured in the investigation laboratory also it comprises a microporous crystalline framework compositing of aluminosilicates. Zeolites were broadly applied in the carbon dioxide elimination in the concern of their molecular sieving influence, and the electrostatic interactions occurred among carbon dioxide and alkali cations inside the zeolite frameworks (Singh et al. 2020). The gas uptake features of the zeolites are notably reliant upon the size, the density of charges and the distribution of the commutable cations in the pored framework (Zhang et al. 2008).

The replacement of aluminium ions with silicon ions produces a negative charge, that can be rebalanced via the exchangeable cation into the construction of alkalies such as sodium and potassium cations or alkaline earth metal calcium and magnesium ions. Zeolites possess many traditional kinds such as zeolite $\mathrm{A}, \mathrm{X}$ and $\mathrm{Y}$ or natural zeolites such as chabazites, clintopiles, ferrierites and mordenite (Dong et al. 1999). The zeolites 13X and 5A that possess reasonable pores size exhibit more proper for $\mathrm{CO}_{2}$ uptake than their rival that have pores with little sizes such as Chabazite and Na-A in the low applied pressures (Song et al. 2018). Mason et al. (2015) have reported that the zeolite 5A (Na0.28Ca0.36AlSiO4) including Linde Type A composition and zeolite 13X(NaAlSi1.18O4.36) with Faujasite composition comprising calcium and sodium cations exhibited amazing $\mathrm{CO}_{2}$ uptake potential $0.0031 \mathrm{~mol} / \mathrm{g}$ at pressure 0.15 bar.

Wang et al. (2020b) have prepared X zeolite via waste rice hull ash and qualified via rare-earth metals ( $\mathrm{La}$ and $\mathrm{Ce}$ ) ion-exchange into the zeolite (Fig. 14). The NaX exhibited high $\mathrm{CO}_{2}$ uptake $\left(0.0061 \mathrm{~mol} \mathrm{~g}^{-1}\right)$, whereas LaLiX shows $0.0043 \mathrm{~mol} \mathrm{~g}^{-1}$ for $\mathrm{CO}_{2}$ uptake. Also, the selectivity of carbon dioxide and nitrogen for $\mathrm{LaNaX}$ was improved more than three times. Further, the qualified zeolite samples lost about $3.5 \%$ of its original adsorption over 20 adsorptiondesorption cycles.

Liu et al. (2020) have prepared (3-Aminopropyl)triethoxysilane and alkyl-functionalised(3-Aminopropyl)-triethoxysilane and grafted it on zeolite beta by a reflux reaction. The results showed that the alkyl-functionalised- (3-Aminopropyl)-triethoxysilane @ zeolite displayed an uptake potential of about $0.00144 \mathrm{~mol} / \mathrm{g}$. Also, the studied absorbent sample displayed an extraordinary uptake rate of about $\sim 0.7$ min (after $90 \%$ of the whole uptake potential in five min), and great stability after 20 cycles. Furthermore, alkyl-functionalised- (3-Aminopropyl)triethoxysilane @ zeolite beta provided more chief uptake potential and stability than (3-Aminopropyl)-triethoxysilane @ zeolite at $\mathrm{CO}_{2}$ mixture uptake and $\mathrm{CO}_{2}$ flow regeneration.

The affected metal ions incorporated in the zeolitic framework could likewise promote the $\mathrm{CO}_{2}$ uptake potentials. Theoretical and practical examination of nontreated zeolite (13X), lithium comprising zeolite (LiX) and polymetallic zeolite ( $\mathrm{LiPdAgX})$ with Faujasite composition proved that the $\mathrm{LiPdAgX}$ system is a more efficient candidate not alone for $\mathrm{CO}_{2}$ uptake but likewise for the selectivity of carbon dioxide and nitrogen as compared to $13 \mathrm{X}$ and LiX samples. Further, the LiPdAgX system presented $\sim 25 \%$ greater $\mathrm{CO}_{2}$ uptake and $\sim 180 \%$ more chief selectivity (Chen et al. 2018b).

Notwithstanding the superior merits of affected metal qualified zeolite, the progress remarked in the isosteric heat of uptake was not notably great. A related statement decided that the thermal conductivity was improved through the incorporation of palladium and silver ions within the zeolite framework could efficiently consume the heat of uptake, appearing in the enrichment of the $\mathrm{CO}_{2}$ uptake potential at post-combustion uptake conditions (Chen et al. 2017).

Silica materials The materials based on silica are different types of adsorbed non-carbonaceous substances for carbon dioxide uptake, which distinguish with an extraordinary surface area, pore size and excellent mechanical stability. Silica is commonly applied as a support on which different substances are combined for $\mathrm{CO}_{2}$ elimination. Consequently, most of the investigation goes on adsorbents based on silica are principally induced in adjusting several natures of silica and utilising proper amines types since numerous investigations noted the performance of silica materials-based adsorbents for $\mathrm{CO}_{2}$ (Qin et al. 2014; Sanz-Pérez et al. 2018).

Henao et al. (2020) have estimated the $\mathrm{CO}_{2}$ uptake performance of a range of amine-functionalised silicas with distinct pore compositions: SBA-15 (2D hexagonal), SBA11 (3D cubic) and disordered silica. The rice husk ash was utilised as a silica source. Afterwards, the silica is functionalised by polyethyleneimine through wet impregnation. The $\mathrm{CO}_{2}$ uptake achievement is considered sensitive to the pore characteristics of the silica supports and the impregnated value of polyethyleneimine. Between the developed samples, the polyethyleneimine on SBA-15 presented the most superior amine employ and $\mathrm{CO}_{2}$ uptake potential $(0.0616 \mathrm{~g}$ for every $1 \mathrm{~g}$ of $\mathrm{CO}_{2}$ ) under moderate conditions.

Minju et al. (2017) have prepared sorbents and used three amines (tetraethylenepentamine, tetraethylenepentamine 

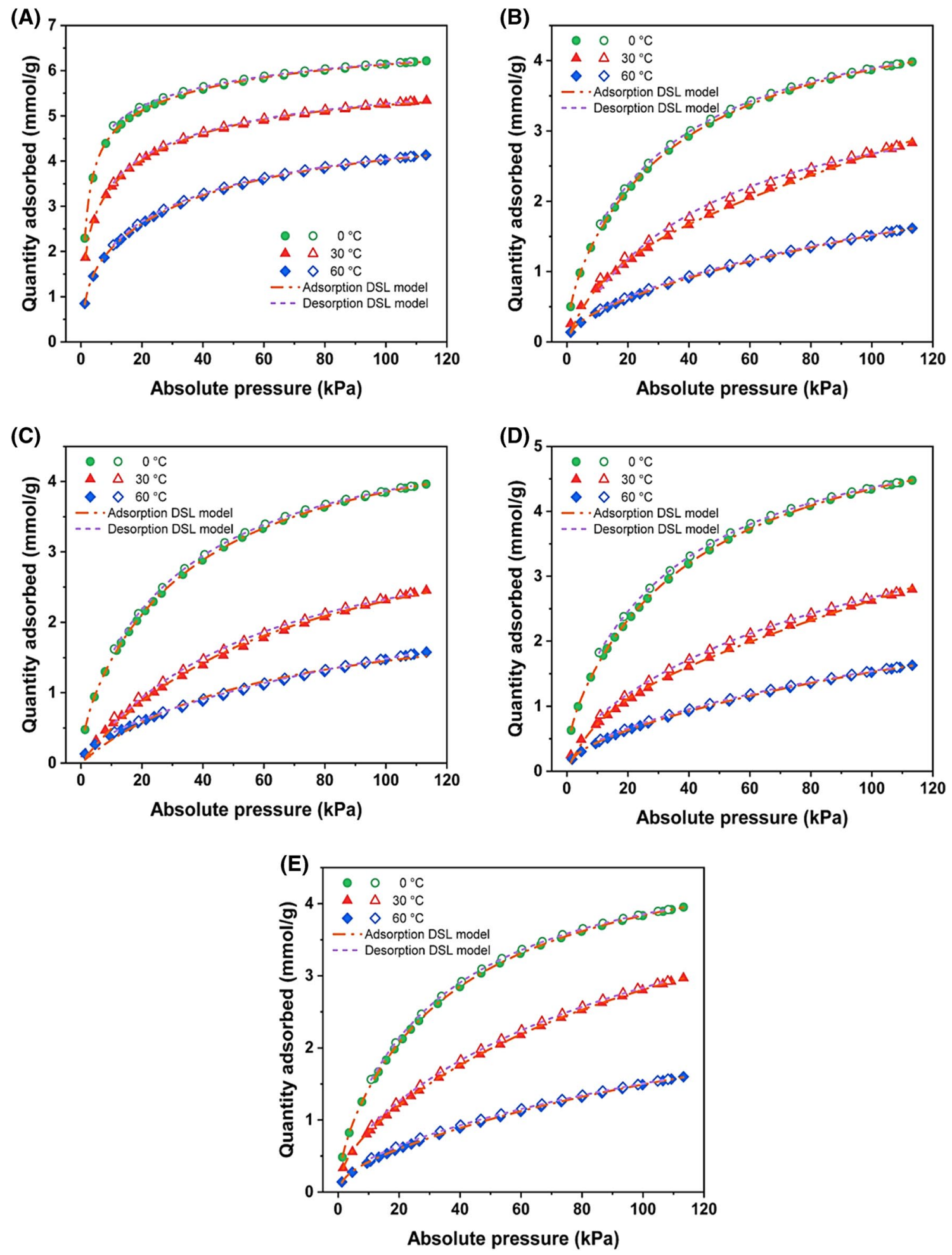

Fig. 14 Isotherms of uptake of $\mathrm{CO}_{2}$ via a NaX zeolite, $\mathbf{b}$ LaNaX zeolite, $\mathbf{c}$ CeNaX zeolite, $\mathbf{d}$ LaLiX zeolite and e CeLiX zeolite Adapted with permission from Wang et al. (2020b), Copyright 2020, Elsevier

acrylonitrile and a hybrid of aminopropyltrimethoxysilane coupled with the two amines individually) for the surface qualification intention. The $\mathrm{CO}_{2}$ uptake isotherms of the modified samples revealed that the sorbents coupled with aminopropyltrimethoxysilane presented excellent uptake achievement than the other samples. The specimen, 
including a hybrid of aminopropyltrimethoxysilane and tetraethylenepentamine, exhibited the most remarkable achievement between the other samples for a $\mathrm{CO}_{2}$ uptake potential about of $0.00326 \mathrm{~mol} / \mathrm{g}$. The tetraethylenepentamine acrylonitrile immobilised sorbents displayed more accelerated kinetics at all applied temperatures.

Lashaki and Sayari (2018) have examined the influence of the provider pore composition on the $\mathrm{CO}_{2}$ uptake achievement of triamine-tethered SBA-15 silica. The SBA15 silica compounds assistance by varying pore extents and pore volumes have been manufactured, accompanied via triamine functionalisation by grafting process. The results of $\mathrm{CO}_{2}$ uptake estimations confirmed the certain influence of support large pore size and extraordinary pore capacity on uptake features, with the former signifying predominant. Also, the exceptional pore promotes showing the principal surface density about amine groups, and exceptional $\mathrm{CO}_{2}$ elimination $\left(\sim 0.0019 \mathrm{~mol} \mathrm{~g}^{-1}\right)$. Further, if the pore capacity declined to $47 \%$ of its original value of samples including likewise pore sizes, the $\mathrm{CO}_{2}$ adsorption declined to $\sim 63 \%$ and more delayed adsorption kinetics has been seen.

Fayaz and Sayari (2017) have examined the hydrothermal durability of triamine-grafted commercial-grade silica for $\mathrm{CO}_{2}$ adsorption. The results of uptake showed extraordinary $\mathrm{CO}_{2}$ uptake of $0.0019 \mathrm{~mol} / \mathrm{g}$ at best grafting statuses $\left(1.5 \mathrm{~cm}^{3}\right.$ of amino silane per each gram of silica with a small volume of water). Also, the increase of the duration exposure time for steam lessened $\mathrm{CO}_{2}$ capture to $44 \%$ of its original value. Nonetheless, the $\mathrm{CO}_{2}$ uptake decreased (21-4\%) with increasing the adsorption temperatures by $25^{\circ} \mathrm{C}$.

Metal-organic frameworks materials Metal-organic frameworks materials are a unique type of adsorbed substances that have fabricated via the incorporation of metal cations combined with the coordination bonds ( $\mathrm{Li}$ et al. 2012a, b). The metal-organic frameworks materials had classified as organic-inorganic mixtures, superporous solid materials. Among the identified substances to time, metal-organic frameworks possess an exceptional uptake surface area for every gram. They hold an outstanding achievement for $\mathrm{CO}_{2}$ uptake, able to be flexible in whether structure and function behaviours. All these unique features made these materials broadly applied in the investigation operations of $\mathrm{CO}_{2}$ capture.

Further, the metal-organic frameworks have appeared and first performed via Hoskins and Robson and further recognised as coordination polymers (Abd et al. 2020; Düren 2007). Further to the unique structural chemistry of metal-organic frameworks, the composition agents such as extraordinary surface area around $7 \times 10^{3} \mathrm{~m}^{2} / \mathrm{g}$ and exceptional pore volume $\left(\sim 4.5 \mathrm{~cm}^{3} / \mathrm{g}\right)$ besides with more comfortable control of the pore structure and surface and the other concerning characteristics of metal-organic frameworks, which offer a marked state for their utilisation in the area of $\mathrm{CO}_{2}$ uptake (Farha et al. 2012). The high surface area to weight ratio in the metal-organic frameworks is a remarkably critical agent for their $\mathrm{CO}_{2}$ uptake potential at low pressures, which allow them to perform more reliable $\mathrm{CO}_{2}$ uptake than other substances such as zeolites. Moreover, the metal-organic frameworks had well utilised for the selective uptake of $\mathrm{CO}_{2}$ by utilising the force of polarisable for the $\mathrm{CO}_{2}$ molecule and quadrupole moment.

Liu et al. (2012) have revealed that the metal-organic frameworks possess numerous merits such as tunable threedimensional construction, exceptional values of the surface area, managed pore configurations and tunable porosity of surface characteristics. The cations and a broad array of organic varieties can work to compose metal-organic frameworks. A couple of relevant principles pointers for choosing a suite metal-organic framework for $\mathrm{CO}_{2}$ uptake are that the porosity of the studied adsorbent must be proper with the $\mathrm{CO}_{2}$ molecules' radius. Moreover, the studied adsorbent should originate with polar, where the porosity of the surface possesses a more considerable $\mathrm{CO}_{2}$ storing ascribing to that the carbon dioxide particles possess electric quadrupole moments. Consequently, examining these criteria in the form of the metal-organic frameworks adsorbents can turn in a tremendous enhancement of the $\mathrm{CO}_{2}$ uptake.

$\mathrm{Li}$ et al. (2011a) have divided the metal-organic frameworks into two classes; rigid and dynamic. The rigid type of metal-organic frameworks should possess tunable frameworks that produce more pores alike to zeolite substances. In contrast, the dynamic kind possesses simple frameworks whose constructions alternate via outer influences alike pressure, temperature and the incorporated molecules. The numerous current procedures are to perform an untreated metal position overlying the porous via the release of the molecule of the coordinating solvent.

The enrichment in the potential of metal-organic frameworks to uptake $\mathrm{CO}_{2}$ of the mix of the various gases is reliant on the fundamental features of the metal-organic frameworks. Further, the enrichment is depended on the characteristics of the gases or mix that uptake in the metal-organic frameworks. These features comprise the construction and configuration of the metal-organic frameworks, fabrication and porous of metal-organic frameworks (Li et al. 2011a).

For example, Millward and Yaghi (2005), Furukawa et al. (2010) and Li et al. (1999) has developed four separated uptake materials of metal-organic frameworks, viz. metal-organic framework-180, metal-organic framework-200, metal-organic framework-2015 and metal-organic framework-210. The metal-organic framework-210 uptake material displayed outstanding porous of the surface and extraordinary carbon dioxide uptake achievement. Metal-organic framework-210 uptake material presented carbon dioxide removal of about $2.87 \mathrm{~g} / \mathrm{g}$ of $\mathrm{CO}_{2}$. The 
fabricated adsorbent possesses a density of the bulk around $0.25 \mathrm{~g}$ per unit volume, the volume of porous of $3.6 \mathrm{~cm}^{3}$ per gram and a more exceptional surface area of $6240 \mathrm{~m}^{2}$ per gram that is the greatest recorded for all crystalline substances. Further, they observed that metal-organic framework-2, metal-organic framework-505, $\mathrm{Cu}_{3}(\mathrm{BTC})_{2}$ (BTC $=1,3,5$-benzene tricarboxylate), isoreticular metal-organic frameworks-11, isoreticular metal-organic frameworks-3 and isoreticular metal-organic frameworks- 6 are considerably suitable adsorbents for carbon dioxide elimination. Additionally, they suggested metal-organic framework-177 that possesses a particularly exceptional surface area $\left(4.5 \times 10^{3} \mathrm{~m}^{2} / \mathrm{g}\right)$ with $\mathrm{CO}_{2}$ removal of $\sim 0.014 \mathrm{~mol} \mathrm{~g}^{-1}$ at 35 bars.

The uptake achievement of metal-organic frameworks materials has further enhanced via using a suitable linker, which can alter the surface of adsorbents whether the porous and exceptional surface area for carbon dioxide particles. Zheng et al. (2013) have developed an expanded 4,4-paddlewheel combined metal-organic framework-505 analog of a nanostructured rectangular diisophthalate associated by alkyne associations. The produced adsorbent exhibited extraordinary $\mathrm{CO}_{2}$ uptake of $0.024 \mathrm{~mol} \mathrm{~g}^{-1}$ at room temperature and unique selectivity.

The $\mathrm{CO}_{2}$ uptake into remarkable metal-organic frameworks can improve via the incorporation of heterocyclic ligands. It is obvious that these metal-organic frameworks composite of a heterocyclic ligand that is propitious for improving the $\mathrm{CO}_{2}$ uptake potential of the metal-organic frameworks. Their pristine samples metal-organic frameworks, UiO-67 (the UiO-67 composites of a cubic framework of cationic $\mathrm{Zr}_{6} \mathrm{O}_{4}(\mathrm{OH})_{4}$ nodes and biphenyl-4,4'dicarboxylate (BPDC) linkers), displayed depressed value of $\mathrm{CO}_{2}$ uptake abilities than of those qualified metal-organic frameworks holding heterocyclic ligands in their constructions (Fig. 15) (Hu et al. 2018).

\section{Membranes separation}

Among the substitutional technologies obtainable, membrane technology deems the most suitable. Also, it offers many merits in terms of energy lost and cost-effective. Membrane technology categorised into three classes based on the technique operated such as non-dispersive contact through microporous membranes, gas penetration into high-density membranes, and supported (Sreedhar et al. 2017b).

The non-dispersive contact via microporous membranes that utilised concerning post-combustion carbon separation. It possesses merits additionally, traditional uptake columns, viz. elasticity in working conditions and classes of membrane contactors that could be applied (Xu and Hedin 2014). The $\mathrm{CO}_{2}$ uptake by gas permeation results ascribed to selectivity and permeability of a high-density membrane towards an appropriate gas coupled in a mixture. The membrane

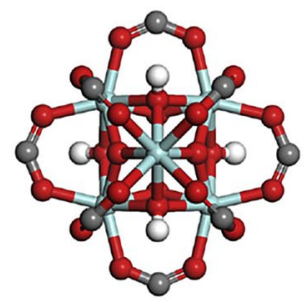

(A) $\mathrm{Zr}$ core

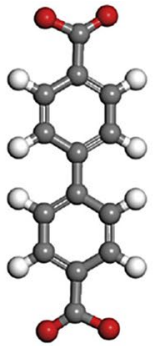

(B) BPDC

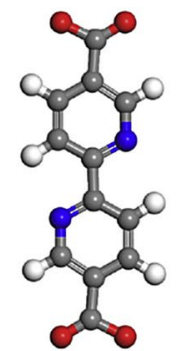

(C) BPYDC

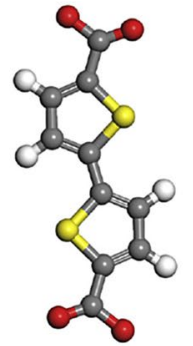

(D) BTDC

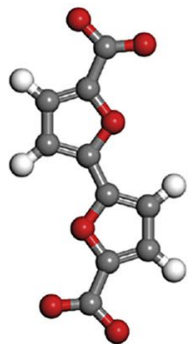

(E) BFDC

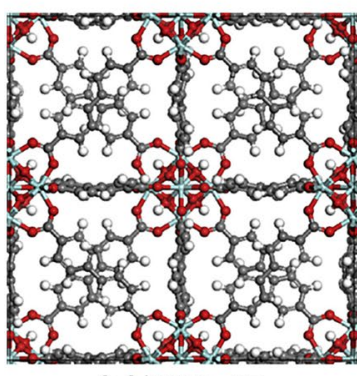

(F) UiO-67

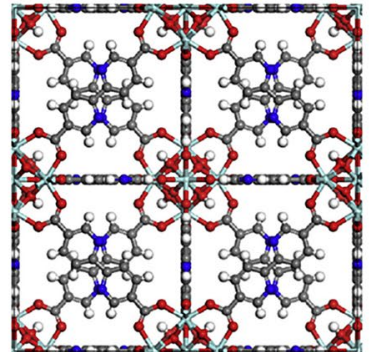

(G) $\mathrm{UiO}(\mathrm{BPYDC})$

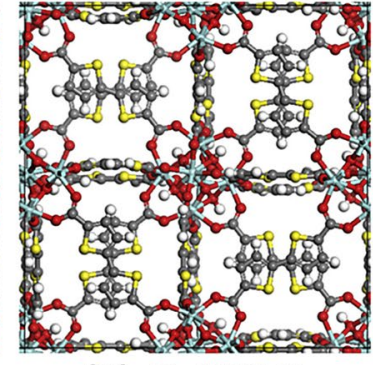

(H) Zr-BTDC

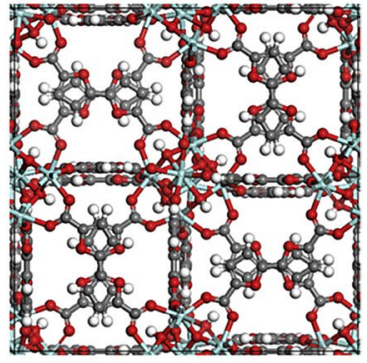

(I) Zr-BFDC

Fig. 15 Geometries of a $\mathrm{Zr}$ core and b biphenyl-4, 40-dicarboxylate (BPDC), c 2, 20-bipyridine-5, 50-dicarboxylate (BPYDC), d 2, 20-bithiophene-5, 50-dicarboxylic (BTDC), e 2, 20-bifuran-5, 50-dicarboxylic (BFDC)ligands. Crystal structure of f UiO-67 (the UiO-67 composites of a cubic framework of cationic $\mathrm{Zr}_{6} \mathrm{O}_{4}(\mathrm{OH})_{4}$

nodes and biphenyl-4,4'-dicarboxylate (BPDC), g UiO(BPYDC), h Zr-BTDC and i Zr-BFDC. (Zr: cyan; C: grey; O: red; N: blue; S: yellow; H: white). Adapted with permission from $\mathrm{Hu}$ et al. (2018), Copyright 2020, Elsevier 
has comprised of polymer in which the highest layer is a particular high-density layer posted on a cost-effective nonselective membrane (Lee et al. 2013). In supported liquid membranes, the liquid has loaded into the porous of the surface. The principal-agent that manages the selectivity in supported liquid membranes is the attraction towards $\mathrm{CO}_{2}$. The backing does not influence the membrane permeability, restricts the stability of the complete construction (Krull et al. 2008).

Guo et al. (2020) have reported amino-decorated organosilica membranes that utilise bis(triethoxysilyl)acetylene (BTESA) and (3-aminopropyl) triethoxysilane (APTES) raw materials. The studied membranes exhibit high $\mathrm{CO}_{2}$ permeance in the range 2550 gas permeance unit to 3230 gas permeance unit, while the selectivity for carbon dioxide and nitrogen reached values ranged between 31 to 42 during the carbon dioxide and nitrogen separation (Fig. 16).

The metal-organic frameworks have further examined for membrane synthesis. Usually, there are two techniques to utilise metal-organic frameworks into a membrane: the establishment of metal-organic frameworks into a polymer matrix to produce a combined form membrane and the deposition of a thin film of the metal-organic framework on a spongy substrate (Prasetya et al. 2019). Habib et al. (2020) have addressed simultaneous improvement in $\mathrm{CO}_{2}$ permeability and selectivity using unique metal-organic frameworks $\left[\mathrm{Al}_{2}(\mathrm{OH})_{2}(\mathrm{~L})\right](\mathrm{L}=$ biphenyl-3,3',5,5'-tetracarboxylate) NOTT-300 and polyether-block-amide (Pebax ${ }^{\circledR 1657)}$ as a polymer matrix. In contrast to the unadulterated polyetherblock-amide membrane, the incorporation of the framework $\left[\mathrm{Al}_{2}(\mathrm{OH})_{2}(\mathrm{~L})\right](\mathrm{L}=$ biphenyl-3,3',5,5' -tetracarboxylate $)$ with filler ratio $40 \%$ improved the permeability of $\mathrm{CO}_{2}$ with $380 \%$, and selectivity to $68 \%$ for $\mathrm{CO}_{2} / \mathrm{CH}_{4}$ and $\mathrm{CO}_{2} / \mathrm{N}_{2}$ selectivity $26 \%$. The outcomes confirmed the possibility of NOTT-300 as filler material for commixed matrix membranes endeavour at $\mathrm{CO}_{2}$ uptake ascribed to their extraordinary porosity and $\mathrm{CO}_{2}$ specific properties.

Also, Jiamjirangkul et al. (2020) have studies on gas sorption suggested that the immersion of chitosan nanofibres in Cu-BTC (copper benzene-1,3,5-tricarboxylate) metal-organic frameworks. The chitosan nanofibres on (copper benzene-1,3,5-tricarboxylate) metal-organic frameworks presented great specific surface area $\left(104.6 \mathrm{~m}^{2} / \mathrm{g}\right)$, with uptake potential of $\mathrm{CO}_{2} / \mathrm{N}_{2}$ above 14 times possesses an exceptional potential for uptake and filtration of $\mathrm{CO}_{2}$.

Magnesium oxide $\mathrm{MgO}$ is a suitable filler substance in commixed matrix membranes ascribed to its exceptional carbon dioxide uptake potential and cost-effective in contrast with metal-organic frameworks. Lee et al. (2020) have synthesised bimodal-porous, hollow magnesium oxide $\mathrm{MgO}$ spheres by spray pyrolysis and precipitation technique. The synthesised bimodal- magnesium oxide spheres were injected into poly (vinyl chloride)-graft-poly(oxyethylene methacrylate), forming commixed matrix membranes for carbon dioxide to nitrogen separation. Furthermore, particular interactions that occurred within the bimodal-magnesium oxide and carbon dioxide surface molecules improved the solubility carbon dioxide and accelerated the carbon dioxide molecules compared to those for the nitrogen molecules. The bifunctional bimodal-magnesium oxide improved the carbon dioxide permeability within physical and chemical mechanisms, together. The most suitable gas separation
Fig. 16 Structure of bis(triethoxysilyl)acetylene (BTESA) and (3-aminopropyl) triethoxysilane (APTES) raw materials and the produced materials. Adapted with permission from Guo et al. (2020), Copyright 2020, Elsevier

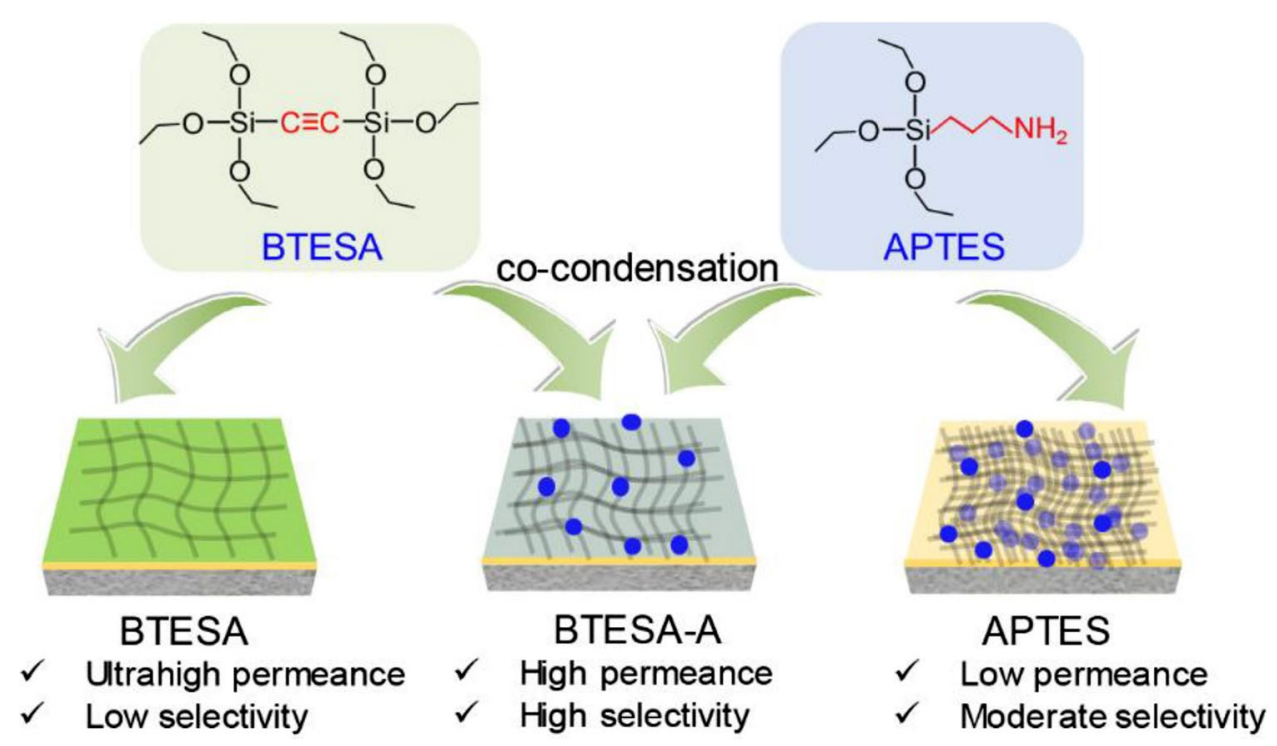

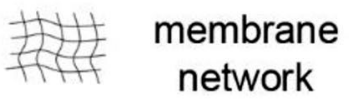

network

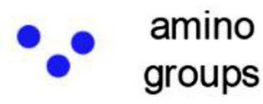


achievement was achieved in the commixed matrix membranes with bimodal-magnesium oxide fillers (10 wt \%), which confirmed a carbon dioxide permeability of 179.2 gas permeance unit and about of 42.6 of carbon dioxide to nitrogen selectivity.

Hydrophobic membranes with anti-moistening surfaces assist as the interface separating the aqueous amine absorbents and the $\mathrm{CO}_{2}$ combined gases. The $\mathrm{CO}_{2}$ gases go along into the first frontage of a hydrophobic membrane and are uptake via the amine solvent that streams on the opposite frontage of the hydrophobic membrane. If the membranes possess weak porosity and are moisten over the amine solution, the resistance of the transportation for the $\mathrm{CO}_{2}$ gases, will be improved, pointing to a reduction in $\mathrm{CO}_{2}$ uptake fluxes (Tuteja et al. 2007; Kobaku et al. 2012). Lin et al. (2018) have successfully synthesised ecofriendly, fluorine-free and watertight breathable polydimethylsiloxane on polystyrene membranes with extraordinary porosity reached about $89 \%$ via an electrospinning technique. Contrasted among pure polystyrene nanofibrous membranes, polydimethylsiloxane incorporating in polystyrene nanofibrous membranes succeeded inhibits liquid droplets from agglutinating on their surfaces, appearing in the prosperous synthesis of a membrane possess antimoistening surface. The $\mathrm{CO}_{2}$ uptake flux of the studied polydimethylsiloxane on polystyrene membranes is around $0.0019 \mathrm{~mol} / \mathrm{m}^{2} \mathrm{~s}$.

\section{Absorption-microalgae}

Microalgae $\mathrm{CO}_{2}$ fixation possesses the benefit of extraordinary photosynthetic performance, quick growth rate, excellent environment ductility, great lipid richness and the capacity to isolate carbon and therefore has been considered as a suitable approach for post-combustion $\mathrm{CO}_{2}$ uptake and utilisation (Cheah et al. 2015; Zhou et al. 2017). Normally, dissolved inorganic carbon presences in culture solution water cover carbon dioxide, bicarbonate, carbonate and carbonic acid during the dynamic ionisation equilibrium are given, unless, particularly carbon dioxide and bicarbonate are fundamental dissolved inorganic carbon patterns which can be applied by microalgae cells in several approaches (Zhao and Su 2014). The bicarbonate has proved to be practised not exclusively through a straight approach, viz. active transportation and cation exchange, but additionally through an indirect approach which catalyses bicarbonate as carbon dioxide and hydroxyl ions with periplasmic carbonic anhydrase. It gave the feasibility of incorporating microalgae agriculture with carbon dioxide uptake methods through utilising bicarbonate assembled at the uptake column as a carbon origin rather of carbon dioxide (Zhao and Su 2014; Song et al. 2019b).

Yang et al. (2020) have applied purified terephthalic acid wastewater was as the growing medium of chlorella pyrenoidosa microalgae for $\mathrm{CO}_{2}$ biouptake (Fig. 17). The alga was incapable of originating in the unmodified wastewater ascribed to low $\mathrm{pH}$ value, while it favoured bearing and
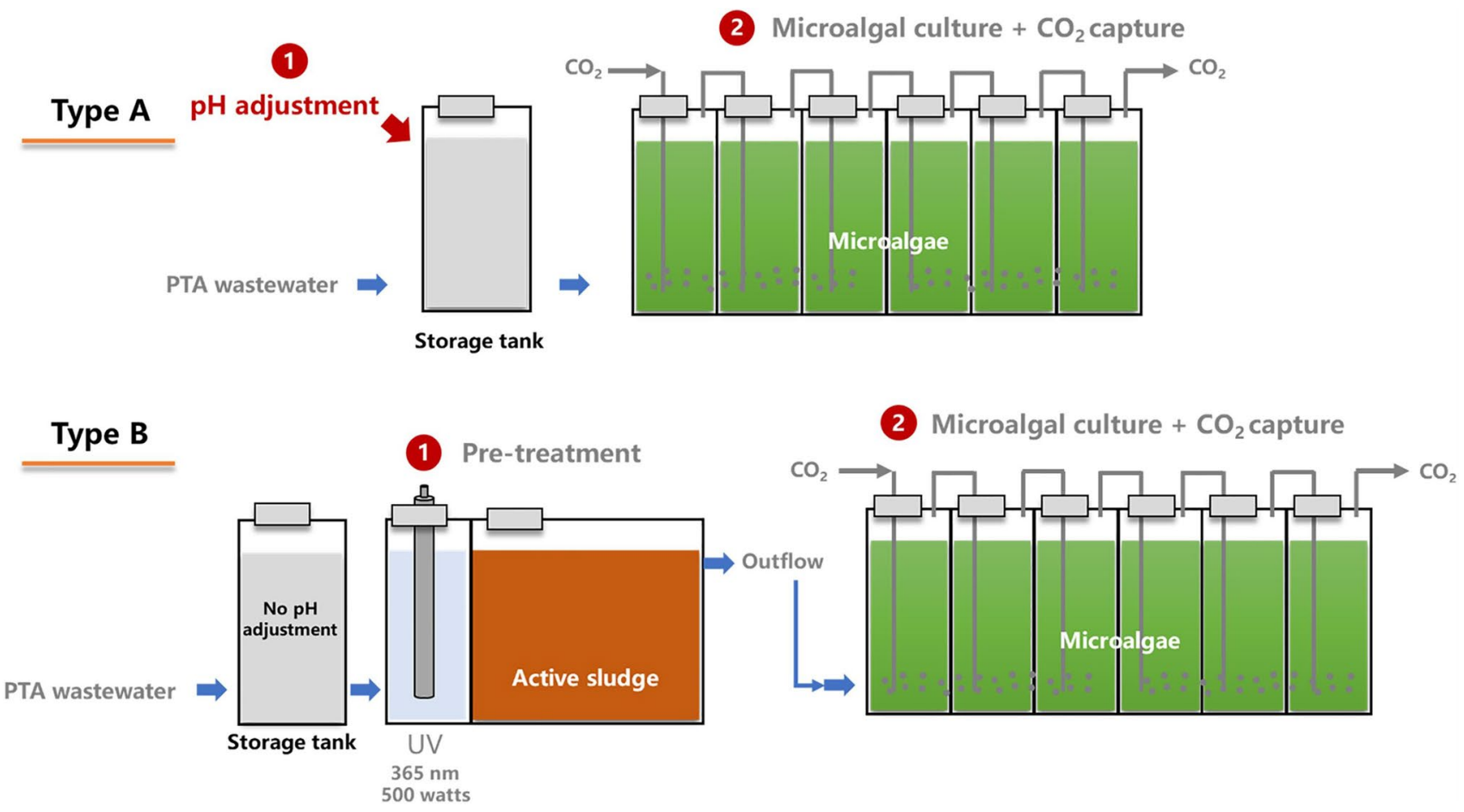

Fig. 17 The two stages of the untreated (Type A) and treated (Type B) purified terephthalic acid wastewater for $\mathrm{CO}_{2}$ uptake. Adapted with permission from Yang et al. (2020), Copyright 2020, Elsevier 


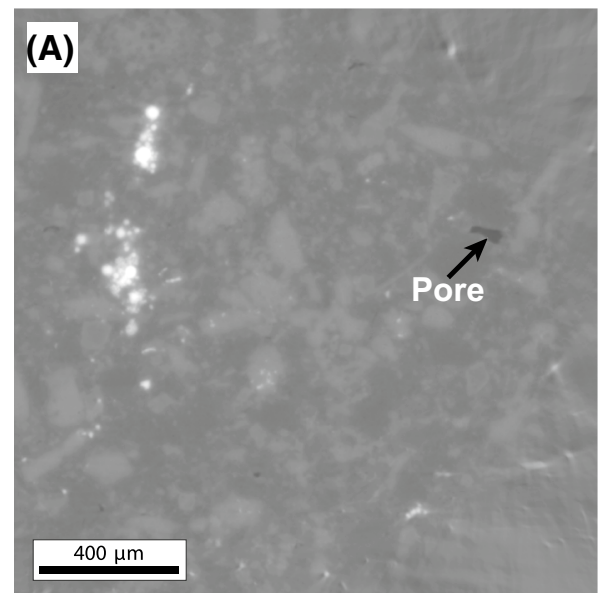

Fig. 18 A visual comparison in the pore-connectivity system between aquitard rocks (a) and the reservoir or aquifer rocks (b). Each of these images represents a 2D slice through the volume of Synchrotron Radiation X-ray Tomographic Microscopy (SRXTM) dataset with voxel size is $0.65 \mu \mathrm{m}^{3}$. a SRXTM's image for Posidonia shale-a typical cap-

acclimation in the $\mathrm{pH}(\mathrm{pH}=7.40)$ conform wastewater and the modified wastewater. The obtained outcomes confirmed that the rate of $\mathrm{CO}_{2}$ uptake and the photosynthetic rate of the algae if the growing medium is treated by wastewater were greater than these with the untreated using wastewater. The most chief algal $\mathrm{CO}_{2}$ capture rate was obtained around $\sim 82.2 \%$ for the growing medium unmodified with wastewater and $\sim 91.6 \%$ for growing medium modified with wastewater.

Azhand et al. (2020) have conducted the hydrodynamic comparison of inner and outer spargers in an airlift bioreactor and carbon dioxide biofixation investigation below various gas speeds. Also, they reviewed the input gas speed influence on the fixation of carbon dioxide through chlorella vulgaris microalgae in an airlift reactor with an outer sparger. The investigation reveals that the hydrodynamic outcome of inner and outer spargers considerably relies on the cross-sectional area. Besides, the outcomes designate that chlorella vulgaris can increase to $\sim 2.695 \times 10^{7}$ cell $/ \mathrm{mL}$ and eliminate the carbon dioxide with $94 \%$ performance in the smallest outer gas speed of $\sim 1.9 \times 10^{-3} \mathrm{~m} \mathrm{~s}^{-1}$.

As an example of the numerous considered carbon uptake techniques, thermal regeneration of intense $\mathrm{CO}_{2}$ uptake solvent is a significant challenge due to its rising energy exhaustion. Song et al. (2019a) have offered a concept of bioregeneration via microalgae for bicarbonate transform to amount-attached biomass. Also, various intense solutions (including ammonium bicarbonate, potassium bicarbonate and sodium bicarbonate) were examined to estimate the achievement of bioregeneration. The outcomes showed that ammonium bicarbonate could be a suitable bicarbonate carrier for the aimed uptake-microalgae mixture method, which possessed more extraordinary biomass productivity opposed to potassium bicarbonate and sodium bicarbonate and carbon

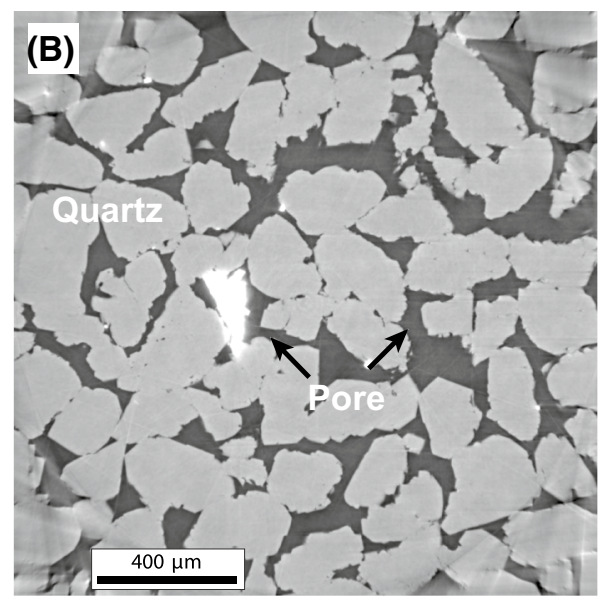

rock found in the Molasse Basin, Switzerland. b SRXTM's image for Nubian Sandstone-a typical reservoir rock found in the Gulf of Suez Basin, Egypt. Dark grey areas are pore space (air), while light grey areas represent the mineral grains (quartz). The full SRXTM raw dataset $(2560 \times 2560 \times 4320$ pixels and 8 -bits $)$ is provided by Hefny (2019)

sequestration potential reached up to $\sim 0.16 \mathrm{~g} / \mathrm{L}$ per day. At the same time, $\mathrm{pH}$ modification was an efficient procedure to additional enhance the achievement of the hybrid method.

\section{Geological $\mathrm{CO}_{2}$ storage}

\section{Global $\mathrm{CO}_{2}$ storage}

In order to limit the global warming to $1.5^{\circ} \mathrm{C}$ above the preindustrial level, IPCC (2014) estimated that the amount of $\mathrm{CO}_{2}$ that must be captured and permanently stored by the middle of this century are around 5000-10,000 million tonnes per year. Carbon Capture and Geological Storage is a process whereby $\mathrm{CO}_{2}$ is captured from flue gases, transported, compressed and finally injected in supercritical or liquefied form into suitable subsurface formations, either in a saline aquifer (Bradshaw et al. 2007; Michael et al. 2010) or, potentially, used for enhanced oil recovery (Godec et al. 2013). Ideally, the storage formation, which needs to be at a depth greater than $1 \mathrm{~km}$ to ensure that $\mathrm{CO}_{2}$ remains in the supercritical phase, is characterised by numerous intercalations of tight aquitrade rocks, e.g. shales, within the reservoir rock units, e.g. sandstone or carbonate. Such multiple confinements ensure the retention security necessary to impede the upward migration and leakage of the injected $\mathrm{CO}_{2}$ (Benson and Cole 2008).

The petrophysical properties of shale, where the porosity's range (-) is $0.01-0.10$, the mean pore size's range $\mathrm{nm}$ is $5-100$, a high capillary pressure's range (MPa) up to $\sim 400$ and the permeability's range $\left(\mathrm{m}^{2}\right)$ is $10^{-21}$ to $10^{-19}$, make the favourable conditions for the aquitrade in limiting the potential $\mathrm{CO}_{2}$ leakage to be minimal (Armitage et al. 2010) (Fig. 18a). Compared to the basement complex, 
Table 1 Adsorbents for carbon dioxide capture

\begin{tabular}{|c|c|c|c|c|}
\hline Adsorbent & $\begin{array}{l}\text { BET Surface } \\
\text { area }\left(\mathrm{m}^{2} / \mathrm{g}\right)\end{array}$ & Pore size $(\mathrm{nm})$ & $\begin{array}{l}\mathrm{CO}_{2} \text { adsorp- } \\
\text { tion capacity } \\
\left(\mathrm{mol} \mathrm{g}^{-1}\right)\end{array}$ & References \\
\hline Activated carbon/coconut shell & 370.72 & 1.63 & 0.0018 & Rashidi et al. (2014) \\
\hline Activated carbon/sustainable palm & - & - & 0.00732 & Nasri et al. (2014) \\
\hline Activated carbon/cellulose & 2370 & 1.2 & 0.0058 & Sevilla and Fuertes (2011) \\
\hline Activated carbon/starch & 2850 & 1.2 & 0.0055 & Sevilla and Fuertes (2011) \\
\hline Activated carbon/olive stone & 1215 & - & 0.0031 & González et al. (2013) \\
\hline Activated carbon/algae & 2390 & 1.8 & 0.0038 & Sevilla et al. (2012) \\
\hline Activated carbon/baggase & 923 & - & 0.0017 & Boonpoke et al. (2012) \\
\hline Activated carbon/bamboo & 1846 & - & 0.007 & Wei et al. (2012) \\
\hline Activated carbon/rice husk & 927 & - & 0.0013 & Boonpoke et al. (2011) \\
\hline Activated carbon/coffee ground & 831 & - & 0.0049 & Plaza et al. (2012) \\
\hline Activated carbon/nut shell & 573 & - & 0.00348 & Bae and $\mathrm{Su}(2013)$ \\
\hline Three-dimensional graphene & 477 & - & 0.0007 & \\
\hline $\begin{array}{l}\text { N-doped porous carbon@polypyrrole/reduced graphene } \\
\text { oxide }\end{array}$ & 1588 & 14.7 & 0.0043 & Chandra et al. (2012) \\
\hline Polyaniline@graphene & - & - & 0.075 & Mishra and Ramaprabhu (2012) \\
\hline Graphene-manganese oxide & 541 & 4.3 & 0.00259 & Zhou et al. (2012) \\
\hline Zeolitic imidazolate frameworks-8@ graphene oxide & 1120 & - & 0.01636 & Kumar et al. (2013) \\
\hline $\mathrm{Fe}_{3} \mathrm{O}_{4}$-graphene & 98.2 & 3.8 & 0.06 & Mishra and Ramaprabhu (2014) \\
\hline ZnO-based N-doped reduced graphene oxide & 1122 & 0.71 & 0.0355 & Li et al. (2016) \\
\hline Montmorillonite clay/reduced graphene oxide & 50.77 & - & 0.00049 & Stanly et al. (2019) \\
\hline Zeolite SSZ-13 & - & - & 0.00398 & Hudson et al. (2012) \\
\hline Zeolite $\mathrm{NaX}$ & 672.09 & - & 0.00553 & Xu et al. (2019) \\
\hline Zeolite-5A@meta-organic framework-74 & - & - & 0.0138 & Al-Naddaf et al. (2020) \\
\hline Silica@ amine-like motifs & 199 & 67 & 0.0014 & Zhao et al. (2010) \\
\hline Sodium metasilicate & 908 & - & 0.00292 & Lin and Bai (2010) \\
\hline Amines immobilised double-walled silica nanotubes & 348 & - & 0.0023 & Ko et al. (2013) \\
\hline Amino-modified silica fume & 271.2 & - & 0.0013 & Liu and Lin (2013) \\
\hline HMS (wormhole) & 1181 & - & 0.0056 & Sanz-Pérez et al. (2015) \\
\hline 3-Aminopropyltriethoxysilane@ SBA-15 silica & 572 & - & 0.0041 & Ribeiro et al. (2019) \\
\hline$\left[\mathrm{Co}_{4}(\mathrm{OH})_{2}(p-\mathrm{CDC})_{3} \mathrm{DMF}_{2}\right]_{n}$ & 1080 & - & 0.0037 & Farha et al. (2009) \\
\hline Amine-chromium terephthalate metal-organic framework & 2297 & - & 0.002 & Yan et al. (2013) \\
\hline Metal-organic framework MIL-53(Al)/graphene nanoplates & 1281 & - & 0.001295 & Pourebrahimi et al. (2015) \\
\hline
\end{tabular}

BET Brunauer-Emmett-Teller

sedimentary rocks, e.g. sandstone, fall into the category of a porous medium where the injected fluids can freely move through, or be stored in the intrinsic void space without requiring hydraulic stimulation. Figure $18 \mathrm{~b}$ shows a $2 \mathrm{D}$ grey-level slice of a high-resolution Synchrotron Radiation X-ray Tomographic Microscopy for the Nubian Sandstone, a typical reservoir rock type found in the Gulf of Suez Basin (Egypt) with a porosity (-) up to 0.3 , a mean pore size (nm of $44 \times 10^{4}$, capillary pressure (MPa) 25.3 and permeability $\left(\mathrm{m}^{2}\right)$ of $2.56 \times 10^{-12}$ (Hefny et al. 2020).

Sedimentary basins are the subsidence areas of the earth's crust that is underlain by a thick sequence of such sedimentary rocks (Selley and Sonnenberg 2015). Over 800 sedimentary basins worldwide based on basement outcrop, structure, total sediment isopachs, subsidence regime, basin evolution and petroleum systems and other public data are defined and shown in Fig. 19 (IPCC 2005). Mostly, the sedimentary rocks are inherently heterogeneous assemblages of depositional lithofacies, each with characteristic mineralogical content and bedding architectures (i.e. foliation, shear and compaction banding). These geological variations are resulting directly from the formation of the rock, from the stress fields applied to it later (Zoback and Byerlee 1976) or from diagenetic changes (Aplin et al. 2006). Moreover, the orientation of both the mineral grains and the pores (Wright et al. 2009) or crack (Guéguen and Schubnel 2003) along a preferential direction can also constitute barriers to flow, or at least reduce it (Clavaud et al. 2008), and resulting in 
different elastic responses (Helbig and Thomsen 2005). Therefore, the deployment challenges of large-scale $\mathrm{CO}_{2}$ storage in the geological formations will be affected by quantification of the geological heterogeneity which influences both the microscopic fluid displacement processes, thermo-hydro-mechanical (THM) processes, caprock integrity, induced seismicity and well's $\left(\mathrm{CO}_{2}\right)$ injectivity. These challenges will be discussed in details as follows.

Given the fact that CCUS entails cyclic fluid(s) injection into (and possibly retrieval from) these geological formations, unintended changes in dynamic reservoir properties (e.g. saturation, pressure) will be often induced and needs to be quantified using the inversion of the geophysical field data (such as time-lapse seismic data, gravity data). However, the time-lapse seismic inversion will be quite problematic, if not impossible, without proper rock physics models which can capture these geological features at small scale and find the relationship of that complexity to the fluids flow (and seismic waves propagation) through it. The regional heterogeneities at field scale include lithofacies geometries and continuity, thickness variability, preferential alignment of the faults network and bulk reservoir properties (Fig. 19). On the other hand, the heterogeneities of wellbore scale can be extended down to the microscopic pore network, grain size and mineral contents and orientation. Therefore, the impact of these geological features (such as heterogeneity scale, anisotropic behaviour, the topology of a porous medium and mineralogical contents) on rock physics model (including seismic-waves velocity, permeability tensor, two-phase constitutive relationships) needs to be considered for the geophysical data inversion.

Moreover, the geological heterogeneity contributes towards the quantification of the basin-scale $\mathrm{CO}_{2}$ storage capacity of the reservoir. For a consistency with methods used in previous studies to assess the prospective geologic storage of buoyant fluids in subsurface formations (van der Meer 1995; Doughty et al. 2001; Kopp et al. 2009; Goodman et al. 2011; NETL 2015; Hefny et al. 2020), Eq. (6) is used to estimate the theoretical (in a conservative approach) reservoir storage capacity.

$M_{\mathrm{CO}_{2}}^{\text {eff }}=\zeta_{\text {eff }} V_{\text {res }}^{\text {bulk }} \rho_{\mathrm{CO}_{2}}(T, p)$,

where, $M_{\mathrm{CO}_{2}}^{\text {eff }}$ is the effective storage capacity $(\mathrm{kg}), V_{\text {res }}^{\text {bulk }}$ is the bulk reservoir volume $\left(\mathrm{m}^{3}\right)$ and $\rho_{\mathrm{CO}_{2}}$ is the $\mathrm{CO}_{2}$ density $\left(\mathrm{kg} \mathrm{m}^{-3}\right)$ as a function of the corresponding reservoir temperature and pressure. The dimensionless $\mathrm{CO}_{2}$-storage efficiency factor, $\zeta_{\text {eff }}(-)$, represents the fraction of the total pore volume that can be occupied by the injected $\mathrm{CO}_{2} . \zeta_{\text {eff }}$ can be estimated based on a combination of coefficients for the geometric capacity, the geological heterogeneity capacity and reservoir porosity.

An additional parameter for the safekeeping of underground stored $\mathrm{CO}_{2}$ is the sealing capacity of the caprock, despite faults and fractures, which may occur in it. The $\mathrm{CO}_{2}$ injection pressure at the bottom-hole must remain below the fracture stress gradient to avoid caprock integrity, while being larger the in situ fluid pressure to displace the resident formation fluid (brine) by $\mathrm{CO}_{2}$. As a continuous $\mathrm{CO}_{2}$ injection, excess fluid pressure will be built up in the reservoir-a condition that develops high permeability pathways within the caprock unless water-extraction wells operate concurrently with $\mathrm{CO}_{2}$ injection (Bergmo et al. 2011). Ideally and according to Espinoza and Santamarina (2017), a leak rate of $3 \mathrm{~kg} / \mathrm{m}^{2} /$ year corresponds to $\sim 2 \mathrm{~cm}$ of the $\mathrm{CO}_{2}$ pool height is enough to saturate the pore water in a shallow $100 \mathrm{~m}$ sediment column in 100 years.

Moreover, the potential physicochemical interactions between the dry supercritical $\mathrm{CO}_{2}$, the resident formation fluid and rocks may cause formation dry-out, whereby minerals (mainly salts) precipitate due to continuous evaporation of water into the $\mathrm{scCO}_{2}$ stream. Depending on the spatial distribution of the salt precipitate within the pore system, the intrinsic permeability can be significantly impaired, leading to a considerable decrease in the well's $\left(\mathrm{CO}_{2}\right)$ injectivity index (Muller et al. 2009; Grimm Lima et al. 2020).

Of the previously mentioned technologies, Carbon Capture and Geologically Storage has been implemented in practice, albeit thus far only at relatively small scales, with the Norwegian Sleipner site in the North Sea being the longest-running and largest-scale carbon capture and storage project in the world (Furre and Eiken 2014; Eiken et al. 2011; Eiken 2019). Roughly 0.85 million tonnes of $\mathrm{CO}_{2}$ are injected annually for a cumulative total of over 16.5 million tonnes as of January 2017. In Sleipner site, 2D, 3D and 4D geophysical data have been acquired to ensure that there is no $\mathrm{CO}_{2}$ leakage.

The time-lapse high-quality seismic field datasets have been acquired covering roughly the same $4 \times 7 \mathrm{~km}^{2}$ area. The seismic data consist of (1) the benchmark (base) model and (2) twelve (a huge number, given the complexity of acquiring 3D seismic data in the field, in this case even off-shore in the North Sea) time-lapse seismic surveys as a function of $\mathrm{CO}_{2}$ injection. All surveys and differences have high signalto-noise ratios due to the large contrast in acoustic properties between the in situ saline aquifer and the injected $\mathrm{CO}_{2}$ and have been valuable for understanding the $\mathrm{CO}_{2}$-plume development (Fig. 20).

\section{Thermophysical fluid properties}

The subsurface $\mathrm{CO}_{2}$-plume migration at a representative geological scale depends on: (1) rock properties at the pore scale, such as relative permeability and capillary pressure curves in addition to their intrinsic characteristic features, and (2) fluid pairs $\left(\mathrm{CO}_{2}\right.$-brine) properties such as density and viscosity differences, mobility ratios, interfacial tensions 


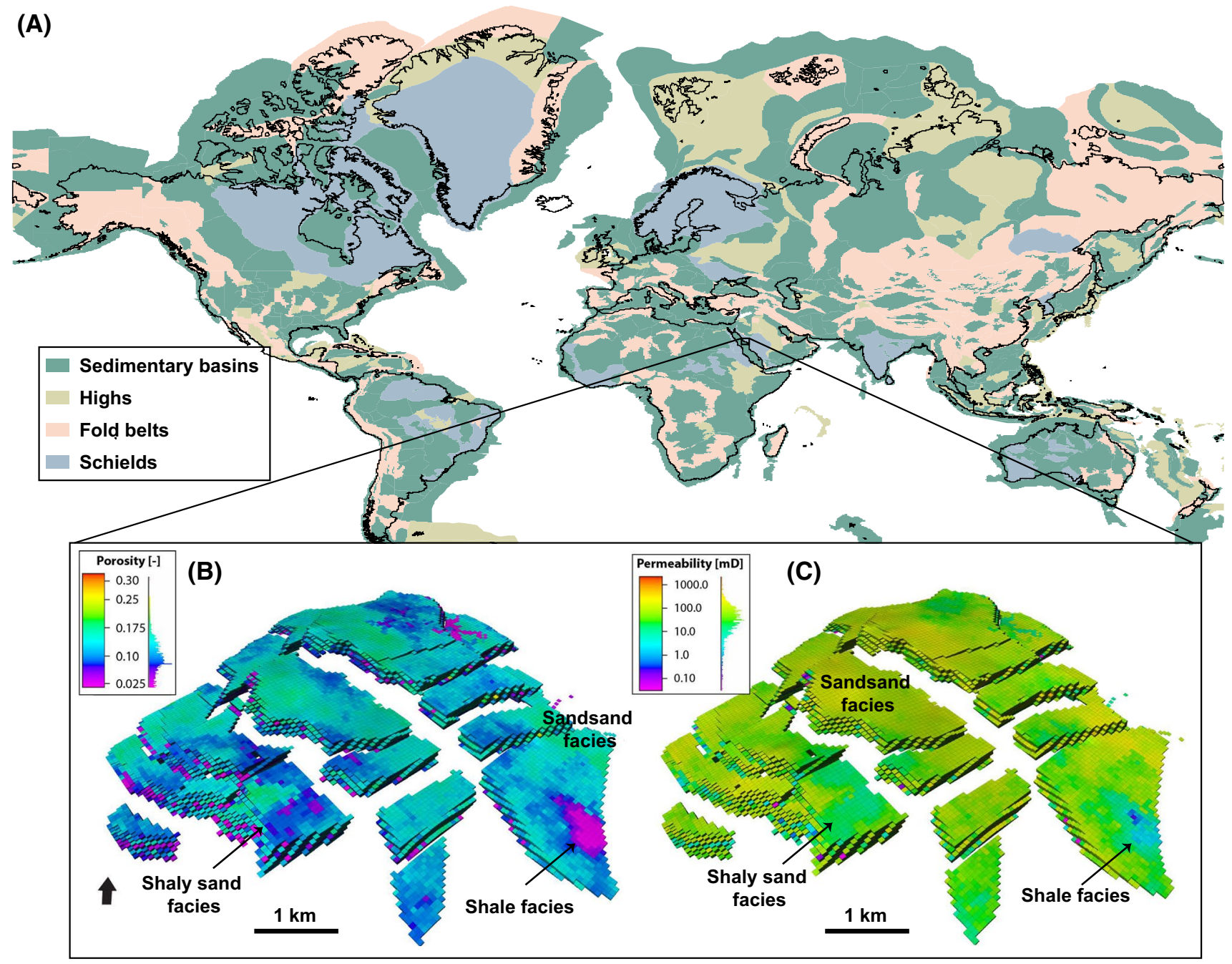

Fig. 19 a Distribution of sedimentary basins around the world showing the potential sites for $\mathrm{CO}_{2}$ geosequestration. The map is modified after IPCC (2005), Bradshaw et al. (2005) and USGS (2001). Threedimensional perspective views of $\mathbf{b}$ porosity distribution model and $\mathbf{c}$ the calculated permeability distribution model of Nubian Sandstone III compartmentalised reservoir at the Gulf of Suez Basin (Egypt), (Hefny 2020). The calculated permeability is based on a realisation of the rock physics model biased with lithofacies well-logs. The pref-

and $\mathrm{CO}_{2}$ solubilities. Two $\mathrm{NaCl}$ brine molalities have been chosen to replicate the salinity at (I) the Gulf of Suez in Egypt $(0.66 \mathrm{~mol} / \mathrm{kg})$ and (II) the Aquistore Carbon Capture and Storage site in Canada (4.63 mol/ $\mathrm{kg}$ ). Moreover, regions with large geothermal gradients exhibit different thermophysical properties than those regions that exhibit smaller geothermal gradients.

The thermophysical properties of the fluid pairs $\left(\mathrm{CO}_{2}\right.$ and brine) describe the multiphase flow behaviour and define the functionality of a CPG system. The thermophysical properties of fluids were chosen to represent those found in a deep geological formation, typical for depleted oil and gas reservoirs. Above these conditions $\left(T_{\text {crit }}=31.1^{\circ} \mathrm{C}\right.$ and erential alignment of faults (white channels among fault blocks) are considered as sources of regional anisotropy and potential hydraulic transmissive structures. This 3D rendering of property models is representing only the blocks of Nubian Sandstone III reservoir and showing how field-scale heterogeneities can affect the fluids injectivity. Histograms showing the dominance of the distributed property values are included in the legend box. A generalised depth to the reservoir top is $\sim 3350 \mathrm{~m}$ with an average reservoir thickness of $\sim 38 \mathrm{~m}$

$\left.P_{\text {crit }}=7.38 \mathrm{MPa}\right), \mathrm{CO}_{2}$ acts as a super-critical fluid with a gas-like viscosity but a liquid-like density.

\section{Density and dynamic viscosity}

For a given pressure and temperature, the density and dynamic viscosity of supercritical $\mathrm{CO}_{2}$ are iteratively calculated using the Span and Wagner equation of state Span and Wagner (1996) and Fenghour et al. (1998)'s correlation, respectively. The results are shown in Fig. 21. Primarily, the densities $\left(\mathrm{kg} / \mathrm{m}^{3}\right)$ and dynamic viscosities $(\mu \mathrm{Pa} . \mathrm{s})$ for both $\mathrm{CO}_{2}$ and brine increase with increasing pressure and decreasing temperature. 


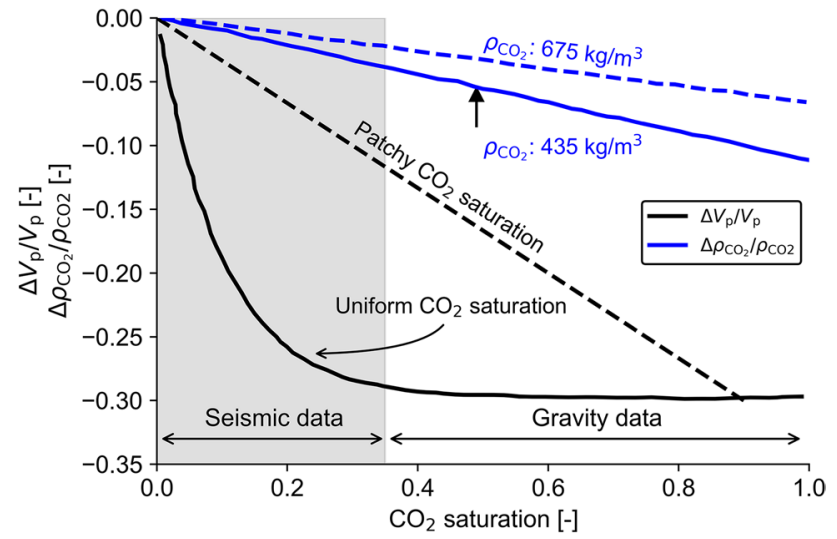

Fig. 20 Relative changes in seismic p-wave velocity (solid and dashed black lines) and density assuming $\mathrm{CO}_{2}$ density of $675 \mathrm{~kg} / \mathrm{m}^{3}$ (dashed blue line) and density assuming $\mathrm{CO}_{2}$ density of $425 \mathrm{~kg} / \mathrm{m}^{3}$ (solid blue line) versus $\mathrm{CO}_{2}$ saturation. The two double arrows indicate which saturation bands can be resolved by time-lapse seismic (grey box) and gravity data, respectively. These parameters (velocity and density) are key input parameters to estimate the changes in seismic impedance and the reflection coefficients. The figure is modified after Eiken (2019)

The density can then be used to calculate the other fluid properties, such as internal energy, directly. In fact, the $\mathrm{CO}_{2}$ dynamic viscosity is one of the most crucial parameters for successful implementation and forecasting of numerous applications including $\mathrm{CO}_{2}$-based geothermal system and $\mathrm{CO}_{2}$-Enhanced Oil Recovery. In $\mathrm{CO}_{2}$-based geothermal system, such as $\mathrm{CPG}$, dividing the density of $\mathrm{CO}_{2}$ by its dynamic viscosity results in high mobility (i.e. the inverse of kinematic viscosity) compared to brine. The mobility will be described in details in "CO2 mobility ratio" section. Moreover, the dynamic viscosity can be indirectly related through the Reynolds number with the pressure drop during flow in pipelines, which in turn affects the power consumption of pumps. It was reported that a viscosity underestimation of $30 \%$, will lead to a $30 \%$ underestimation of the pumpcompressor power consumption (Li et al. 2011b).

\section{Interfacial tension in $\mathrm{CO}_{2}$-brine systems}

We used the empirical relationships derived from the most comprehensive dataset after Li et al. (2012c) and Bachu and Bennion (2009) in order to calculate the interfacial tension between supercritical $\mathrm{CO}_{2}$ and aqueous solutions with different salt molalities (mol $/ \mathrm{kg}$ ). The interfacial tension is developed as a function of pressure, temperature and brine salinity and primarily decreases with increasing $\mathrm{CO}_{2}$ solubility. At conditions relevant to the CPG subsurface reservoir, the interfacial tension ranges from $24 \mathrm{mN} / \mathrm{m}$ at high temperature, low salinity $(0.66 \mathrm{~mol} / \mathrm{kg})$ and high-pressure conditions
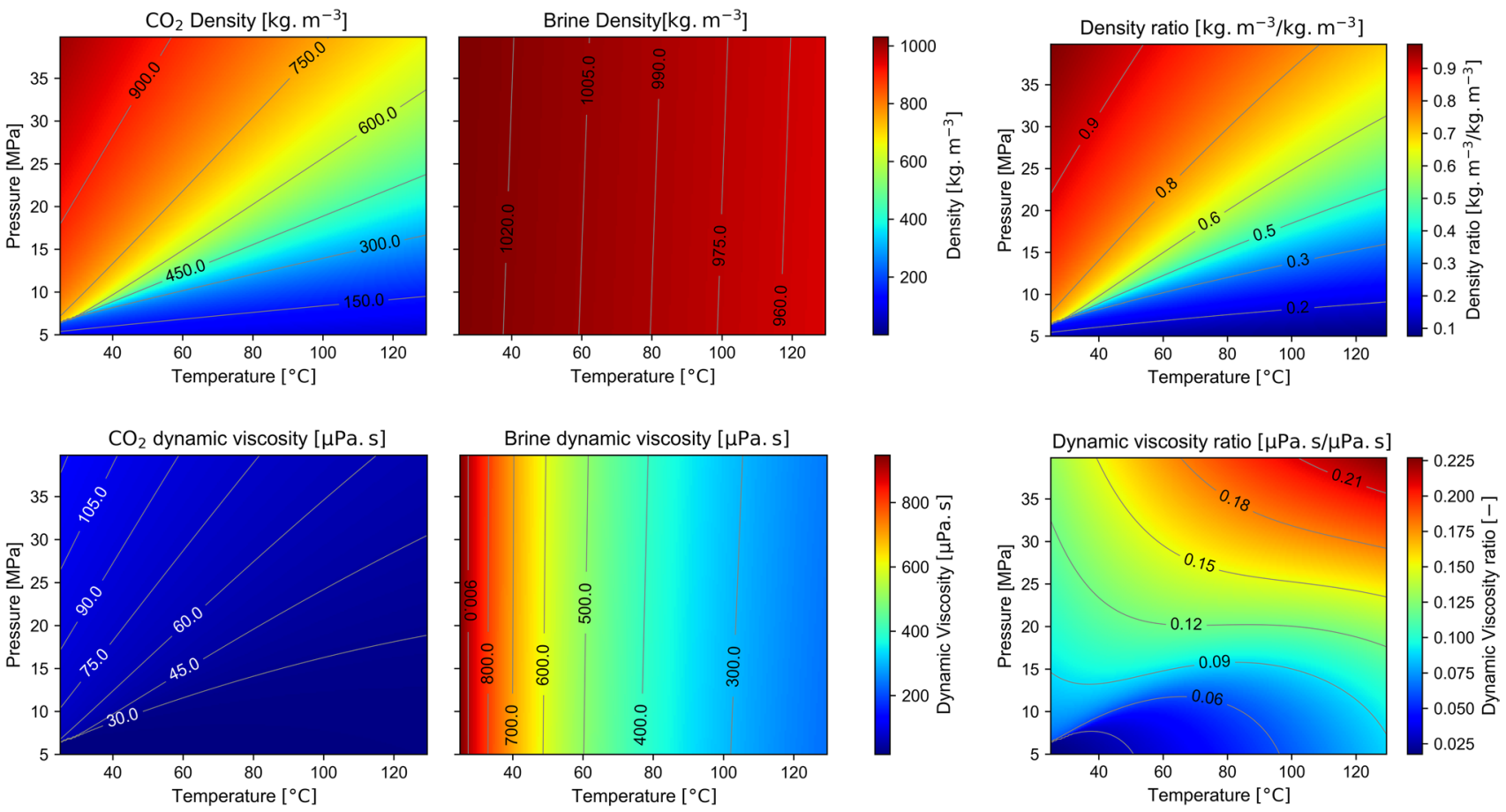

Fig. 21 Thermophysical properties of the fluids, brine and supercritical $\mathrm{CO}_{2}$, used for fluid flow simulation. The P-T conditions are representative of relevant conditions typical of CCUS reservoirs.
(Top) Densities and density ratio of the $\mathrm{CO}_{2}$-brine system calculated at $0.66 \mathrm{~mol} / \mathrm{kg}$ salinity. (Bottom) Dynamic viscosities and viscosity ratio of the $\mathrm{CO}_{2}$-brine system calculated at $0.66 \mathrm{~mol} / \mathrm{kg}$ salinity 
to $52 \mathrm{mN} / \mathrm{m}$ at low-temperature, high-salinity $(4.63 \mathrm{~mol} / \mathrm{kg})$ and high-pressure conditions (Fig. 22).

\section{$\mathrm{CO}_{2}$ solubility in aqueous solution}

Given that the dissolution of $\mathrm{CO}_{2}$ in aqueous solution is extremely slow, it can minimally affect the $\mathrm{CO}_{2}$ circulation during the time frames considered in CPG systems. Alternatively and during carbon capture and storage, convective dissolution, driven by a small increase in brine density with $\mathrm{CO}_{2}$ saturation, is considered to be the primary mechanism of $\mathrm{CO}_{2}$ dissolution trapping, critical for the long-term fate of $\mathrm{CO}_{2}$ and storage security (Martinez and Hesse 2016; Kong and Saar 2013).

The most commonly used thermodynamic models to describe the mole fraction (solubility) of $\mathrm{CO}_{2}$ for a $\mathrm{CO}_{2}-$ brine system are provided by Duan and Sun (2003) and Duan et al. (2006). Generally, $\mathrm{CO}_{2}$ solubility in brine increases with increasing pressure and temperature and decreasing brine salinity, but at the pressures relevant to geologic $\mathrm{CO}_{2}$ storage, the $\mathrm{CO}_{2}$ solubility decreases with increasing temperature (Fig. 22).

\section{$\mathrm{CO}_{2}$ mobility ratio}

In the continuity equation, we assume that fluid flow obeys Darcy's law and that heat is both advected by the fluids and conducted through the rock-fluid system.

$Q=\Delta P \frac{k A}{L} \frac{\rho}{\mu} c_{\mathrm{p}} \Delta T$,

where $P$ is the pressure (Pa), $L$ is the reservoir thickness (m), $k$ is the reservoir permeability $\left(\mathrm{m}^{2}\right), A$ cross-sectional area $\left(\mathrm{m}^{2}\right), c_{\mathrm{p}}$ is specific heat capacity at constant pressure $\left[\mathrm{kJ} /\left(\mathrm{kg} .{ }^{\circ} \mathrm{C}\right)\right], \mu$ is the dynamic viscosity $(\mu \mathrm{Pa} . \mathrm{s}), \rho$ is the density $\left(\mathrm{kg} / \mathrm{m}^{3}\right)$ and $T$ is the temperature $\left({ }^{\circ} \mathrm{C}\right)$. The fluid mass flowrates for any given driving force is proportional to the ratio of density to dynamic viscosity, also known as Mobility, $M=\rho / \mu$ (i.e. the inverse of kinematic viscosity), given all else parameters in Eq. (7) being equal. In the case of water, $M$ is mostly a function of temperature and much less pressure that reflects the primary dependence of both water's density and viscosity on temperature as previously introduced. In the case of $\mathrm{CO}_{2}$, density and viscosity have significant dependence on both temperature and pressure. For conditions relevant for fluid injection (i.e. $T$ lower than $\left.50^{\circ} \mathrm{C}\right), \mathrm{CO}_{2}$ mobility is larger than for water by factors ranging from 4 to 10 . For temperatures near $100^{\circ} \mathrm{C}, \mathrm{CO}_{2}$ is larger by a factor of approximately 4 than that of water. Additionally, the mobility ratio between $\mathrm{CO}_{2}$ and brine depends on salinity. Figure 22 shows that the mobility ratio is large for a more saline aqueous solution than those with less salinity.

\section{Specific heat capacity}

The specific heat capacity is the ratio of the heat transfer to a body to the associated temperature change and its weight. It describes the ability of a material to store heat and is temperature-dependent. The volumetric heat capacity is the product of specific heat capacity and density and is used to calculate the thermal capacity of geothermal projects. The constantpressure (isobaric) specific heat capacity, $c_{\mathrm{p}}\left[\mathrm{kJ} /\left(\mathrm{kg} .{ }^{\circ} \mathrm{C}\right)\right]$, of the working fluid, as it flows through the reservoir, is calculated by Eq. (8).

$c_{\mathrm{p}}=\left.\frac{\partial \mathrm{h}}{\partial \mathrm{T}}\right|_{\mathrm{p}}$,

where $\partial \mathrm{h}$ is the fluid's heat changes for a given fluid's temperature changes, $\partial \mathrm{T}$. A comparison of the specific heat capacity for water and supercritical $\mathrm{CO}_{2}$ is shown in Fig. 23. At high pressure of more than $30 \mathrm{MPa}$, the increase in specific heat capacity with constant temperature for $\mathrm{CO}_{2}$ is less than half of the increase of water, indicating that more than twice the $\mathrm{CO}_{2}$ mass flowrate would be needed to achieve the same rate of sensible heat transport.

\section{$\mathrm{CO}_{2}$ utilisation pathways}

Various $\mathrm{CO}_{2}$ utilisation routes were successfully researched in term of technical and economic feasibility. Currently, the gross global utilisation of $\mathrm{CO}_{2}$ is lower than 200 million tonnes per year which is roughly negligible compared with the extent of global anthropogenic $\mathrm{CO}_{2}$ emissions (higher than 32,000 million tonnes per year) (Rafiee et al. 2018). Applicability of waste $\mathrm{CO}_{2}$ in different fields such as direct routes (i.e. beverage carbonation, food packaging and oil or gas recovery), material and chemical industries (i.e. acrylates, carbamates, carbonates, polyurethanes, polycarbonates, formaldehyde and urea) and fuels (i.e. biofuels, dimethyl ether, tertiary butyl methyl ether and methanol) are currently operated (Srivastava et al. 2020). Poliakoff et al. (2015) stated 12 principles to assess $\mathrm{CO}_{2}$ utilisation approaches. In another comprehensive study articulated by Otto et al. (2015), they evaluated 123 reaction pathways to divert into chemicals (i.e. 100 for fine chemicals and 23 for bulk chemicals). Lee (2016) investigated $\mathrm{CO}_{2}$ capture and utilisation based on industrial waste-desulphurisation gypsum $\left(\mathrm{CaSO}_{4}\right)$ and waste concrete $\left(\mathrm{Ca}(\mathrm{OH})_{2}\right)$ through biobutanol and green polymer that utilises nearly 5.55 million tonnes per year of $\mathrm{CO}_{2}$. Masel et al. (2016) claimed the successful conversion (98\%) of $\mathrm{CO}_{2}$ to $\mathrm{CO}$ with an overall energy efficiency of $80 \%$. Besides, they announced the economic feasibility of acrylic acid, carbon monoxide, formaldehyde and formic acid of $\mathrm{CO}_{2}$ separation costs of $\$ 60$ 

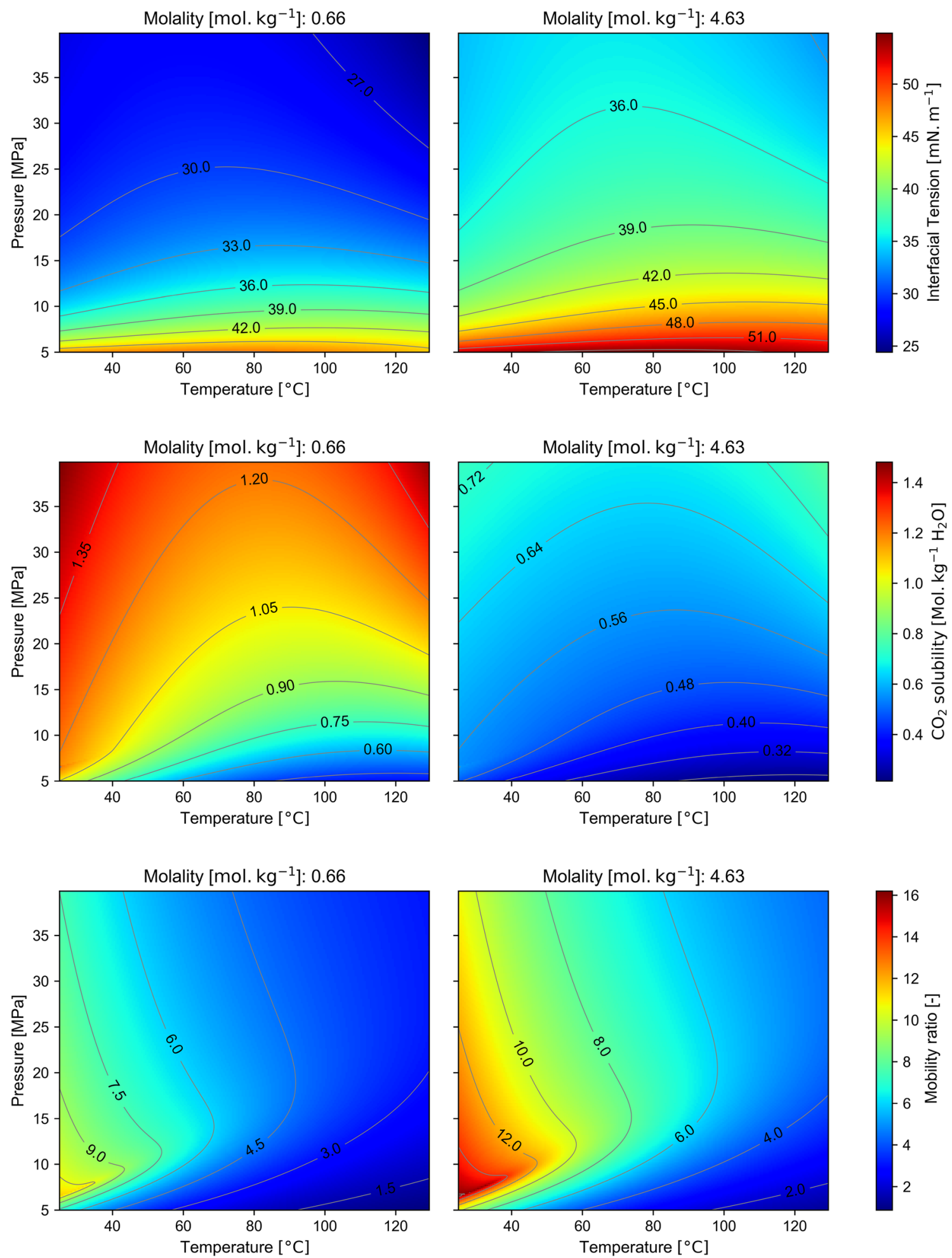

Fig. 22 Thermophysical properties of the $\mathrm{CO}_{2}$-brine system calculated for brine with molality ( $\mathrm{mol} / \mathrm{kg}$ ) of 0.66 (left column) reflecting the salinity conditions in the Gulf of Suez and 4.63 (right column) reflecting the salinity conditions in Aquistore (Canada). (Top):

Interfacial tension, (Middle): $\mathrm{CO}_{2}$ Solubility in aqueous solution and (bottom): Mobility ratio between $\mathrm{CO}_{2}$ and brine (inverse of kinematic viscosity) 


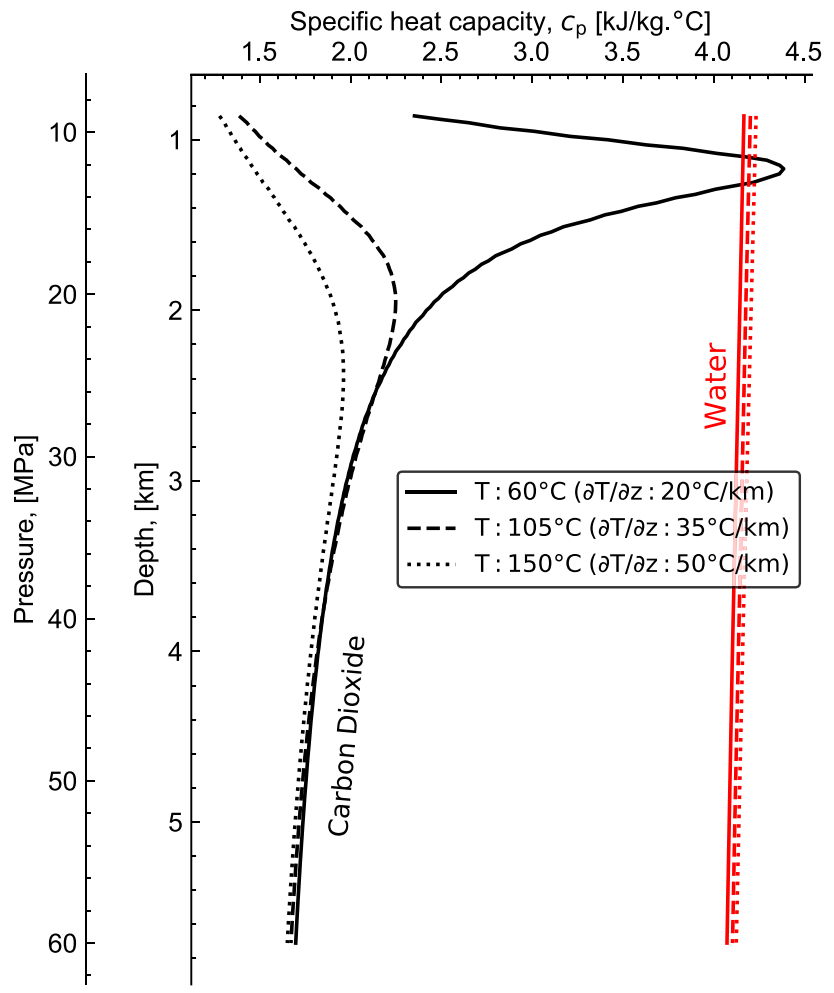

Fig. 23 Specific heat capacity, $c_{\mathrm{p}}\left[\mathrm{kJ} /\left(\mathrm{kg} .{ }^{\circ} \mathrm{C}\right)\right]$ of water and supercritical $\mathrm{CO}_{2}$ as a function of pressure and at a constant temperature. These thermal conditions correspond to a geological formation at depth ranges from 0.8 to $5.7 \mathrm{~km}$ and with three different geothermal gradients. The figure is prepared from the data published by Lemmon et al. (2018)

per tonne and without a tax on emissions. Lifecycle and techno-economic analyses were performed for $\mathrm{CO}_{2}$ (waste gas) recovery from power plant into algal biomass production system (annual $\mathrm{CO}_{2}$ production rate of 30.3 million $\mathrm{kg}$ per year). The algal process captured $70 \%$ of the flue-gas $\mathrm{CO}_{2}$ and produced 42,400 ton of dry algal biomass per year.

\section{Production of fuel, biofuel and chemicals from $\mathrm{CO}_{2}$}

Because of the growing reliance on fossil fuels and dwindling resources, seeking alternatives to them is considered a high priority worldwide. Generally speaking, the sustainable alternative of converting $\mathrm{CO}_{2}$ from harmful greenhouse gas, causing global warming into a renewable carbon source has become a critical issue. $\mathrm{CO}_{2}$ can be converted directly into a number of valuable chemicals via either exergonic or endergonic reactions (Rafiee et al. 2018). During the reforming process, converting non-value-materials into valuable fuels and chemicals is associated with the release of syngas (intermediate product). Often, it consists of major fractions of hydrogen and carbon monoxide accompanied by small fractions of water and carbon dioxide (Ayodele et al. 2015). Reforming can take place in a solid state and with or without gaseous state into syngas throughout pyrolysis or gasification of biomass or natural gas conversion, respectively. Significant quantities of $\mathrm{CO}_{2}$ emitted from different industrial installations (i.e. fossil fuel-fired power plants) can be used as feedstocks in various $\mathrm{CO}_{2}$ recycling routes. The availability of source feedstocks (i.e. $\mathrm{CO}_{2}$ and $\mathrm{H}_{2}$ ) is the main factor controlling large-scale applications of biofuel developed. Numerous biofuel products such as methanol $\left(\mathrm{CH}_{3} \mathrm{OH}\right)$ and dimethyl ether $\left(\mathrm{CH}_{3} \mathrm{OCH}_{3}\right)$ may be produced from $\mathrm{CO}_{2}$ utilisation. This direction opens up the possibility of developing a wide variety of fuels for both stationary and mobile applications.

\section{Production of methanol $\left(\mathrm{CH}_{3} \mathrm{OH}\right)$ based on $\mathrm{CO}_{2}$}

Generally, methanol is one of the most appropriate alternative fuels due to its relatively high energy content of $726.3 \mathrm{~kJ} / \mathrm{mol}$ (Din et al. 2019). Its productivity is the third in the world after ethylene and propylene. It is exploited in the manufacturing of different industrial chemicals (i.e. formaldehyde and methyl tertiary butyl ether) in addition to be a good hydrogen carrier. Despite its lower energy content ( $\sim 57,250 \mathrm{Btu} / \mathrm{ga})$ compared with gasoline $(\sim 116,090 \mathrm{Btu} /$ gal), it is suitable for vehicles powered by internal combustion engines due to its perfect combustion features. The price rate of a gallon for methanol is $\$ 3.23$ per gallon, which is a little bit lower than that of a gallon of gasoline $\$ 3.80$ (Olah et al. 2009). Despite, its cetane number value is low, it can operate in the diesel engines; nevertheless, it cannot be considered the best alternate for diesel fuel. The self-ignition propensity of the fuel under environmental conditions of high temperature and pressure defines the fuel's cetane number. Higher cetane number is required for providing feasible operation of the engine. Chemists have studied the reaction of $\mathrm{CO}_{2}$ conversion into methanol for more than 80 years. In fact, in the 1920s and 1930s, the emitted $\mathrm{CO}_{2}$ (waste gases) produced from other process was subjected into methanol production in the first methanol operating plant located in USA (Dinca et al. 2018). Commonly, the catalytic conversion of $\mathrm{CO}_{2}$ in the presence of hydrogen is the most studied scenario to produce methanol-based $\mathrm{CO}_{2}$ as given by Eq. (9):

$\mathrm{CO}_{2}+3 \mathrm{H}_{2} \leftrightarrow \mathrm{CH}_{3} \mathrm{OH}+\mathrm{H}_{2} \mathrm{O}$

The use of captured $\mathrm{CO}_{2}$ can be considered as an acceptable alternative over the traditional synthesis method. From the technical, financial and environmental aspects, production of methanol using $\mathrm{CO}_{2}$ and $\mathrm{H}_{2}$ has been commercially developed (Quadrelli et al. 2011). Numerous plants in Iceland and Japan have already been developed via integrating $\mathrm{CO}_{2}$ with renewable $\mathrm{H}_{2}$ plants (González-Aparicio et al. 2017). In 2011, Carbon Recycling International opened the first plant in Iceland with a productivity of $5 \mathrm{Mt} /$ year of 
methanol production in order to boost the plant economy for larger scales. Besides, Carbon Research International is interested in the Horizon 2020 project, which aims to subject overabundant and intermediate sources of renewable energy for the development of $\mathrm{CO}_{2}$ chemicals and fuels obtained from coal-fired power plants (An et al. 2007). Besides, for this conversion, an effective catalyst (i.e. metals and their oxides) was proposed, for instance combining zinc and copper oxides. In order to promote the synthesis of methanol, carbon monoxide $(\mathrm{CO})$ found in the syngas can be diverted into $\mathrm{CO}_{2}$ employing the water gas shift reaction (WGSR) to produce excessive $\mathrm{H}_{2}$ and $\mathrm{CO}_{2}$ forms. After that, methanol is produced based on the reaction of $\mathrm{CO}_{2}$ with hydrogen (Jadhav et al. 2014):

The overall reaction for the synthesis of methanol is given by Eq. (10):

$\mathrm{CO}_{2}+2 \mathrm{H}_{2} \leftrightarrow \mathrm{CH}_{3} \mathrm{OH}$

Iaquaniello et al. (2017) defined a methodology to exploit untapped municipal solid wastes (carbon source) for producing methanol via gasification pathway. The estimated economic analysis reported that running plant generates methanol at $110 € / \mathrm{t}$ with manipulating of $300 \mathrm{t} / \mathrm{d}$ of wastes in term of waste to methanol. Efficacy of waste to methanol plant operates with a capacity of $40 \%$ under $30-35 \%$ decrement in greenhouse gas emissions. Other study established by Rezaei and Catalan (2020) aimed to investigate the operability of a plant to afford 2000 tonnes/day of methanol using $\mathrm{CH}_{4}$ tri-reforming for syngas production. The optimised operational parameters in terms of feed composition $\left(\mathrm{CO}_{2}: \mathrm{H}_{2} \mathrm{O}: \mathrm{O}_{2}\right)$ were $0.20,0.35$ and 0.48 , respectively, for each mole of $\mathrm{CH}_{4}$. This has led to a successful $\mathrm{CO}_{2}$ conversion of $50 \%$ and a stoichiometric number of 1.57 . The net current value of the facility was evaluated to be $\$ 161$ million for a 15-year economic life considering the advertised selling price of $\$ 390$ for tonne methanol. Economically, Monte Carlo studies affirmed the applicability of $84 \%$ for the plant, simultaneously considered the uncertainties of the global economy. Environmentally, the net $\mathrm{CO}_{2}$ emissions of the plant are $0.91 \mathrm{~kg} \mathrm{CO}_{2} / \mathrm{Kg}$ methanol, which is $50 \%$ and $35 \%$ lower than the traditional running methanol plants based on methane steam reforming and other running plants based on $\mathrm{CH}_{4}$ tri-reforming, respectively.

\section{Production of dimethyl ether (DME) based on $\mathrm{CO}_{2}$}

Dimethyl ether (methoxymethane) is a colourless, environmentally benign and clean gas, widely provided as an additive in diesel engines referring to its autoignition character (Semelsberger et al. 2006). Its high oxygen content improved the combustion, which is evident by a fewer of $\mathrm{CO}, \mathrm{NO} x$, SO $x$ and particulate matter (Cai et al. 2016). Besides, attributing to the similarity of its own properties with the properties of liquid petroleum gas, dimethyl ether can be produced via infrastructure with minor adjustment. Besides, it is proven as a higher quality propellant utilised to produce healthcare commodities safer than other prepared via traditional petroleum-based scenarios. Also, it is believed to be a substitute for various chemicals (i.e. chlorofluorocarbons, ethylene and propylene (Saravanan et al. 2017). Dimethyl ether is usually produced via two pathways; indirect synthesis (dual-step) and direct synthesis (single-step). The indirect route comprises two consecutive steps. Firstly, the feedstock is converted into syngas, followed by the promotion of methanol synthesis process and finally methanol dehydration as given by Eqs. (11) and (12), respectively (Vafajoo et al. 2009). Mitsubishi Gas Company, Toyo Udhe and Lurgi companies are producers of dimethyl ether via the indirect strategy.

\section{Methanol synthesis:}

$\mathrm{CO}+2 \mathrm{H}_{2} \leftrightarrow \mathrm{CH}_{3} \mathrm{OH}$

\section{Methanol dehydration:}

$2 \mathrm{CH}_{3} \mathrm{OH} \leftrightarrow \mathrm{CH}_{3} \mathrm{OCH}_{3}+\mathrm{H}_{2} \mathrm{O}$

However, direct synthesis of dimethyl ether is applied in the hydrogenation process of $\mathrm{CO}_{2}$ via various catalysts (i.e. $\mathrm{ZnO}-\mathrm{Al}_{2} \mathrm{O}_{3}$ ). Zhang et al. (2014) stated that $15 \%$ of the obtainable dimethyl ether with a $\mathrm{CO}_{2}$ conversion rate of $30.6 \%$ was achieved under the optimum concentration of asused $\mathrm{Cu} / \mathrm{ZnO} / \mathrm{Zeolite}$ catalyst. Economically, it is expected that the total worth of dimethyl ether facility to be roughly $\$$ 9.7 billion by the end of 2020 including its main categories; (1) liquid petroleum gas blend, (2) diesel, (3) gas turbine fuel and (4) precursor for various chemicals (i.e. acetic acid and ethers oxygenates). China is the biggest dimethyl ether producer employing $90 \%$ of its productivity in liquid petroleum gas blending (Mondal and Yadav 2019).

\section{Production of methane $\left(\mathrm{CH}_{4}\right)$ based on $\mathrm{CO}_{2}$ (methanation)}

Methane (natural gas) is a prevalent energy carrier globally. It is the major contributor of natural gas supplies, being the most heat supplier to in Germany. Given the strong dynamic characteristics, natural gas power plants have gained a growing share of Germany's power generation compared with the current coal-fired power plants (Billig et al. 2019). Furthermore, its utilisation in vehicles instead of gasoline minimises $\mathrm{CO}_{2}$ emissions compared with the traditional counterpart due to its higher $\mathrm{H}: \mathrm{C}$ ratio. The following are the reactions occurring within the methanation reactor (Bailera et al. 2017): 
$\mathrm{CO}_{2}+4 \mathrm{H}_{2} \leftrightarrow \mathrm{CH}_{4}+2 \mathrm{H}_{2} \mathrm{O}$

$\mathrm{CO}_{2}+\mathrm{H}_{2} \leftrightarrow \mathrm{CO}+\mathrm{H}_{2} \mathrm{O}$

$\mathrm{CO}+3 \mathrm{H}_{2} \leftrightarrow \mathrm{CH}_{4}+\mathrm{H}_{2} \mathrm{O}$

The inertness of $\mathrm{CO}_{2}$ hinders its transformation into valueadded chemicals and causes difficulty in its implementation. However, this issue can be overcome with the help of certain catalysts (Wannakao et al. 2015). Park et al. (2015) reported a twofold increase in the yield of $\mathrm{CH}_{4}$ formation from $\mathrm{CO}_{2}$ through photocatalytic conversion using $\mathrm{TiO}_{2} / \mathrm{Cu}-\mathrm{TiO}_{2}$ (double layer) catalyst compared with traditional $\mathrm{TiO}_{2}$ (film catalyst). Besides, hydrogenation of carbon oxides to methane was carried out to purify syngas in ammonia plants. This could also produce carbon-neutral (methane) fuel (Rafiee et al. 2018). Biological processes such as the use of methanogens may also transform $\mathrm{CO}_{2}$ into methane. An anoxic enrichment of waste activated sludge generates methane-producing organisms (methanogens). The utilisation of the organism's activated cultures caused roughly 70 folds enhancement in the efficacy of methane production (Mohd Yasin et al. 2015).

\section{Production of liquid hydrocarbons based on $\mathrm{CO}_{2}$ (Fischer- Tropsch)}

Liquid hydrocarbons are a suitable alternative for the storage of renewable energy. They are the primary source of energy for transportation and aviation purposes Pietzcker et al. (2014). Among several technologies subjected to upcycling of waste $\mathrm{CO}_{2}$, Fischer-Tropsch is a notable scenario for liquid fuels production. It is hydrogenation of $\mathrm{CO}$ (heterogeneous catalysis) with a polymerisation character. At most, liquid hydrocarbons (i.e. kerosene) can be produced through this process. As a consequence of the catalytic process, the synthesis products are sulphur-free and contain less soot during combustion (König et al. 2015). For Fischer-Tropsch process, syngas may be generated from variable feedstock; (1) steam reforming and (2) gasification in term of gas-toliquid and biomass-to-liquid, respectively. Typically, two stages integrating reverse WGSR and Fischer-Tropsch are involved, as shown in Eqs. (16) and (17).

$\mathrm{CO}_{2}+\mathrm{H}_{2} \leftrightarrow \mathrm{CO}+\mathrm{H}_{2} \mathrm{O} \quad \Delta{\mathrm{H}^{\circ} 298 \mathrm{~K}}^{\circ}=415 \mathrm{~kJ} / \mathrm{mol}$

$\mathrm{nCO}+2 \mathrm{nH}_{2} \leftrightarrow\left(-\mathrm{CH}_{2}-\right) \mathrm{n}+\mathrm{nH}_{2} \mathrm{O} \quad \Delta \mathrm{H}_{\mathrm{r} 298 \mathrm{~K}}^{\circ}=-\mathrm{n} * 152 \mathrm{~kJ} / \mathrm{mol}$

The produced hydrocarbons are segregated from non-reacted feed and gaseous hydrocarbons, and after that, they can be upgraded via undergoing of hydrocracking and isomerisation (Piermartini et al. 2017).

\section{Production of biofuel (green fuel) using $\mathrm{CO}_{2}$}

In contrast to traditional fuels, biofuels derived from renewable sources are ultimately the best appropriate choice given its environment and economic benefits (Santamaría and Azqueta 2015). Algae are a promising green energy source due to their high protein and oil content. Conversion of algal biomass into biofuel was successfully implemented as shown in Fig. 24. Atmospheric carbon, either inorganic or organic origin, can be fixed using different algal species (Singh and Olsen 2011). Successful absorption of $\mathrm{CO}_{2}$ (i.e. $1.83 \mathrm{~kg} \mathrm{CO} / \mathrm{kg}$ biomass) using algal biomass in non-mild water condition was efficiently recorded (Wu et al. 2018). The generated waste (flue) gases released from industrial activities as well as power stations containing a high $\mathrm{CO}_{2}$ concentration, which, in turn, enhances the algal photosynthetic activity (Faried et al. 2017). For instance, the flue gas emitted from ammonia production units (reforming phase) with highly concentrated $\mathrm{CO}_{2}$, can be directly delivered to the vicinity algal production sites. Direct injection of these waste streams (carbon source) into the algal production ponds provides a clean and green opportunity to cultivate the microalgal biomass and hence mitigate the negative impacts on the biosphere as well as their high operational costs (Collotta et al. 2018). Numerous studies have been registered for microalgal cultivation through flue gas pathway. The substitute utilisation of biofuel effectively declined the net carbon emissions (78\%), comparing with the non-renewable petroleum-based fuels (Ali et al. 2017). One of the largest biofuel production centres in the world is located in Western Australia. It was located $50 \mathrm{~km}$ away from the power plant and biocrude oil refinery sites. The anticipation of environmental, economic and sustainable benefits was elucidated regarding the input and output analyses derived from algal biocrude producing plant and conventional crude oil-producing plant using life cycle assessment (LCA) tool. The obtained results revealed the applicability of algal biocrude operating plant over the traditional crude oil-operating plant. The rate of carbon capturing/biocrude output/carbon emission was (1.5:1:0.5 tons), respectively. From an economic point of view, the analysis approximately evidences that one million tons of the biocrude production would generate roughly 13,200 new jobs employment along with a $\$ 4$ billion economic stimulus (Malik et al. 2015).

\section{Bioalcohols}

Alcohol-based fuels (bioalcohols) are other strategic products based on carbon dioxide emissions feedstock. Normally, they are derived from biological sources rather than petroleum sources. Commonly, four bioalcohols; methanol, ethanol, propanol and butanol are employed as motor fuels. In particular, the economic and technical features characterised 


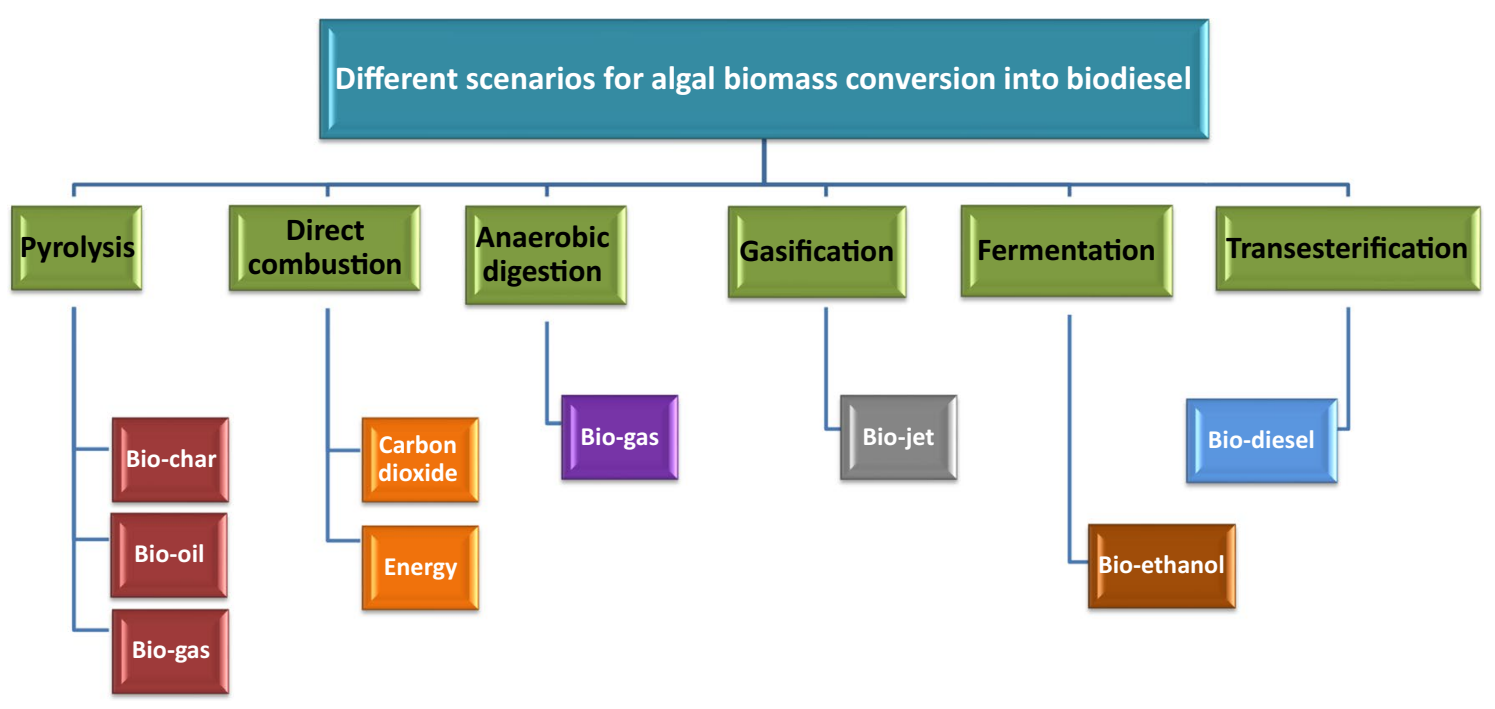

Fig. 24 Scenarios for algal biomass conversion into biodiesel and other biofuels. This can be achieved via various processes such as pyrolysis, direct combustion, anaerobic digestion, gasification, fermentation and transesterification

to methanol and ethanol, allowing them to be suitable as fuels for the internal combustion engines (Demirbas 2008). Despite, the lower energy density of methanol compared with gasoline, its higher-octane rating enhances its compression character before the initiation of the ignition process. Whereas ethanol can be used as a petrol additive through mixing (combining) it with gasoline (Niven 2005), the developed gasohol with the chemical composition of ethanol/gasoline (10:90\%), respectively, can be further applied in the internal combustion engines of most modern automobiles (Larson 2006).

\section{Production of urea from $\mathrm{CO}_{2}$}

Urea is another non-toxic commodity derived from carbon dioxide. Being a rich with nitrogen qualifies it to be excessively used in fertilisers facilities. Furthermore, it can be used as feedstock (backbone) in various chemicals industries (i.e. adhesives, plastics and synthetic resins) (Ishaq et al. 2020). Other derivatives-based urea such as urea (nitrate, formaldehyde and melamine-formaldehyde) are prepared. About $180 \mathrm{Mt} /$ year of urea were estimated to be produced globally. Mathematically, to achieve this aimed amount of urea, $132 \mathrm{Mt} /$ year of $\mathrm{CO}_{2}$ is needed (Koohestanian et al. 2018). The most prevalent way for its synthesis is reforming of natural gas which results in the formation of ammonia and carbon dioxide. Urea synthesis equation is given, as shown in Eq. (18):
$2 \mathrm{NH}_{3}+\mathrm{CO}_{2} \leftrightarrow \mathrm{NH}_{2} \mathrm{CONH}_{2}+\mathrm{H}_{2} \mathrm{O}$

The above reaction comprises two subsequent stages. Firstly, the heterogeneous reaction between ammonia and carbon dioxide results in the formation of ammonium carbamate $\left(\mathrm{NH}_{2} \mathrm{OCONH}_{4}\right)$, as shown in Eq. (19). After that, ammonium carbamate (liquid form) dehydration results in the formation of urea as given by Eq. (20):

$2 \mathrm{NH}_{3}+\mathrm{CO}_{2} \leftrightarrow \mathrm{NH}_{2} \mathrm{OCONH}_{4}$

$\mathrm{NH}_{2} \mathrm{OCONH}_{4} \leftrightarrow \mathrm{NH}_{2} \mathrm{CONH}_{2}+\mathrm{H}_{2} \mathrm{O}$

Moreover, $\mathrm{CO}_{2}$ usage in the manufacture of urea has great economic feasibility taking into account the growing global demand on it. Globally, more than $50 \%$ of the produced $\mathrm{CO}_{2}$ has subjected to the urea synthesis process. Barzagli et al. (2016) studied the potential of $\mathrm{CO}_{2}$ capture via aqueous and gaseous ammonia under ambient conditions. Based on the ammonia concentrations, they emphasised that capturing amounts achieved up to $99 \%$. Also, urea synthesis process from the produced ammonium carbamate was experimentally performed at $120-140^{\circ} \mathrm{C}$. Apak presented research on investigating the role of ammonia to mitigate the emissions of $\mathrm{CO}_{2}$. Indeed, he discussed the possibility of urea formation via a reaction between the emitted $\mathrm{CO}_{2}$ and ammonia (Apak 2007). 


\section{Utilisation of $\mathrm{CO}_{2}$ in different thermochemical processes}

\section{$\mathrm{CO}_{2}$ as a gasifying agent in biomass gasification}

Gasification is a critical thermochemical process that transforms biomass into gaseous products. As natural sequencing of incomplete combustion, combustible gases emitted. Biomass gasification operates at a lower temperature $\left(\sim 900^{\circ} \mathrm{C}\right)$ compared with conventional coal gasification referring to biomass nature (Molino et al. 2016). From the viewpoint of $\mathrm{CO}_{2}$ consumption, the injection of $\mathrm{CO}_{2}$ as a gasifying agent has numerous benefits compared over the conventional gasification atmospheres. Large quantities of $\mathrm{CO}_{2}$ caused by different industrial processes can be recycled as feedstock for post-consumers. Theatrically, the water gas shift unit needed for syngas amendment can be averted (Ye et al. 2020). Additionally, syngas with controllable $\mathrm{H}_{2} / \mathrm{CO}$ ratio can be obtained. Parvez et al. 2016 explored an Aspen Plus ${ }^{\mathrm{TM}}$ estimation on $\mathrm{CO}_{2}$ assisted gasification, clarifying the impacts of $\mathrm{CO}_{2}$ on the performance of biomass gasification. The susceptibility of dimethyl ether produced from biomass gasification to improve the biomass gasification was successfully researched. $\mathrm{CO}_{2}$ contributes to controlling the syngas ratio and hence offers flexibility for the whole process adjustment, which ensures the less effect of the presented biomass on the gasification process (Parvez et al. 2016).

\section{$\mathrm{CO}_{2}$ as an activating medium in biomass pyrolysis}

Biochar is a product (solid form) resulted from biomass pyrolysis in the absence of oxygen content (oxygen-free atmosphere) (Dhyani and Bhaskar 2018; Balajii and Niju 2019). It is beneficial as an energy supplier because of its remarkable merits (i.e. high energy density) (Weber and Quicker 2018). Besides, it has been used in different applications (i.e. wastewater treatment and soil amendment). The physicochemical characters of the produced char differ depending on the operational pyrolysis parameters (i.e. feedstock, heating rate and residence time) (Cha et al. 2016). Physiochemical features of biochar (i.e. surface area, porosity and constituent functional groups) were optimised in $\mathrm{CO}_{2}$ atmosphere rather than pure $\mathrm{N}_{2}$ atmosphere. The presence of $\mathrm{CO}_{2}$ has led to inhibition of polymerisation reaction; cracking of tar compounds into light gases and consequently reducing the secondary char formation and an enhancement in the yield of the produced gas (Guizani et al. 2015).

Moreover, the chemical reaction between $\mathrm{CO}_{2}$ fraction and hydrogenated or oxygenated groups spontaneously occurs and thus enhances the yield of high carbon contentchar. Decrement of the secondary char amount associates with an improvement in its microporosity as well as carbon content. Notably, $\mathrm{CO}_{2}$ had a crucial role in the mitigation of toxic chemicals generated during the pyrolysis process of benzene derivatives and polycyclic aromatic hydrocarbons (Lee et al. 2017b). The profile of as-designed temperatureprogrammed oxidation confirmed that $\mathrm{CO}_{2}$-char gasification and $\mathrm{N}_{2}$-char gasification was portrayed by a single reaction pathway and multiple reaction pathways, respectively. An increase in the secondary char formation may occur by the action of one of these pathways. Deposition of great amounts of impurities (i.e. hydrogenated and oxygenated groups) on the engineered $\mathrm{CO}_{2}$ char has probably led to blocking off of its pores and hence decreases its surface area.

\section{Impact of $\mathrm{CO}_{2}$ on the produced chars}

\section{Surface area and porosity}

Numerous studies investigated the impact of $\mathrm{CO}_{2}$ as a gasifying agent on the textural properties (i.e. surface area, morphology and porosity) on the produced char (Lee et al. 2017a, b, c, d, e). Lee et al. (2017d) used a tubular reactor to study the influence of atmospheric $\mathrm{CO}_{2}$ on the textural properties of the as-formed char. The outlined results confirmed that $\mathrm{CO}_{2}$ promotes the formation of new pores on the produced char. The higher surface area $\left(93 \mathrm{~m}^{2} / \mathrm{g}\right)$ under $\mathrm{CO}_{2}$ atmosphere compared with the other measured under $\mathrm{N}_{2}$ atmosphere $\left(85 \mathrm{~m}^{2} / \mathrm{g}\right)$, may be referred to the heterogeneous reaction between char surface and $\mathrm{CO}_{2}$. Another study established by Lee et al. (2017c) aimed to compare the physiochemical properties characterised to the pyrolysis products prepared from red pepper stalk under a different atmospheric medium $\left(\mathrm{CO}_{2}\right.$ and $\left.\mathrm{N}_{2}\right)$. This greatly confirms the role of $\mathrm{CO}_{2}$ as an expediting agent towards the improvement of the char properties through the thermal cracking of different volatile organic carbons.

\section{Tar reduction}

Numerous studies investigated the impact of $\mathrm{CO}_{2}$ as a gasifying agent on the tar reduction (Wang et al. 2018; Luo et al. 2016; Jeremiáš et al. 2018). For this purpose, various biomasses such as seaweed (Cho et al. 2016), rice (Pinto et al. 2016) and swine manure (Lee et al. 2019) were tested as feedstock for these studies. Results showed that $\mathrm{CO}_{2}$ has multiple effects on the tar reduction as well as an enhancement in the syngas production throughout the pyrolysis process. Briefly, it accelerates the thermal cracking rate of volatile organic carbons and consequently increases the formation of benzene derivatives via carbonisation and dehydrogenation, (2) less formation of polycyclic aromatic hydrocarbon and (3) homogenous reaction directly occurs between $\mathrm{CO}_{2}$ and volatile organic carbons (gas phase reaction). As stated by (Luo et al. 2016), the operating pressure of the gasification process directly affects tar reduction. 
At pressure lower than 5 atm, fewer char was produced in $\mathrm{N}_{2}$ atmosphere compared with the formed one in $\mathrm{CO}_{2}$ atmosphere, whereas, at higher pressure higher than $5 \mathrm{~atm}$, fewer tar amounts were produced at atmospheric $\mathrm{CO}_{2}$. Even though, the magnitude of $\mathrm{CO}_{2}$ sensitivity on the gasification process and $\mathrm{CO}$ emissions mainly depends on other key factors (i.e. feedstock type, temperature and pressure) which directly influence on the gasification products. For example, tar reduction was observed to be $23 \%$ (Lee et al. 2017a), $45 \%$ (Pinto et al. 2016) and 70\% (Cho et al. 2016). In the same way, $\mathrm{CO}$ generation often differs with feedstock type in the $\mathrm{CO}_{2}$ atmosphere.

\section{Syngas production}

Numerous studies evaluated the effect of $\mathrm{CO}_{2}$ addition on the production of syngas from the pyrolysis process (Kim and Lee 2020). An increase in the production rate of CO from the pyrolysis process was announced by several researchers (Lee et al. 2017a)-Jung et al. 2016). This attributes to the chemical composition of $\mathrm{CO}_{2}(\mathrm{C}$ and $\mathrm{O}$ source $)$, which raise the $\mathrm{CO}$ emissions resulting from the conversion of volatile organic carbons. An increment in the $\mathrm{CH}_{4}$ and $\mathrm{H}_{2}$ production rates was successfully investigated to be associated with the existence of $\mathrm{CO}_{2}$, attributing to its expedition ability towards thermal cracking of volatile organic carbons species (Kim et al. 2017).

\section{Desalination of seawater by $\mathrm{CO}_{2}$}

Currently, water scarcity has become one of the most critical challenges facing our world due to different reasons implicated in this global problem such as climate change, environmental contamination and uncontrollable population growth. An urgent necessity of clean water for different biota cannot be ignored (Dadson et al. 2017). Recently, World Bank states that about 450 million people around the world in about 29 countries do not have the accessibility for clean freshwater supply. Roughly, $71 \%$ of the world's population suffers from water shortage for a minimum one month per year, which leads to sociopolitical instability (Hanjra and Qureshi 2010). Mostly, surface water and seawater have a salinity content of 10,000 ppm and (35,000 and 45,000 ppm), respectively (Zhou and Tol 2005). World Health Organization reports that the acceptable limits of salinity content in water to be 500 ppm (Tavakkoli et al. 2017). Desalination scenario was adapted by different countries to face the global issue of water scarcity. The global quota of desalination (i.e. services and products) was expected to be $\$ 13.4$ billion in 2015 . More than 11,000 water desalination treatment plants located in 150 countries supply fresh water to 300 million people with an annual enhancement of $8 \%$ (Morad et al. 2017). Commonly, desalination is operated in two ways: distillation and reverses osmosis (RO). Distillation is a heat-based treatment process at which a large volume of warm seawater was predominantly treated. Contrarily, reverse osmosis is a membrane-based treatment process at which brackish water was manipulated.

\section{Seawater desalination working mechanism using $\mathrm{CO}_{2}$}

Naturally, the reaction between $\mathrm{CO}_{2}$ and water in a specific depth of ocean (low temperature and high pressure) produces crystalline $\mathrm{CO}_{2}$ hydrates in the form of crystalline aggregates, as shown in Fig. 25. They characterise by possessing a three-dimensional, hydrogen bounded and $\mathrm{CO}_{2}$ molecules can be entrapped inside them. An induced of pressure transition between orthorhombic and cubic hexagonal forms has dependently brought by the crystalline nature of $\mathrm{CO}_{2}$ hydrates. They are denser than water and so that they sink to the seafloor and stay on it for a longer period without returning to the atmosphere. Due to of their negative charge, they are suitable for $\mathrm{CO}_{2}$ sequestration. However, a positively charged hydrates are approached for seawater desalination purpose. Therefore, it can be achieved by injecting the dense $\mathrm{CO}_{2}$ (liquid form) to an ocean depth (below $1000 \mathrm{~m}$ ) where the surrounding temperature of the medium is slightly above $0{ }^{\circ} \mathrm{C}$. Moreover, injection of $\mathrm{CO}_{2}$ (liquid form) will positively mitigate the harmful threats associated with injection of $\mathrm{CO}_{2}$ (gas form). $\mathrm{CO}_{2}$ injection at the stability zone of the formed hydrates, especially at these conditions of low temperature and high pressure retained formation of hydrant shells $(\sim 4-10 \mu \mathrm{m}$ thick) on the water surface. These shells rise and are collected before the unstable hydrate zone. The rounded shape crystals (solid form) can be easily removed from saline water. By sudden shifting the temperature and pressure to ambient conditions, purified water can be delivered. Recycling of $\mathrm{CO}_{2}$ is suggested to continue in the next cycle, and because of its nature as a chemicals-free technique, membrane separation is not required.

\section{Utilisation of $\mathrm{CO}_{2}$ in construction and building materials}

Globally, the prolonged usage of cement and concrete based materials in construction materials are attributed to their remarkable merits (i.e. high strength and durability). The cement industry is one of the most intensive $\mathrm{CO}_{2}$ emitters, accounting for $5-8 \%$ of global anthropogenic $\mathrm{CO}_{2}$ emissions (Scrivener and Kirkpatrick 2008). Incorporation of $\mathrm{CO}_{2}$ into cement-based materials involves a chemical reaction between $\mathrm{CO}_{2}$ and cement hydrates which can be summarised in term of the carbonation process of (calcium hydroxide, calcium silicate hydrates, calcium sulphoaluminate hydrates, cement clinker minerals, magnesium-derived hydrates and supplementary cementitious materials). 


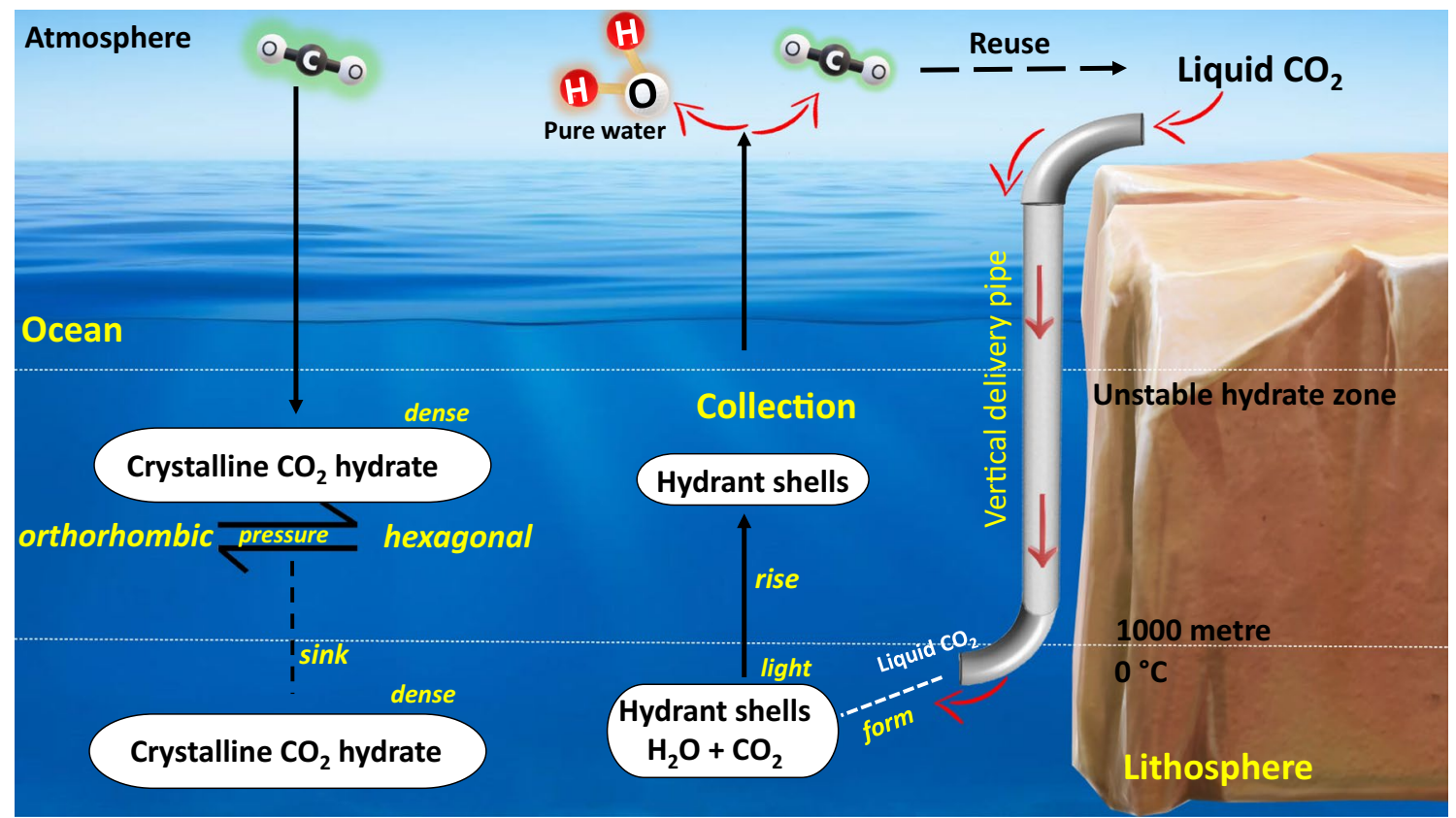

Fig. 25 Seawater desalination working mechanism using $\mathrm{CO}_{2}$. (1) Formation of $\mathrm{CO}_{2}$ crystalline hydrates resulting from $\mathrm{CO}_{2}$ and water reaction under specific conditions (low temperature and high pressure), (2) inducing in the pressure transition between orthorhombic and cubic hexagonal forms, (3) sinking of the $\mathrm{CO}_{2}$ hydrates (aggregates) to the seafloor, (4) injection of $\mathrm{CO}_{2}$ (liquid form) below a depth

\section{Carbonation of calcium hydroxide}

During the carbonation reaction, cement paste hardening was expressed, as shown in Eqs. (21) and (22):

$\mathrm{Ca}(\mathrm{OH})_{2}(\mathrm{~s} \rightarrow \mathrm{aq})+\mathrm{CO}_{2}(\mathrm{~g} \rightarrow \mathrm{aq}) \rightarrow \mathrm{CaCO}_{3}(\mathrm{aq} \rightarrow \mathrm{s})+\mathrm{H}_{2} \mathrm{O}(\mathrm{aq})$

$\mathrm{CO}_{2}+\mathrm{H}_{2} \mathrm{O} \rightarrow \mathrm{H}_{2} \mathrm{CO}_{3} \rightarrow 2 \mathrm{H}^{+} \mathrm{CO}_{3}^{2-}$

$\mathrm{Ca}(\mathrm{OH})_{2}+2 \mathrm{H}_{2} \mathrm{CO}_{3} \rightarrow \mathrm{CaCO}_{3}+2 \mathrm{H}_{2} \mathrm{O}$

$\mathrm{CO}_{2}$ is proceeded to react with calcium hydroxide and upon continuing the reaction, decrement in the content of calcium hydroxide, an opposite increment of calcium carbonate content and reduction in the $\mathrm{pH}$ value of the hardened paste (Jang et al. 2015).

\section{Carbonation of calcium silicate hydrates}

The proportion of each hydration product, calcium silicate hydrate $(\mathrm{C}-\mathrm{S}-\mathrm{H})$, calcium hydroxide $\mathrm{Ca}(\mathrm{OH})_{2}$ and calcium sulphoaluminate hydrates, varies considering the cement composition (Jang and Lee 2016). Once most of calcium hydroxide amount is consumed, carbonation of $(\mathrm{C}-\mathrm{S}-\mathrm{H})$ is suggested to be initiated as shown in Eq. (23): of $1000 \mathrm{~m}$ and temperature around $0^{\circ} \mathrm{C}$, (5) formation of hydrant shells round in shape $(\sim 4-10 \mu \mathrm{m}$ thick), (6) rising of the produced shells and their collection before the unstable hydrate zone and (7) producing of pure water by shifting temperature and pressure to ambient, followed by the possible recycling of $\mathrm{CO}_{2}$ in the next cycles

\section{Carbonation of cement clinker minerals}

As time proceeds, hydration of cement clinker minerals is carried out. As conducted by Papadakis, within the curing period of 28 days, hydration degrees of $67 \%, 79 \%, 91 \%$ and $96 \%$ were recorded for $\mathrm{C}_{2} \mathrm{~S}, \mathrm{C}_{4} \mathrm{AF}, \mathrm{C}_{3} \mathrm{~S}$ and $\mathrm{C}_{3} \mathrm{~A}$, respectively (Jang and Lee 2016). Once, the hydration reaction ends, carbonation is suggested to be initiated. The unreacted $\mathrm{C}_{3} \mathrm{~S}$ and $\mathrm{C}_{2} \mathrm{~S}$ through carbonation in the first stage can form calcite and $\mathrm{C}-\mathrm{S}-\mathrm{H}$, respectively. Finally, calcite and silica gel are produced in the last stage, as expressed in Eqs. (24) and (25).

$3 \mathrm{CaO} \cdot \mathrm{SiO}_{2}+3 \mathrm{CO}_{2}+\mathrm{nH}_{2} \mathrm{O} \rightarrow \mathrm{SiO}_{2} \cdot \mathrm{nH}_{2} \mathrm{O}+3 \mathrm{CaCO}_{3}$

$2 \mathrm{CaO} \cdot \mathrm{SiO}_{2}+2 \mathrm{CO}_{2}+\mathrm{nH}_{2} \mathrm{O} \rightarrow \mathrm{SiO}_{2} \cdot \mathrm{nH}_{2} \mathrm{O}+2 \mathrm{CaCO}_{3}$

\section{$\mathrm{CO}_{2}$-curing of cement-based materials}

The utilisation of $\mathrm{CO}_{2}$ in cement industries (carbonation) has been proposed during the product-curing stage (Jang and Lee 2016). Numerous studies have shown the role of $\mathrm{CO}_{2}$

$x \mathrm{CaO} \cdot y \mathrm{SiO}_{2} \cdot z \mathrm{H}_{2} \mathrm{O}+x \mathrm{CO}_{2} \rightarrow x \mathrm{CaCO}_{3}+y\left(\mathrm{SiO}_{2 . t} \mathrm{H}_{2} \mathrm{O}\right)+(\mathrm{z}-y) \mathrm{H}_{2} \mathrm{O}$ 
in improving the characteristics of cement-based materials (i.e. microstructure densification, mechanical stability and durability). Additionally, $\mathrm{CO}_{2}$-curing is preferred over the conventional methods of curing using (i.e. heat, water and steam) (Zhan et al. 2016). Shao and Morshed (2013) concluded that $\mathrm{CO}_{2}$ significantly decreased the duration of the curing stage and increased the strength compared with the heat curing technique. Incorporation of different admixtures during $\mathrm{CO}_{2}$ curing of cement-based products was retained as a pursuit of environmental-friendliness. For instance, fly ash concrete cured with $\mathrm{CO}_{2}$ for less than $12 \mathrm{~h}$ had higher achievable strength and better durability, accompanied by a reduction in carbon emissions $(\sim 36 \%)$. Furthermore, the strength of fly ash was effectively enhanced by inoculation of magnesium oxide (Mo et al. 2015). Tu et al. (2016) stated that $\mathrm{CO}_{2}$ pressure strongly impacted on the calcium carbonate form; poorly crystalline calcium carbonate and highly crystalline calcium carbonate polymorphs are formed under lower and higher $\mathrm{CO}_{2}$ pressure, respectively.

\section{Utilisation of $\mathrm{CO}_{2}$ for co-polymers and polymer blends}

The development of engineered polymers based on sustainable feedstocks has become necessary to face the growing utilisation of polymers based on finite fossil resources (i.e. plastics) (Mekonnen et al. 2014; Chaterjee and Krupadam 2019). For instance, the extraordinary growth of the plastic synthesising reached about 407 million tons in 2017. Presently, $70 \%$ of the overall commodity plastics production process includes polypropylene, polyvinyl chloride, polystyrene, polyethylene terephthalate, low-density polyethylene, linear low-density polyethylene and high-density polyethylene. Economically, employing $\mathrm{CO}_{2}$ for synthesising different biodegradable polymers is considered a cost-effective approach. The action of microorganisms can degrade these biopolymers under specific optimised conditions. One of the direct ways for $\mathrm{CO}_{2}$ utilisation is the production of polyesters (polyhydroxyalkanoates) via a biological process (Troschl et al. 2018). For example, purple sulphur bacteria have been reported to generate polyhydroxyalkanoates (intracellular energy and carbon storage compound) under anaerobic conditions, by taking advantage of the fact that $\mathrm{CO}_{2}$ and sunlight are sources for carbon and energy, respectively. Despite the nature of $\mathrm{CO}_{2}$ to be thermo-dynamically stable, some reactions are not required to be supplied with external energy because it can be available through co-reactants (i.e. amines and hydroxides). Moderate energy can be provided to other reaction types by appending the entire $\mathrm{CO}_{2}$ moiety to the other reactant in order to produce polycarbonates based on $\mathrm{CO}_{2}$ and epoxides. Due to the stable chemical nature of $\mathrm{CO}_{2}$, some active catalysts have been added to promote the activation of inherently inactive $\mathrm{CO}_{2}$ and smoothly stimulate the copolymerisation process. On the contrary of aromatic polycarbonates, aliphatic polycarbonates are thermoplastic polycarbonates with repeating carbonate backbone linkages with no aromatic groups between these linkages. Alternating aliphatic polycarbonate co-polymers are produced by copolymerising of $\mathrm{CO}_{2}$ with some cyclic ethers (i.e. aziridines and cyclohexene). Other aliphatic polycarbonates such as poly (ethylene, propylene, butylene, hexane, styrene, cyclohexene, cyclopentene and cyclohexadiene) carbonates are synthesised through copolymerisation of $\mathrm{CO}_{2}$ with epoxides (Darensbourg et al. 2013; Honda et al. 2014). Among them, poly (propylene, ethylene, butylene and cyclohexene) carbonates are the master of industrial $\mathrm{CO}_{2}$ applications (Klaus et al. 2011). Significantly, fixation of waste $\mathrm{CO}_{2}$ into polypropylene carbonate is an exceptional accomplishment referring to its versatility in different polypropylene carbonate-related products (i.e. foaming, electrolyte, etc.). In 2006, a polypropylene carbonate production facility with a design capacity of $5000 \mathrm{t} / \mathrm{annum}(\mathrm{t} / \mathrm{a})$ was established in Tian-Guan Enterprise (Group) Co. Ltd, Henan, China. With the tremendous scientific progress, the capacity has raised to 25,000 t/annum (t/a) in 2012 (Murcia Valderrama et al. 2019). Annually, the company produces nearly 550 (kt/a) of ethanol using corn via the alcoholic fermentation process. The importance of waste $\mathrm{CO}_{2}$ recycling instead of releasing to the atmosphere has been realised in recent years. Copolymerisation of propylene oxide with the recycled $\mathrm{CO}_{2}$ facilities the production of biodegradable polypropylene carbonates $\left(43 \%\right.$ wt. $\left.\mathrm{CO}_{2}\right)$. Eventually, zero pollution scope was accomplished by converting waste $\mathrm{CO}_{2}$ emissions into biodegradable plastic (Murcia Valderrama et al. 2019).

\section{Utilisation of $\mathrm{CO}_{2}$ in food processing}

In general, $\mathrm{CO}_{2}$ is usually advantageous in food processing as it can be used as a food preserving as well as antimicrobial agents (dual benefits) (Puligundla et al. 2012). Frequently, it is employed as a flushing gas in modified atmosphere packaging. Presence of $\mathrm{CO}_{2}$ in the package's atmosphere may minimise the package's pressure or volume attributing to its high solubility character in food matrices and thus balancing (managing) the pressure between the inside of headspace and the outside of the package. This is sometimes helpful for good products marketing in the environment of low pressure and temperature (Chaix et al. 2014). The $\mathrm{CO}_{2}$ -based modified atmosphere packaging strategy should be applied with high professionalism in line with food properties and operational conditions to avoid high $\mathrm{CO}_{2}$ dissolution into foods. A high concentration of dissolute $\mathrm{CO}_{2}$ negatively results in package collapse associated with very poor quality (i.e. bad texture and flavour). Besides, $\mathrm{CO}_{2}$ is used to prevent food oxidation. $\mathrm{N}_{2}$ gas is widely used to inhibit oxidation; 
however, a combination of $\mathrm{CO}_{2}$ with $\mathrm{N}_{2}$ is desirable for antioxidative food packaging (Lee 2016).

On the other hand, the antimicrobial behaviour of $\mathrm{CO}_{2}$ was documented in different literature. This helps enormously in the preservation of food freshness and hence, enhances its shelf life. The antimicrobial activity is closely related to the solubility rate as well as the dissolved amount of $\mathrm{CO}_{2}$ in the food product. Readily, it is soluble in aqueous and fatty food with observable high solubility rate at a lower temperature. Besides, its solubility differs considering food properties (i.e. $\mathrm{pH}$, surface area and composition) in addition to the partial pressure of the as-used gas. Numerous published papers largely focused on high-pressure carbon dioxide (HPCD) as a novel methodology for the food facilities, as shown in Fig. 26. Briefly, it is nonthermal pasteurisation, operates pressurised $\mathrm{CO}_{2}(1-500$ bar) at most microbes can be inhibited (inactivation process). Different operational factors directly affect the whole process (i.e. microorganism species, cell concentration, $\mathrm{pH}$, water content, the physical state of $\mathrm{CO}_{2}$, operational time, pressure and temperature) (Corbo et al. 2009). Briefly, the subjected $\mathrm{CO}_{2}$ can damage and disturb cell surface and intracellular organisation, respectively. There is an alteration in the microbial cell morphology intracellular organisation, respectively. An alteration in the microbial cell morphology after HPCD treatment was clarified by scanning and transmission electron microscopes (SEM and TEM). A great number of bulges appeared on the extracellular surface of HPCD-treated cell, intracellular organisation, respectively. An alteration in the microbial cell morphology after HPCD treatment was clarified by

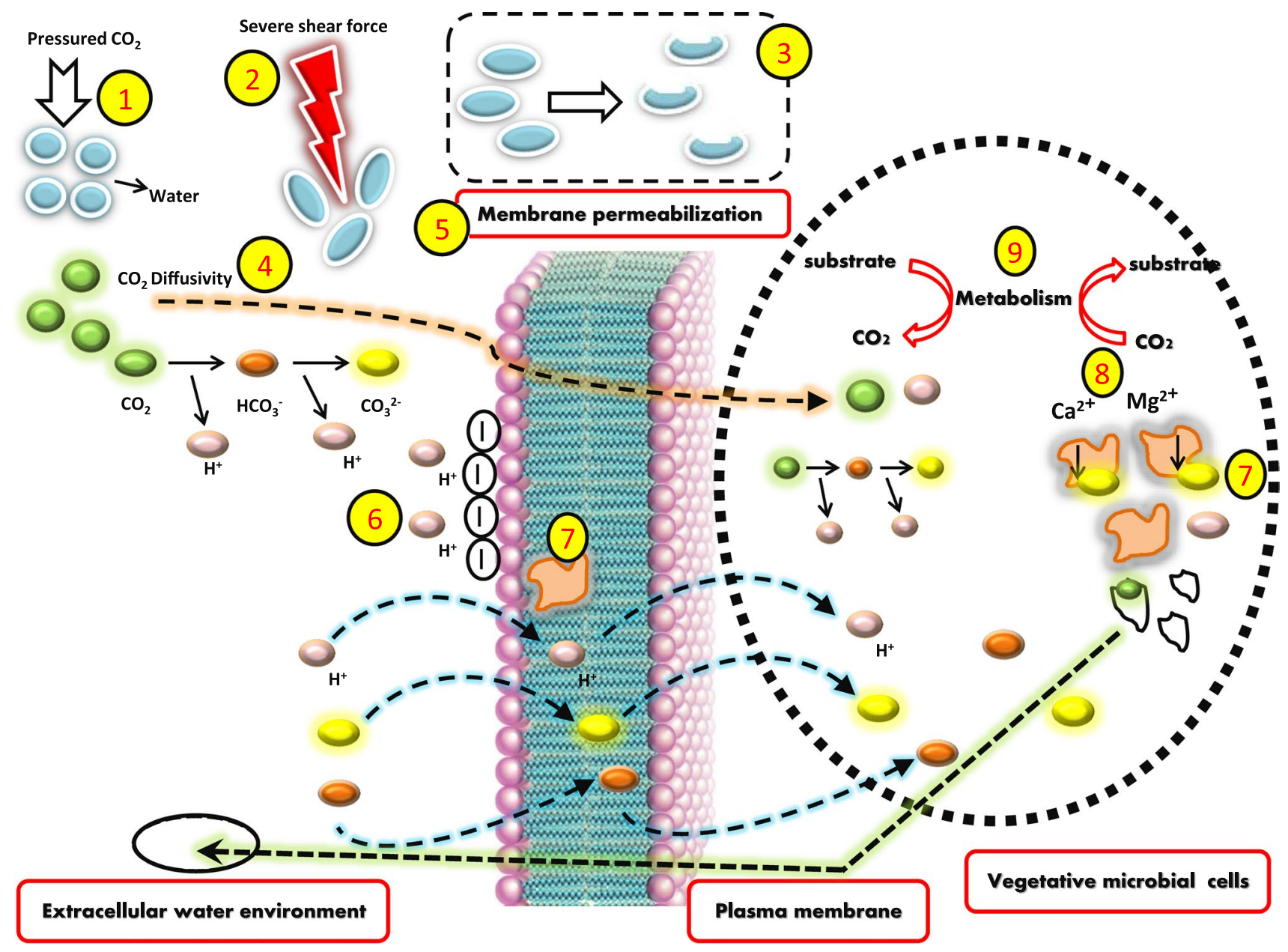

Fig. 26 High-pressure carbon dioxide (HPCD) inactivation mechanisms on vegetative microbial cells. (1) subjecting of bacterial cells to high pressurised $\mathrm{CO}_{2}$ (HPCD), (2) higher clumping of bacterial cells because of severe shear force effect resulting from HPCD technique, (3) disruption of the intracellular organisation (cell surface damage) associated with numerous bulges presence on the extracellular surface of HPCD-treated cells, (4) enhancement in the $\mathrm{CO}_{2}$ diffusion rate as well as the conversion of $\mathrm{CO}_{2}$ into $\mathrm{HCO}_{3}^{-}$and $\mathrm{CO}_{3}^{2-}$, (5) an increase in the membrane permeabilisation and fluidity, (6) destroying the charge balance of membrane surface attributing to decrement in the $\mathrm{pH}$ and $\mathrm{HCO}_{3}^{-}$generated from $\mathrm{CO}_{2}$, (7) loss of activity characterised to some proteins and enzymes due to HPCD treatment, (8) inducing of intracellular precipitation by the internal ribosomes and $\mathrm{CO}_{3}^{2-}$ produced from $\mathrm{CO}_{2}$ and (9) stimulation and inhibition of metabolic pathways that require and produce $\mathrm{CO}_{2}$, respectively 
scanning and transmission electron microscopes (Del PozoInsfran et al. 2006).

\section{$\mathrm{CO}_{2}$ utilisation: turning $\mathrm{CO}_{2}$ into a power resource}

Carbon capture and permanent geologic storage of $\mathrm{CO}_{2}$ can be utilised (U) threefold to U1) $\mathrm{CO}_{2}$-based geothermal energy extraction and conversion to electricity at about twice the efficiency of standard water-based geothermal power plants, U2) provide grid-scale subsurface energy storage that can operate over a range of duration from a diurnal to biannual (seasonal) energy storage cycle and U3) operate as a heat sink that provides cold for district cooling and cryogenic direct air $\mathrm{CO}_{2}$ capture. All-above mentioned technologies are constituting a $\mathrm{CCU}^{3} \mathrm{~S}$ system (Fig. 27), which entails cyclic fluid(s) injection into (and possibly retrieval from) the subsurface geological formations. Therefore, unintended changes in dynamic reservoir properties (e.g. saturation, pressure) will be often induced and need to be quantified and properly monitored by the inversion of the geophysical field data (such as time-lapse seismic data). The $\mathrm{CCU}^{3} \mathrm{~S}$ system will be documented in details upon what follows.

\section{$\mathrm{CO}_{2}$-based geothermal system: U1}

The base $\mathrm{CCU}^{3} \mathrm{~S}$ system is a so-called $\mathrm{CO}_{2}$-plume geothermal power system (CPGs), where the captured $\mathrm{CO}_{2}$ is circulated underground in deep saline aquifers or hydrocarbon reservoirs (e.g. during enhanced oil recovery) (Randolph and Saar 2011; Adams et al. 2015; Garapati et al. 2015; Ezekiel et al. 2020). In these reservoirs, the $\mathrm{CO}_{2}$ is naturally geothermally heated and produced to the surface, where it is expanded in a turbine to generate electricity. At the surface power plant, $\mathrm{CO}_{2}$ is subsequently cooled using wet cooling towers to increase its density, compressed and then combined with any $\mathrm{CO}_{2}$ stream, from a $\mathrm{CO}_{2}$ emitter, before it is reinjected into the subsurface reservoir (Fig. 27). The reinjection of cold and dense $\mathrm{CO}_{2}$ results in the continued growth of the subsurface $\mathrm{CO}_{2}$ plume and ensures that $100 \%$ of the subsurface-injected $\mathrm{CO}_{2}$ is eventually permanently stored underground. This combined cycle couples $\mathrm{CO}_{2}$ sequestration with geothermal energy utilisation in low-tomedium enthalpy systems; the conditions that are widely distributed across global sedimentary basins and correspond to a depth range of $2.0-5.0 \mathrm{~km}$ (Fig. 19).

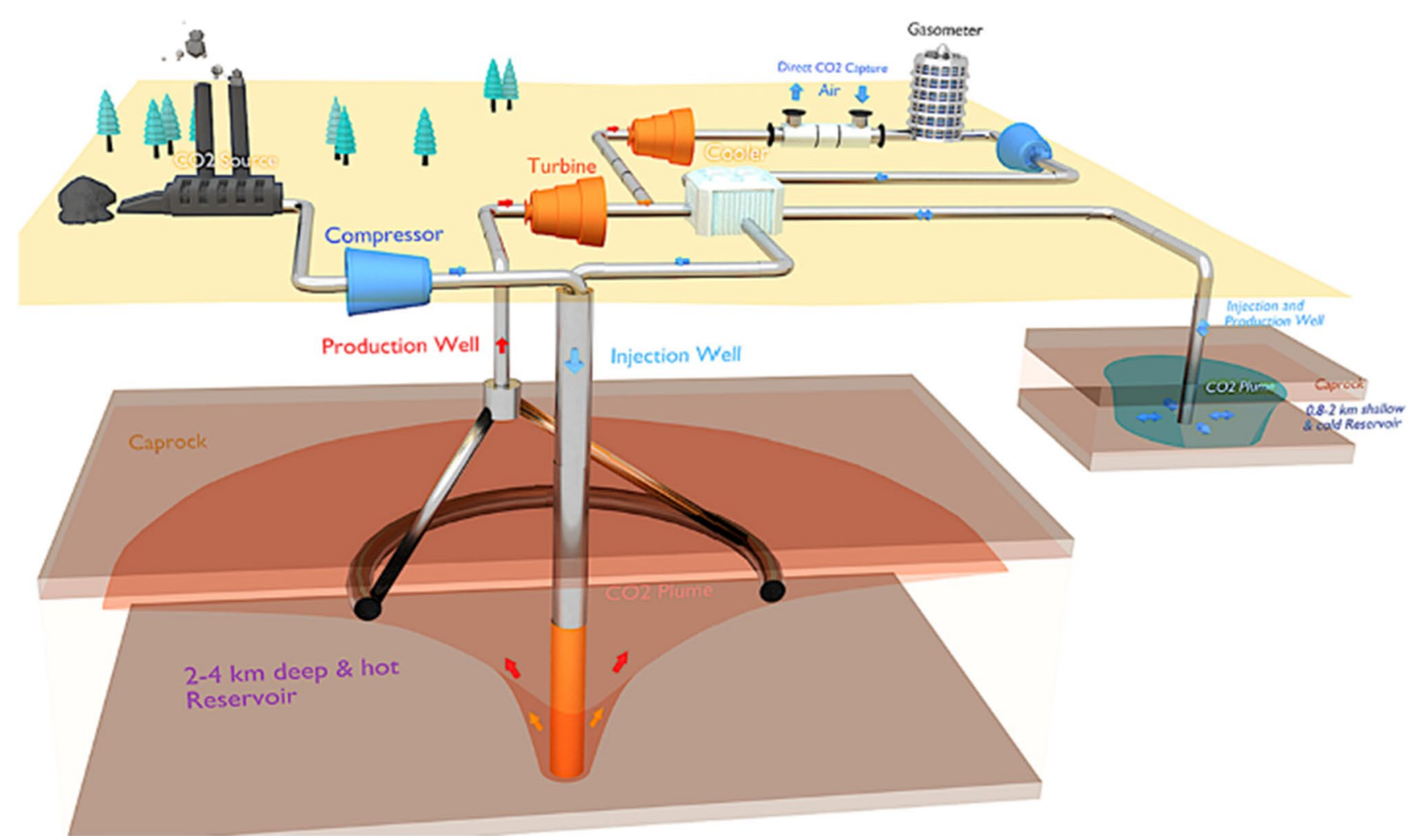

Fig. 27 A conceptual model on how carbon capture, threefold utilisation and geological storage $\left(\mathrm{CCU}^{3} \mathrm{~S}\right)$ system operates using the three different modes: [U1] generate geothermal power that roughly doubles the electricity output, compared to using groundwater to extract the geothermal heat, all else being equal, [U2] Energy storage where the system consumes electrical power to cool, compress the $\mathrm{CO}_{2}$, and injected into a shallow (temporal storage) reservoir. Power is produced by extracting $\mathrm{CO}_{2}$ from the shallow reservoir to the surface, expanded in a turbine to produce power, partially cooled and injected into a shallow, storage reservoir and [U3] district cooling and cryogenic direct air $\mathrm{CO}_{2}$ capture. The figure is a perspective drawing from Fleming et al. (2018)'s results 
Alternatively, when geologic $\mathrm{CO}_{2}$ storage is uneconomic, CPGs could be operated with a limited, finite amount of $\mathrm{CO}_{2}$, initially stored underground and thereafter run with little or no additional makeup $\mathrm{CO}_{2}$ (Garapati et al. 2015). Compared to brine, the favourable properties of $\mathrm{CO}_{2}$ (Brown 2000; Adams et al. 2014) are:

1. The density of $\mathrm{CO}_{2}$ changes substantially between the geothermal reservoir and surface plant, resulting in a buoyancy-driven convective current-a strong $\mathrm{CO}_{2}$ thermosiphon phenomenon-that increases the mass flowrate, compared to water, while reducing or eliminating parasitic pumping power required for fluid circulation through the injection and production boreholes (Fig. 21).

2. Given the fact that the fluid flow in porous media obeys Darcy's law and that heat is both advected by the fluids and conducted through the rock-fluid system, an effective heat advection using CPG system can be secured because the kinematic viscosity of supercritical $\mathrm{CO}_{2}$ is low (i.e. high mobility).

3. $\mathrm{CO}_{2}$-based geothermal energy utilisation can result in diminished mineral dissolution-precipitation - a major problem often encountered during water-based geothermal energy extraction and utilisation.

\section{Underground grid-scale energy storage: U2}

There will be an urgent need to diversify the portfolio of grid-connected storage technologies to ensure inter-seasonal energy security from a system that generates power at higher than $80 \%$ from intermittent renewables. For underground (solar and wind) energy storage, the CPGs cycle is separated into two operations (energy discharge and energy storage) by temporarily storing the $\mathrm{CO}_{2}$, after expansion in the turbine and subsequent cooling in a shallow $(\sim 1 \mathrm{~km}$ deep) reservoir during the energy discharge mode (Fig. 27). For energy storage, the $\mathrm{CO}_{2}$ is released from the shallow reservoir and reinjected into the deep $(\sim 2.5 \mathrm{~km}$ deep $)$ and thus warm "geothermal" reservoir. Fleming et al. (2018) found that the seasonal energy storage cycle has power ratios (i.e. the total generation energies to the total storage energies) of 1.55 and 1.05 , for the $200 \mathrm{~kg} / \mathrm{s}$ and $300 \mathrm{~kg} / \mathrm{s}$ mass flowrate cases, respectively. However, these ratios increase to 2.93 and 1.95 , because of the increase in the storage energy consumption, the decrease in the generation energy output and variation in the duty cycle. This type of subsurface (solar and wind) energy storage in the deep and warm reservoir is highly efficient, as geothermal energy is added during pressurised $\mathrm{CO}_{2}$ (energy) storage underground and at the power-grid scale (i.e. in the several $\mathrm{GWh}$ ranges).

\section{Gasometer-based $\mathrm{CO}_{2}$-plume geothermal energy storage} system: U3

In the above-described subsurface- $\mathrm{CO}_{2}$-based energy storage system, the "shallow" reservoir may be replaced by a gasometer, which results in a heat sink (cold source), enabling district cooling and cryogenic direct air $\mathrm{CO}_{2}$ capture (cryoDACC), powered by geothermal energy (Fig. 27). Thus, if desired, the system can, after initial priming with sufficient $\mathrm{CO}_{2}$ (to begin operation), capture its own $\mathrm{CO}_{2}$ from the air and thus grow in size as more $\mathrm{CO}_{2}$ is captured and permanently stored in the deep geologic reservoir.

\section{Bibliometric analysis}

To acquire the appropriate data from the web of science core collection database and the exported data files, some Boolean operator logic was implemented in the search methodology to find suitable publications and identify evidence gaps in the knowledge and research surrounding carbon capture storage and utilisation. The raw data of the bibliometric mappings in Fig. 28a, b were collected from the Web of Science then plotted with the VOSviewer software showing the co-occurrence of keywords in the literature between 2010 and 2020. The research methodology is shown below where 1748 results were collected from the Web of Science Core Collection

You searched for: Title: (" $\mathrm{CO}_{2}$-capture and utilization" OR "pre-combustion" OR "pre combustion" OR "oxyfuel combustion" OR "oxy-fuel combustion" OR "post-combustion" OR "post combustion" OR "carbon capture and storage utilization" AND "chemical looping" AND "monoethanolamine" AND "membrane separation" AND "chemical absorption" AND "physical adsorption")

Refined by: DOCUMENT TYPES: (ARTICLE OR PROCEEDINGS PAPER OR REVIEW)

Timespan: 2010-2020.

The bibliometric mapping over the last ten years (2010-2020) shows that the post-combustion route is dominating the keywords in the literature, with significant keywords such as absorption, amines, optimisation of postcombustion and flue gas. Interestingly, the oxyfuel combustion approach has attracted the attention of scientists and engineers over the last decade with keywords such as oxyfuel combustion, oxy-combustion and oxygen. The oxyfuel combustion route is linked through the literature with biomass and pulverised coal. The pre-combustion technology is represented with major keywords such as gasification, hydrogen production and gasification combined cycle, as shown in Fig. 28a.

The density visualisation mapping, as shown in Fig. 28b, shows that the literature during the last decade focused on 
Fig. 28 The bibliometric mapping of technologies used in the carbon capture and storage route: (top) network visualisation of most of the prominent keywords in literature in the period of 2010-2020, (bottom) the density visualisation of most of the prominent keywords in literature in the period of 2010-2020, where the lighter areas are studied and investigated more in the literature and vice versa
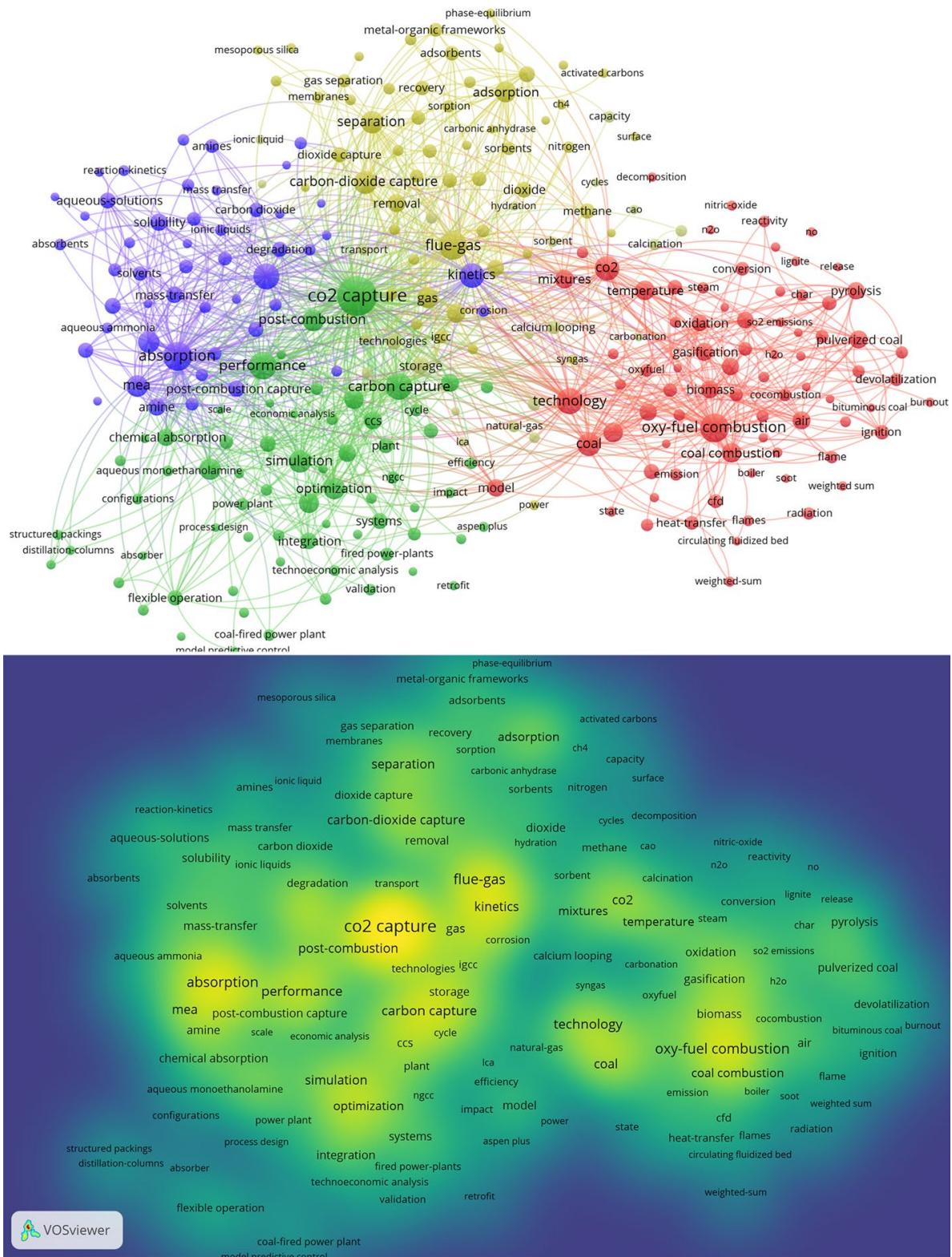

the area of post-combustion, especially the absorption route. Furthermore, keywords such as oxyfuel combustion, flue gas, kinetics, coal and separation showed frequent utilisation in carbon capture and storage during the last ten years. The less dense (darker) areas in the bibliometric mapping of Fig. 28b show the research gap in the literature in this field that need intensive investigation in the near future. For instance, the area of designing new and stable ionic liquids, pore size and selectivity of metal-organic frameworks (MOFs) and enhancing the adsorption capacity of novel solvents needs further examination. Moreover, areas such as the techno-economic evaluation of novel solvents, process design and dynamic simulation need further effort in the laboratory-scale and research \& development before pilot- and commercial-scale trials.

\section{A promising approach for carbon capture and conversion into recycled fuel}

One of the most promising approaches in CCUS route is $\mathrm{CO}_{2}$ capture using physical adsorption where the sorbent is in the form of a metal oxide (MeO, where Me denotes the metal species), such as calcium oxide (CaO), as shown in Fig. 29. After $\mathrm{CO}_{2}$ adsorption, the metal adsorbent becomes a metal carbonate in the form of $\mathrm{MeCO}_{3}$, where the later reacts with renewable hydrogen derived from water electrolysis, and the source of electricity is renewable; either from solar or wind energies. The interaction between the metal carbonate and the renewable hydrogen will lead to the formation of methane (Fig. 29), which is the main constituent in natural gas, that consequently can be compressed and used as 


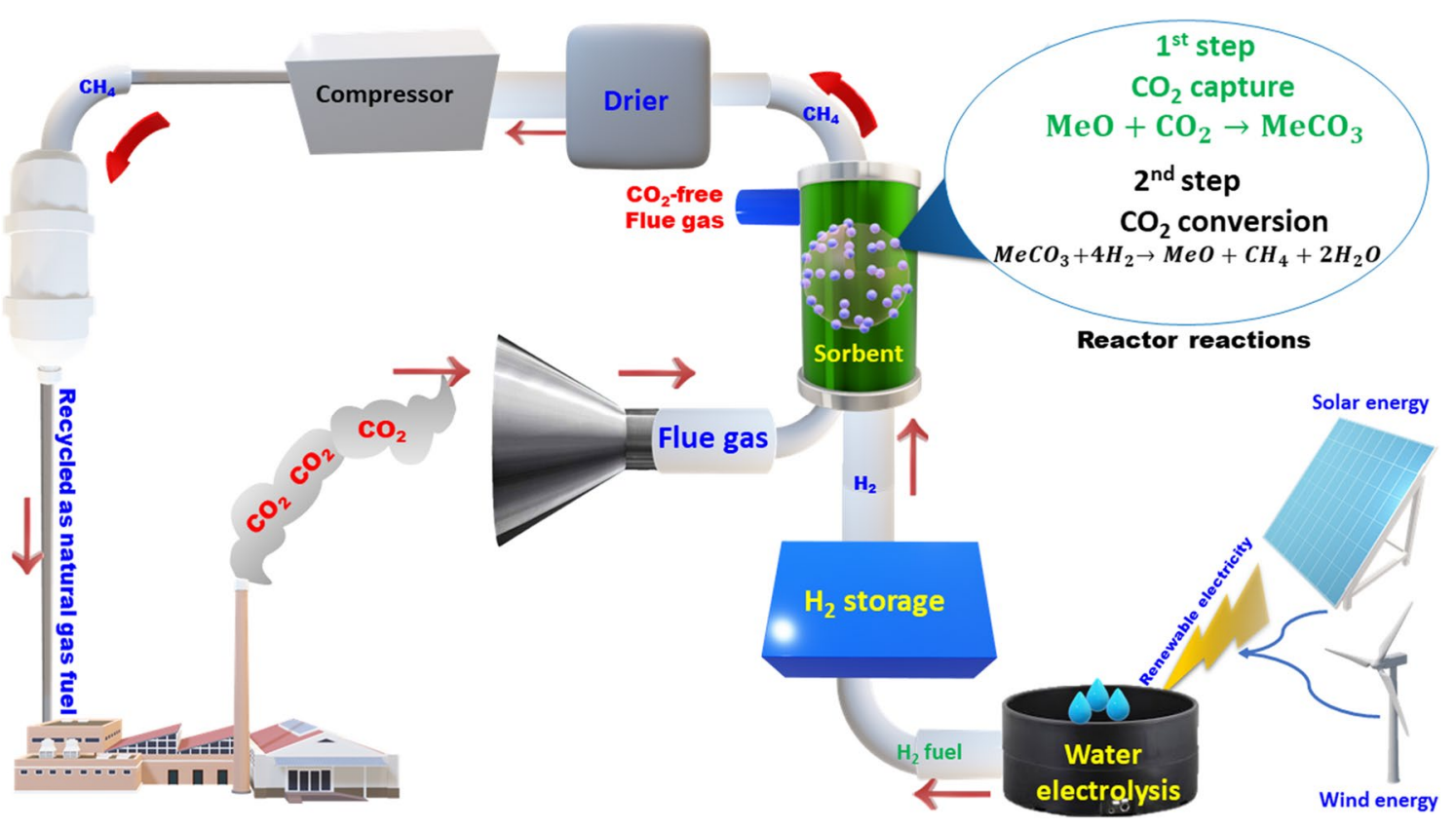

Fig. 29 The loop process where the flue gas derived from power plants or any other source of $\mathrm{CO}_{2}$ is then combined with renewable hydrogen gas over adsorbent materials to produce methane as recycled fuel. The hydrogen fuel could be obtained from water hydroly-

a recycled fuel in power plants (Sun et al. 2021; Lux et al. 2018). When combusting natural gas (methane), it releases a large amount of heat along with lower emissions compared to other hydrocarbons (Osman et al. 2018b). Thus, this CCUS approach, when integrated with biomass utilisation as a solid fuel, could eventually lead to a negative carbon emission system if the $\mathrm{CO}_{2}$ is stored or utilised in applications such as construction, where the possibility of $\mathrm{CO}_{2}$ entering the atmosphere once more is eliminated.

\section{Conclusion}

Despite the speed of maturity in renewable technologies, we still rely on fossil-based fuels to generate the energy demand needed globally. While waiting for renewable energy technologies to mature enough and replace fossil-based fuel, carbon capture storage and utilisation of fossil-based emissions are crucial as a transition state. Herein, we reviewed the three main routes of carbon capture, storage and utilisation: pre-combustion, post-combustion and oxy-fuel combustion routes along with the carbon storage and utilisation technologies.

Pre-combustion technology is promising in carbon capture, while there are many challenges to improving its overall efficiency. For instance, the solvent regeneration temperature needs to be conducted at a lower temperature than currently used to avoid any reduction in the solvent. In the sis, where the source of electricity is either from solar or wind energy sources. The recycled methane (main consistent in natural gas) is then dried and compressed before further utilisation in the process

oxy-fuel combustion route, investigating new novel routes of air separation is quite important herein, such as ion-transport and oxygen-transport membranes along with chemical looping methods. Traditional and novel technologies that are used in carbon capture have been evaluated such as postcombustion (traditional) and partial oxy-combustion (novel). In the post-combustion technology, there are desirable properties in novel solvents such as the high cyclic capacities, low production cost, low corrosiveness, lower degradation and thus lower by-products along with the environmental impact. At the same time, there are many challenges associated with membrane separation, such as water condensation on the membrane, rapid diminution of selectivity and permeance after operation along with emissions (NO $x$ and $\mathrm{SO} x$ ) that pass through the membrane. Although the precombustion technology offers higher efficiency than that of post-combustion technology, it is more expensive. To reduce the cost associated with the pre-combustion route, finding a superior absorption solvent is crucial. Currently, post-combustion technology is the most mature and widely used route among the three main routes of carbon capture and storage.

Valorisation of the captured $\mathrm{CO}_{2}$ was divided into two main categories; (1) conversion into fuels or chemicals and (2) physical utilisation of $\mathrm{CO}_{2}$. It may be used directly in other uses, in addition to carbonated beverages (i.e. fire extinguisher, refrigerant and welding medium). Direct applications of $\mathrm{CO}_{2}$ are limited in scope and have a minor impact on the overall reduction of $\mathrm{CO}_{2}$ emissions. Additionally, 
indirect utilisation of $\mathrm{CO}_{2}$ in large-scale industries is conceived to improve the performance of different processes. Such geologically stored and geothermally heated $\mathrm{CO}_{2}$ can be utilised for a base-load power generation with doubles of the electricity output, compared to using groundwater to extract the geothermal heat, all else being equal.

Acknowledgements The authors would like to acknowledge the support given by the EPSRC project "Advancing Creative Circular Economies for Plastics via Technological-Social Transitions" (ACCEPT Transitions, EP/S025545/1). AO wishes to acknowledge the support of The Bryden Centre project (Project ID VA5048). The Bryden Centre project is supported by the European Union's INTERREG VA Programme, managed by the Special EU Programmes Body (SEUPB). The authors would like to thank Samer Fawzy and Charlie Farrell who assisted in the proofreading of the manuscript.

Open Access This article is licensed under a Creative Commons Attribution 4.0 International License, which permits use, sharing, adaptation, distribution and reproduction in any medium or format, as long as you give appropriate credit to the original author(s) and the source, provide a link to the Creative Commons licence, and indicate if changes were made. The images or other third party material in this article are included in the article's Creative Commons licence, unless indicated otherwise in a credit line to the material. If material is not included in the article's Creative Commons licence and your intended use is not permitted by statutory regulation or exceeds the permitted use, you will need to obtain permission directly from the copyright holder. To view a copy of this licence, visit http://creativecommons.org/licenses/by/4.0/.

\section{References}

Abd AA, Naji SZ, Hashim AS, Othman MR (2020) Carbon dioxide removal through physical adsorption using carbonaceous and non-carbonaceous adsorbents: a review. J Environ Chem Eng 8(5):104142. ISSN 2213-3437. https://doi.org/10.1016/j. jece. 2020.104142

Abdeen FRH, Mel M, Jami MS, Ihsan SI, Ismail AF (2016) A review of chemical absorption of carbon dioxide for biogas upgrading. Chin J Chem Eng 24(6):693-702. ISSN 1004-9541. https://doi. org/10.1016/j.cjche.2016.05.006

Abdel Maksoud MIA, Fahim RA, Shalan AE, Elkodous MA, Olojede SO, Osman AI, Farrell C, Al-Muhtaseb AH, Awed AS, Ashour AH, Rooney DW (2020) Advanced materials and technologies for supercapacitors used in energy conversion and storage: a review. Environ Chem Lett. ISSN 1610-3661. https://doi. org/10.1007/s10311-020-01075-w

Abuilaiwi FA, Laoui T, Al-Harthi M, Atieh MA (2010) Modification and functionalization of multiwalled carbon nanotube (MWCNT) via fischer esterification. Arab J Sci Eng 35(1):37-48

Adams BM, Kuehn TH, Bielicki JM, Randolph JB, Saar MO (2014) On the importance of the thermosiphon effect in $\mathrm{CPG}(\mathrm{CO} 2$ plume geothermal) power systems. Energy 69:409-418. ISSN 03605442. https://doi.org/10.1016/J.ENERGY.2014.03.032

Adams BM, Kuehn TH, Bielicki JM, Randolph JB, Saar MO (2015) A comparison of electric power output of $\mathrm{CO} 2$ plume geothermal (CPG) and brine geothermal systems for varying reservoir conditions. Appl Energy 140:365-377. ISSN 0306-2619. https://doi. org/10.1016/J.APENERGY.2014.11.043

Ali M, Sultana R, Tahir S, Watson IA, Saleem M (2017) Prospects of microalgal biodiesel production in Pakistan: a review. Renew
Sustain Energy Rev 80:1588-1596. https://doi.org/10.1016/j. rser.2017.08.062

Al-Naddaf Q, Rownaghi AA, Rezaei FF (2020) Multicomponent adsorptive separation of $\mathrm{CO} 2, \mathrm{CO}, \mathrm{CH} 4, \mathrm{~N} 2$, and $\mathrm{H} 2$ over core-shell zeolite-5A@MOF-74 composite adsorbents. Chem Eng J 384:123251. ISSN 1385-8947. https://doi.org/10.1016/j. cej.2019.123251

An X, Li J, Zuo Y, Zhang Q, Wang D, Wang J (2007) A Cu/Zn/Al/Zr fibrous catalyst that is an improved $\mathrm{CO} 2$ hydrogenation to methanol catalyst. Catal Lett 118(3):264-269. https://doi.org/10.1007/ s10562-007-9182-x

Apak R (2007) Alternative solution to global warming arising from $\mathrm{CO} 2$ emissions-partial neutralization of tropospheric $\mathrm{H} 2 \mathrm{CO} 3$ with NH3. Environ Prog 26(4):355-359. https://doi.org/10.1002/ ep. 10228

Aplin AC, Matenaar IF, McCarty DK, van Der Pluijm BA (2006) Influence of mechanical compaction and clay mineral diagenesis on the microfabric and pore-scale properties of deep-water gulf of mexico mudstones. Clays Clay Miner 54(4):500-514

Armitage PJ, Worden RH, Faulkner DR, Aplin AC, Butcher AR, Iliffe J (2010) Diagenetic and sedimentary controls on porosity in Lower Carboniferous fine-grained lithologies, Krechba field, Algeria: a petrological study of a caprock to a carbon capture site. Mar Pet Geol 27(7):1395-1410. ISSN 02648172. https:// doi.org/10.1016/j.marpetgeo.2010.03.018

Ashkanani HE, Wang R, Shi W, Siefert NS, Thompson RL, Smith K, Steckel JA, Gamwo IK, Hopkinson D, Resnik K, Morsi BI (2020) Levelized cost of CO2 captured using five physical solvents in pre-combustion applications. Int J Greenh Gas Control 101:103135. ISSN 1750-5836. https://doi.org/10.1016/j.ijggc .2020 .103135

Ayodele BV, Khan MR, Cheng CK (2015) Syngas production from $\mathrm{CO} 2$ reforming of methane over ceria supported cobalt catalyst: effects of reactants partial pressure. J Nat Gas Sci Eng 27:10161023. https://doi.org/10.1016/j.jngse.2015.09.049

Azhand N, Sadeghizadeh A, Rahimi R (2020) Effect of superficial gas velocity on $\mathrm{CO} 2$ capture from air by Chlorella vulgaris microalgae in an airlift photobioreactor with external sparger. J Environ Chem Eng 8(4):104022. ISSN 2213-3437. https://doi. org/10.1016/j.jece.2020.104022

Bachu S, Bennion DB (2009) Interfacial tension between CO2, freshwater, and brine in the range of pressure from (2 to 27) MPa, temperature from (20 to 125$) \mathrm{C}$, and water salinity from (0 to 334 000) mg L-1. J Chem Eng Data 54(3):765-775. ISSN 0021-9568. https://doi.org/10.1021/je800529x

Bae J-S, Shi S (2013) Macadamia nut shell-derived carbon composites for post combustion $\mathrm{CO} 2$ capture. Int J Greenh Gas Control 19:174-182. ISSN 1750-5836. https://doi.org/10.1016/j.ijggc .2013 .08 .013

Bailera M, Lisbona P, Romeo LM, Espatolero S (2017) Power to gas projects review: lab, pilot and demo plants for storing renewable energy and CO2. Renew Sustain Energy Rev 69:292-312. https ://doi.org/10.1016/j.rser.2016.11.130

Balajii M, Niju S (2019) Biochar-derived heterogeneous catalysts for biodiesel production. Environ Chem Lett 2019:1-23

Barzagli F, Mani F, Peruzzini M (2016) Carbon dioxide uptake as ammonia and amine carbamates and their efficient conversion into urea and 1,3-disubstituted ureas. J CO2 Util 13:81-89. https ://doi.org/10.1016/j.jcou.2015.12.006

Ben-Mansour R, Habib MA, Bamidele OE, Basha M, Qasem NAA, Peedikakkal A, Laoui T, Ali M (2016) Carbon capture by physical adsorption: materials, experimental investigations and numerical modeling and simulations: a review. Appl Energy 161:225-255. ISSN 0306-2619. https://doi.org/10.1016/j.apene rgy.2015.10.011 
Benson SM, Cole DR (2008) CO2 sequestration in deep sedimentary formations. Elements 4(5):325-331. ISSN 18115209. https://doi. org/10.2113/gselements.4.5.325

Bergmo PES, Grimstad AA, Lindeberg E (2011) Simultaneous CO2 injection and water production to optimise aquifer storage capacity. Int J Greenh Gas Control 5(3):555-564. ISSN 17505836. https://doi.org/10.1016/j.ijggc.2010.09.002

Billig E, Decker M, Benzinger W, Ketelsen F, Pfeifer P, Peters R, Stolten D, Thrän D (2019) Non-fossil CO2 recycling - the technical potential for the present and future utilization for fuels in Germany. J CO2 Util 30:130-141. https://doi.org/10.1016/j. jcou.2019.01.012

Bohm MC, Herzog HJ, Parsons JE, Sekar RC (2007) Capture-ready coal plants-options, technologies and economics. Int J Greenh Gas Control 1(1):113-120. ISSN 1750-5836. https://doi. org/10.1016/S1750-5836(07)00033-3

Boonpoke A, Chiarakorn S, Laosiripojana N, Towprayoon S, Chidthaisong A (2011) Synthesis of activated carbon and MCM-41 from bagasse and rice husk and their carbon dioxide adsorption capacity. J Sustain Energy Environ 2(2):77-81

Boonpoke A, Chiarakorn S, Laosiripojana N, Towprayoon S, Chidthaisong A (2012) Investigation of CO2 adsorption by bagasse-based activated carbon. Korean J Chem Eng 29(1):89-94. ISSN 19757220. https://doi.org/10.1007/s11814-011-0143-0

Bradshaw J, Boreham C, La Pedalina F (2005) Storage retention time of $\mathrm{co} 2$ in sedimentary basing; examples from petroleum systems. In: Greenhouse gas control technologies, vol 7, Elsevier, pp 541-549

Bradshaw J, Bachu S, Bonijoly D, Burruss R, Holloway S, Christensen NP, Mathiassen OM (2007) CO2 storage capacity estimation: issues and development of standards. Int J Greenh Gas Control 1(1):62-68. ISSN 17505836. https://doi.org/10.1016/S1750 $-5836(07) 00027-8$

Brown DW (2000) A hot dry rock geothermal energy concept utilizing supercritical CO2 instead of water. In: Proceedings, twenty-fifth workshop on geothermal reservoir engineering, Stanford University, Stanford, California

Bui M, Adjiman CS, Bardow A, Anthony EJ, Boston A, Brown S, Fennell PS, Fuss S, Galindo A, Hackett LA et al (2018a) Carbon capture and storage (ccs): the way forward. Energy Environ Sci 11(5):1062-1176

Bui M, Claire SA, Bardow A, Edward JA, Boston A, Brown S, Fennell PS, Fuss S, Galindo A, Hackett LA, Hallett JP, Herzog HJ, Jackson G, Kemper J, Krevor S, Maitland GC, Matuszewski M, Metcalfe IS, Petit C, Puxty G, Reimer J, Reiner DM, Rubin ES, Scott SA, Shah N, Smit B, Martin Trusler JP, Webley P, Wilcox J, Dowell NM (2018b) Carbon capture and storage (CCS): the way forward. Energy Environ Sci 11(5):1062-1176. ISSN 17545692. https://doi.org/10.1039/C7EE02342A

Bui M, Fajardy M, Dowell NM (2018c) Bio-energy with carbon capture and storage (BECCS): opportunities for performance improvement. Fuel 213:164-175. ISSN 0016-2361. https://doi. org/10.1016/j.fuel.2017.10.100

Cai M, Palčić A, Subramanian V, Moldovan S, Ersen O, Valtchev V, Ordomsky VV, Khodakov AY (2016) Direct dimethyl ether synthesis from syngas on copper-zeolite hybrid catalysts with a wide range of zeolite particle sizes. J Catal 338:227-238. https://doi. org/10.1016/j.jcat.2016.02.025

Campbell M (2014) Technology innovation and advancements for shell cansolv co2 capture solvents. Energy Procedia 63:801-807

Cao M, Zhao L, Xu D, Ciora R, Liu PKT, Manousiouthakis VI, Tsotsis TT (2020) A carbon molecular sieve membrane-based reactive separation process for pre-combustion $\mathrm{CO} 2$ capture. J Membr Sci 605:118028.ISSN 0376-7388. https://doi.org/10.1016/j.memsc i. 2020.118028
Carbo MC, Jansen D, Hendriks C, de Visser E, Ruijg GJ, Davison J (2009) Opportunities for CO2 capture through oxygen conducting membranes at medium-scale oxyfuel coal boilers Energy Procedia 1(1):487-494. ISSN 1876-6102. https://doi. org/10.1016/j.egypro.2009.01.065

Cha JS, Park SH, Jung S-C, Ryu C, Jeon J-K, Shin M-C, Park Y-K (2016) Production and utilization of biochar: a review. J Ind Eng Chem 40:1-15. https://doi.org/10.1016/j.jiec.2016.06.002

Chaix E, Guillaume C, Guillard V (2014) Oxygen and carbon dioxide solubility and diffusivity in solid food matrices: a review of past and current knowledge. Compr Rev Food Sci Food Saf 13(3):261-286. https://doi.org/10.1111/1541-4337.12058

Chandra V, Yu SU, Kim SH, Yoon YS, Kim DY, Kwon AH, Meyyappan M, Kim KS (2012) Highly selective CO2 capture on $\mathrm{N}$-doped carbon produced by chemical activation of polypyrrole functionalized graphene sheets. Chem Commun 48(5):735-737. ISSN 1359-7345. https://doi.org/10.1039/C1CC15599G

Chaterjee S, Krupadam RJ (2019) Amino acid-imprinted polymers as highly selective co2 capture materials. Environ Chem Lett 17(1):465-472

Cheah WY, Show PL, Chang J-S, Ling TC, Juan JC (2015) Biosequestration of atmospheric $\mathrm{CO} 2$ and flue gas-containing $\mathrm{CO} 2$ by microalgae. Bioresour Technol 184:190-201. ISSN 0960-8524. https://doi.org/10.1016/j.biortech.2014.11.026

Chen SJ, Zhu M, Fu Y, Huang YX, Tao ZC, Li WL (2017) Using 13X, LiX, and $\mathrm{LiPdAgX}$ zeolites for $\mathrm{CO} 2$ capture from postcombustion flue gas. Appl Energy 191:87-98. ISSN 0306-2619. https://doi.org/10.1016/j.apenergy.2017.01.031

Chen S, Jun H, Xiang W (2018a) Application of chemical looping air separation for MILD oxy-combustion: identifying a suitable operational region. Appl Therm Eng 132:8-17. ISSN 1359-4311. https://doi.org/10.1016/j.applthermaleng.2017.12.070

Chen S, Zhu M, Tang Y, Yue F, Li W, Xiao B (2018b) Molecular simulation and experimental investigation of $\mathrm{CO} 2$ capture in a polymetallic cation-exchanged $13 \mathrm{X}$ zeolite. J Mater Chem A 6(40):19570-19583. ISSN 2050-7488. https://doi.org/10.1039/ C8TA05647A

Chen S, Ran Yu, Soomro A, Xiang W (2019) Thermodynamic assessment and optimization of a pressurized fluidized bed oxy-fuel combustion power plant with CO2 capture. Energy 175:445-455. ISSN 0360-5442. https://doi.org/10.1016/j.energy.2019.03.090

Cho D-W, Kwon EE, Song H (2016) Use of carbon dioxide as a reaction medium in the thermo-chemical process for the enhanced generation of syngas and tuning adsorption ability of biochar. Energy Convers Manage 117:106-114. https://doi.org/10.1016/j. enconman.2016.03.027

Clavaud JB, Maineult A, Zamora M, Rasolofosaon P, Schlitter C (2008) Permeability anisotropy and its relations with porous medium structure. J Geophys Res Solid Earth. https://doi. org/10.1029/2007JB005004

Collotta M, Champagne P, Mabee W, Tomasoni G (2018) Wastewater and waste $\mathrm{CO} 2$ for sustainable biofuels from microalgae. Algal Res 29:12-21. https://doi.org/10.1016/j.algal.2017.11.013

Cook PJ (2009) Demonstration and deployment of carbon dioxide capture and storage in Australia. Energy Procedia 1(1):3859-3866. ISSN 1876-6102. https://doi.org/10.1016/j.egypro.2009.02.188

Corbo MR, Bevilacqua A, Campaniello D, D'Amato D, Speranza B, Sinigaglia M (2009) Prolonging microbial shelf life of foods through the use of natural compounds and non-thermal approaches - a review. Int J Food Sci Technol 44(2):223-241. https://doi.org/10.1111/j.1365-2621.2008.01883.x

Cormos C-C (2020) Energy and cost efficient manganese chemical looping air separation cycle for decarbonized power generation based on oxy-fuel combustion and gasification. Energy 191:116579. ISSN 0360-5442. https://doi.org/10.1016/j.energ y.2019.116579 
Dadson S, Hall JW, Garrick D, Sadoff C, Grey D, Whittington D (2017) Water security, risk, and economic growth: insights from a dynamical systems model. Water Resour Res 53(8):6425-6438. https://doi.org/10.1002/2017WR020640

Darensbourg DJ, Wei S-H, Yeung AD, Ellis WC (2013) An efficient method of depolymerization of poly(cyclopentene carbonate) to its comonomers: cyclopentene oxide and carbon dioxide. Macromolecules 46(15):5850-5855. https://doi.org/10.1021/ma401 286x

de Ribeiro J, Nunes EH, Vasconcelos DC, Vasconcelos WL, Nascimento JF, Grava WM, Derks PW (2019) Role of the type of grafting solvent and its removal process on APTES functionalization onto SBA-15 silica for CO2 adsorption. J Porous Mater 26(6):1581-1591. ISSN 1573-4854. https://doi.org/10.1007/ s10934-019-00754-6

Del Pozo-Insfran D, Balaban MO, Talcott ST (2006) Microbial stability, phytochemical retention, and organoleptic attributes of dense phase $\mathrm{CO} 2$ processed muscadine grape juice. J Agric Food Chem 54(15):5468-5473. https://doi.org/10.1021/jf060854o

Demirbas A (2008) Biofuels sources, biofuel policy, biofuel economy and global biofuel projections. Energy Convers Manage 49(8):2106-2116. https://doi.org/10.1016/j.encon man.2008.02.020

Dhyani V, Bhaskar T (2018) A comprehensive review on the pyrolysis of lignocellulosic biomass. Renew Energy 129:695-716. https:// doi.org/10.1016/j.renene.2017.04.035

Din IU, Shaharun MS, Alotaibi MA, Alharthi AI, Naeem A (2019) Recent developments on heterogeneous catalytic $\mathrm{CO} 2$ reduction to methanol. J CO2 Util 34:20-33. https://doi.org/10.1016/j. jcou.2019.05.036

Dinca C, Slavu N, Cormoş C-C, Badea A (2018) CO2 capture from syngas generated by a biomass gasification power plant with chemical absorption process. Energy 149:925-936. https://doi. org/10.1016/j.energy.2018.02.109

Ding M, Flaig RW, Jiang HL, Yaghi OM (2019) Carbon capture and conversion using metal-organic frameworks and MOF-based materials. Chem Soc Rev 48(10):2783-2828. ISSN 0306-0012. https://doi.org/10.1039/C8CS00829A

Dong SL (2016) Carbon dioxide absorbers for food packaging applications. Trends Food Sci Technol 57:146-155. https://doi. org/10.1016/j.tifs.2016.09.014

Dong F, Lou H, Kodama A, Goto M, Hirose T (1999) The Petlyuk PSA process for the separation of ternary gas mixtures: exemplification by separating a mixture of CO2-CH4-N2. Sep Purific Technol 16(2):159-166. ISSN 1383-5866. https://doi.org/10.1016/ S1383-5866(98)00122-1

Doughty C, Pruess K, Benson SM, Hovorka SD, Knox PR, Green CT (2001) Capacity investigation of brine-bearing sands of the Frio Formation for geologic sequestration of $\mathrm{CO}_{2}$. In: First national conference on carbon sequestration, May 14-17, Washington, DC, sponsored by National Energy Technology Laboratory, CDROM. GCCC Digital Publication Series \#01-03

Duan Z, Sun R (2003) An improved model calculating CO2 solubility in pure water and aqueous $\mathrm{NaCl}$ solutions from 273 to $533 \mathrm{~K}$ and from 0 to 2000 bar. Chem Geol 193(3-4):257-271. ISSN 00092541. https://doi.org/10.1016/S0009-2541(02)00263-2

Duan Z, Sun R, Zhu C, Chou IM (2006) An improved model for the calculation of $\mathrm{CO} 2$ solubility in aqueous solutions containing $\mathrm{Na}+, \mathrm{K}+, \mathrm{Ca} 2+, \mathrm{Mg} 2+, \mathrm{Cl}-$, and SO42-. Mar Chem 98(24):131-139. ISSN 03044203. https://doi.org/10.1016/j.march em.2005.09.001

Düren T (2007) How does the pore morphology influence the adsorption performance of metal-organic frameworks? A molecular simulation study of methane and ethane adsorption in Zn-MOFs. In: Xu R, Gao Z, Chen J, Yan W (eds) Studies in surface science and catalysis, vol 170, Elsevier, pp 2042-2047. ISBN 0167-2991. https://doi.org/10.1016/S0167-2991(07)81097-4

Eiken O (2019) Twenty years of monitoring CO2 injection at sleipner. In: Geophysics and geosequestration, vol 4, Cambridge University Press, pp 209-234. https://doi.org/10.1017/9781316480 724.014

Eiken O, Ringrose P, Hermanrud C, Nazarian B, Torp TA, Høier L (2011) Lessons learned from 14 years of CCS operations: sleipner. In: Energy procedia, vol 4, Elsevier Ltd, pp 5541-5548. https ://doi.org/10.1016/j.egypro.2011.02.541

Endo K, Nguyen QS, Kentish SE, Stevens GW (2011) The effect of boric acid on the vapour liquid equilibrium of aqueous potassium carbonate. Fluid Phase Equilibria 309(2):109-113. ISSN 03783812. https://doi.org/10.1016/j.fluid.2011.06.031

Espinoza DN, Santamarina JC (2017) CO2 breakthrough-Caprock sealing efficiency and integrity for carbon geological storage. Int J Greenh Gas Control 66:218-229. ISSN 17505836. https://doi. org/10.1016/j.ijggc.2017.09.019

Ezekiel J, Ebigbo A, Adams BM, Saar MO (2020) Combining natural gas recovery and $\mathrm{CO} 2$-based geothermal energy extraction for electric power generation. Appl Energy 269:115012. ISSN 03062619. https://doi.org/10.1016/j.apenergy.2020.115012

Farha OK, Spokoyny AM, Mulfort KL, Galli S, Hupp JT, Mirkin CA (2009) Gas-sorption properties of cobalt(II)-carborane-based coordination polymers as a function of morphology. Small 5(15):1727-1731. ISSN 1613-6810. https://doi.org/10.1002/ smll.200900085

Farha OK, Eryazici I, Jeong NC, Hauser BG, Wilmer CE, Sarjeant AA, Snurr RQ, Nguyen ST, Yazaydın AO, Hupp JT (2012) Metalorganic framework materials with ultrahigh surface areas: Is the sky the limit? J Am Chem Soc 134(36):15016-15021. ISSN 0002-7863

Faried M, Samer M, Abdelsalam E, Yousef RS, Attia YA, Ali AS (2017) Biodiesel production from microalgae: processes, technologies and recent advancements. Renew Sustain Energy Rev 79:893-913. https://doi.org/10.1016/j.rser.2017.05.199

Farmahini AH, Friedrich D, Brandani S, Sarkisov L (2020) Exploring new sources of efficiency in process-driven materials screening for post-combustion carbon capture. Energy Environ Sci 13(3):1018-1037. ISSN 1754-5692. https://doi.org/10.1039/ C9EE03977E

Fawzy S, Osman AI, Doran J, Rooney DW (2020) Strategies for mitigation of climate change: a review. Environ Chem Lett. ISSN 1610-3661. https://doi.org/10.1007/s10311-020-01059-w

Fayaz M, Sayari A (2017) Long-term effect of steam exposure on CO2 capture performance of amine-grafted silica. ACS Appl Mater Interfaces 9(50):43747-43754. ISSN 1944-8244. https://doi. org/10.1021/acsami.7b15463

Fenghour A, Wakeham WA, Vesovic V (1998) The viscosity of carbon dioxide. J Phys Chem Ref Data 27(1):31-39. ISSN 00472689. https://doi.org/10.1063/1.556013

Fleming MR, Adams BM, Randolph JB, Ogland-Hand JO, Kuehn TH, Buscheck TA, Bielicki JM, Saar MO (2018) High efficiency and large-scale subsurface energy storage with $\mathrm{CO} 2$. In: 43rd Workshop on geothermal reservoir engineering, Stanford, CA

Furre AK, Eiken O (2014) Dual sensor streamer technology used in Sleipner CO2 injection monitoring. Geophys Prospect 62(5):1075-1088. ISSN 13652478. https://doi. org/10.1111/1365-2478.12120

Furukawa H, Ko N, Go, Aratani N, Choi SB, Choi E, Yazaydin A, Snurr RQ, O'Keeffe M, Kim J (2010) Ultrahigh porosity in metal-organic frameworks. Science 329(5990):424-428. ISSN 0036-8075. https://doi.org/10.1126/science.1192160

Fu K, Sema T, Liang Z, Liu H, Na Y, Shi H, Idem R, Tontiwachwuthikul (2012) Correction for "investigation of mass-transfer performance for $\mathrm{CO} 2$ absorption into diethylenetriamine (DETA) 
in a randomly packed column”. Ind Eng Chem Res 51(49):16162. ISSN 0888-5885. https://doi.org/10.1021/ie303149h

Gao J, Yin J, Zhu F, Chen X, Tong M, Kang W, Zhou Y, Lu J (2016) Integration study of a hybrid solvent MEA-methanol for post combustion carbon dioxide capture in packed bed absorption and regeneration columns. Sep Purific Technol 167:17-23. ISSN 1383-5866. https://doi.org/10.1016/j.seppur.2016.04.033

Garapati N, Randolph JB, Saar MO (2015) Brine displacement by CO2, energy extraction rates, and lifespan of a $\mathrm{CO} 2$-limited $\mathrm{CO} 2$ Plume Geothermal (CPG) system with a horizontal production well. Geothermics 55:182-194. ISSN 0375-6505. https://doi. org/10.1016/J.GEOTHERMICS.2015.02.005

GCCSI (2017) The Global Status of CCS: 2017, Docklands, Australia. https://www.globalccsinstitute.com/wp-content/ uploads/2018/12/2017-Global-Status-Report.pdf. Accessed on 17 Sep 2020. https://www.globalccsinstitute.com/wp-content/ uploads/2018/12/2017-Global-Status-Report.pdf

Ghosh S, Ramaprabhu S (2019) Green synthesis of transition metal nanocrystals encapsulated into nitrogen-doped carbon nanotubes for efficient carbon dioxide capture. Carbon 141:692-703. ISSN 0008-6223. https://doi.org/10.1016/j.carbon.2018.09.083

Gladis A, Gundersen MT, Fosbøl PL, Woodley JM, von Solms N (2017) Influence of temperature and solvent concentration on the kinetics of the enzyme carbonic anhydrase in carbon capture technology. Chem Eng J 309:772-786. ISSN 1385-8947. https ://doi.org/10.1016/j.cej.2016.10.056

Gładysz P, Ziębik A (2016) Environmental analysis of bio-CCS in an integrated oxy-fuel combustion power plant with $\mathrm{CO} 2$ transport and storage. Biomass Bioenergy 85:109-118. ISSN 0961-9534. https://doi.org/10.1016/j.biombioe.2015.12.008

Godec ML, Kuuskraa VA, Dipietro P (2013) Opportunities for using anthropogenic $\mathrm{CO} 2$ for enhanced oil recovery and $\mathrm{CO} 2$ storage. In: Energy and fuels, vol 27, American Chemical Society, pp 4183-4189. https://doi.org/10.1021/ef302040u

González JF, Román S, González-García CM, Valente Nabais JM, Ortiz AL (2009) Porosity development in activated carbons prepared from walnut shells by carbon dioxide or steam activation. Ind Eng Chem Res 48(16):7474-7481. ISSN 0888-5885. https ://doi.org/10.1021/ie801848x

González AS, Plaza MG, Rubiera F, Pevida C (2013) Sustainable biomass-based carbon adsorbents for post-combustion co2 capture. Chem Eng J 230:456-465

González-Aparicio I, Pérez-Fortes M, Zucker A, Tzimas E (2017) Opportunities of integrating $\mathrm{CO} 2$ utilization with RES-E: a power-to-methanol business model with wind power generation. Energy Procedia 114:6905-6918. https://doi.org/10.1016/j.egypr o.2017.03.1833

Goodman A, Hakala A, Bromhal G, Deel D, Rodosta T, Frailey S, Small M, Allen D, Romanov V, Fazio J, Huerta N, McIntyre D, Kutchko B, Guthrie G (2011) US DOE methodology for the development of geologic storage potential for carbon dioxide at the national and regional scale. Int J Greenh Gas Control 5(4):952-965. ISSN 17505836. https://doi.org/10.1016/j.ijggc .2011 .03 .010

Grimm Lima M, Schädle P, Green CP, Vogler D, Saar MO, Kong XZ (2020) Permeability impairment and salt precipitation patterns during $\mathrm{CO}_{2}$ injection into single natural brine-filled fractures. Water Resour Res 56(8): 8. ISSN 0043-1397. https://doi. org/10.1029/2020WR027213

Guéguen Y, Schubnel A (2003) Elastic wave velocities and permeability of cracked rocks. Tectonophysics 370(1-4):163-176

Guizani C, Louisnard O, Escudero Sanz FJ, Salvador S (2015) Gasification of woody biomass under high heating rate conditions in pure CO2. Biomass Bioenergy 83:169-182. https://doi.org/10.1016/j. biombioe.2015.09.017
Guo M, Kanezashi M, Nagasawa H, Yu L, Ohshita J, Tsuru T (2020) Amino-decorated organosilica membranes for highly permeable CO2 capture. J Membr Sci 611:118328. ISSN 0376-7388. https ://doi.org/10.1016/j.memsci.2020.118328

Habib N, Shamair Z, Tara N, Nizami A, Hassan Akhtar F, Ahmad NM, Gilani MA, Bilad MR, Khan AL (2020) Development of highly permeable and selective mixed matrix membranes based on Pebax ${ }^{\circledR} 1657$ and NOTT-300 for CO2 capture. Sep Purific Technol 234:116101. ISSN 1383-5866. https://doi.org/10.1016/j. seppur.2019.116101

Hanjra MA, Ejaz Qureshi M (2010) Global water crisis and future food security in an era of climate change. Food Policy 35(5):365-377. https://doi.org/10.1016/j.foodpol.2010.05.006

Hasib-ur Rahman M, Siaj M, Larachi F (2010) Ionic liquids for CO2 capture-development and progress. Chem Eng Process Process Intensif 49(4):313-322. ISSN 0255-2701

He S, Chen G, Xiao H, Shi G, Ruan C, Ma Y, Dai H, Yuan B, Chen X, Yang X (2010) Facile preparation of N-doped activated carbon produced from rice husk for $\mathrm{CO} 2$ capture. J Colloid Interface Sci 582(Pt A):90-101. ISSN 0021-9797. https://doi.org/10.1016/j. jcis.2020.08.021

Hefny M (2019) Dataset for "Synchrotron-based pore-network modeling of two-phase flow in Nubian Sandstone and implications for capillary trapping of carbon dioxide”. ETH Zurich 11:2019. https://doi.org/10.3929/ETHZ-B-000377881

Hefny M (2020) Rock physics and heterogeneities characterization controlling fluid flow in reservoir rocks. PhD thesis, ETH Zurich, Zurich

Hefny M, Qin CZ, Saar MO, Ebigbo A (2020) Synchrotron-based pore-network modeling of two-phase flow in Nubian Sandstone and implications for capillary trapping of carbon dioxide. Int $\mathrm{J}$ Greenh Gas Control 103:103164. ISSN 17505836. https://doi. org/10.1016/j.ijggc.2020.103164

Helbig K, Thomsen L (2005) 75-plus years of anisotropy in exploration and reservoir seismics: a historical review of concepts and methods. Geophysics 70(6):9ND-23ND

Henao W, Jaramillo LY, López D, Romero-Sáez M, Buitrago-Sierra $\mathrm{R}$ (2020) Insights into the CO2 capture over amine-functionalized mesoporous silica adsorbents derived from rice husk ash. J Environ Chem Eng 8(5):104362. ISSN 2213-3437. https://doi. org/10.1016/j.jece.2020.104362

Honda S, Mori T, Goto H, Sugimoto H (2014) Carbon-dioxide-derived unsaturated alicyclic polycarbonate: synthesis, characterization, and post-polymerization modification. Polymer 55(19):48324836. https://doi.org/10.1016/j.polymer.2014.08.002

Hong SM, Kim SH, Lee KB (2013) Adsorption of carbon dioxide on 3-aminopropyl-triethoxysilane modified graphite oxide. Energy Fuels 27(6):3358-3363. ISSN 0887-0624. https://doi. org/10.1021/ef400467w

Hong J, Field R, Gazzino M, Ghoniem AF (2010) Operating pressure dependence of the pressurized oxy-fuel combustion power cycle. Energy 35(12):5391-5399. ISSN 0360-5442. https://doi. org/10.1016/j.energy.2010.07.016

Hsan N, Dutta PK, Kumar S, Bera R, Das N (2019) Chitosan grafted graphene oxide aerogel: synthesis, characterization and carbon dioxide capture study. Int J Biol Macromol 125:300-306. ISSN 0141-8130. https://doi.org/10.1016/j.ijbiomac.2018.12.071

Huang C, Chen L, Tadikamalla PR, Gordon MM (2020) Valuation and investment strategies of carbon capture and storage technology under uncertainties in technology, policy and market. J Oper Res Soc. ISSN 0160-5682. https://doi.org/10.1080/01605 682.2019.1678402

Hudson MR, Queen WL, Mason JA, Fickel DW, Lobo RF, Brown CM (2012) Unconventional, highly selective CO2 aAdsorption in zeolite SSZ-13. J Am Chem Soc 134(4):1970-1973. ISSN 0002-7863. https://doi.org/10.1021/ja210580b 
Hu J, Liu Y, Liu J, Gu C, Wu D (2018) High CO2 adsorption capacities in UiO type MOFs comprising heterocyclic ligand. Microporous Mesoporous Mater 256:25-31. ISSN 1387-1811. https:// doi.org/10.1016/j.micromeso.2017.07.051

Iaquaniello G, Centi G, Salladini A, Palo E, Perathoner S, Spadaccini L (2017) Waste-to-methanol: process and economics assessment. Bioresour Technol 243:611-619. https://doi.org/10.1016/j.biort ech.2017.06.172

International Energy Agency (2008) CO2 capture and storage: a key carbon abatement option. https://doi.org/10.1787/9789264041 417-en

IPCC (2005) IPCC special report on carbon dioxide capture and storage. Technical report, Cambridge University Press, Cambridge

IPCC (2014) Climate change 2014 mitigation of climate change: working group III contribution to the IPCC fifth assessment report of the intergovernmental panel on climate change, Cambridge University Press, Cambridge. ISBN 9781107415416 . https://doi. org/10.1017/CBO9781107415416

Ishaq H, Siddiqui O, Chehade G, Dincer I (2020) A solar and wind driven energy system for hydrogen and urea production with $\mathrm{CO} 2$ capturing. Int J Hydrogen Energy. https://doi.org/10.1016/j.ijhyd ene.2020.01.208

Jadhav SG, Vaidya PD, Bhanage BM, Joshi JB (2014) Catalytic carbon dioxide hydrogenation to methanol: a review of recent studies. Chem Eng Res Des 92(11):2557-2567. https://doi.org/10.1016/j. cherd.2014.03.005

Jahandar Lashaki M, Sayari A (2018) CO2 capture using triaminegrafted SBA-15: the impact of the support pore structure. Chem Eng J 334:1260-1269. ISSN 1385-8947. https://doi. org/10.1016/j.cej.2017.10.103

James RE, Kearins D, Turner M, Woods M, Kuehn N, Zoelle A (2019) Cost and performance baseline for fossil energy plants volume 1: bituminous coal and natural gas to electricity. Technical report 2019

Jang JG, Lee HK (2016) Microstructural densification and CO2 uptake promoted by the carbonation curing of belite-rich Portland cement. Cem Concr Res 82:50-57. https://doi.org/10.1016/j. cemconres.2016.01.001

Jang JG, Kim HJ, Park SM, Lee HK (2015) The influence of sodium hydrogen carbonate on the hydration of cement. Constr Build Mater 94:746-749. https://doi.org/10.1016/j.conbuildma t.2015.07.121

Jansen D, Gazzani M, Manzolini G, van Dijk E, Carbo M (2015) Precombustion CO2 capture. Int J Greenh Gas Control 40:167-187. ISSN 1750-5836. https://doi.org/10.1016/j.ijggc.2015.05.028

Jena KK, Panda AP, Verma S, Mani GK, Swain SK, Alhassan SM (2019) MWCNTs-ZnO-SiO2 mesoporous nano-hybrid materials for CO2 capture. J Alloys Compd 800:279-285. ISSN 09258388. https://doi.org/10.1016/j.jallcom.2019.06.011

Jeremiáš M, Pohořelý M, Svoboda K, Skoblia S, Beňo Z, Šyc M (2018) CO2 gasification of biomass: the effect of lime concentration in a fluidised bed. Appl Energy 217:361-368. https://doi. org/10.1016/j.apenergy.2018.02.151

Jiamjirangkul P, Inprasit T, Intasanta V, Pangon A (2020) Metal organic framework-integrated chitosan/poly(vinyl alcohol) (PVA) nanofibrous membrane hybrids from green process for selective CO2 capture and filtration. Chem Eng Sci 221:115650. ISSN 0009-2509. https://doi.org/10.1016/j.ces.2020.115650

Jian-Gang L, Li X, Zhao Y-X, Ma H-L, Wang L-F, Wang X-Y, Yu-Fan Yu, Shen T-Y, Hao X, Zhang Y-T (2019) Co2 capture by ionic liquid membrane absorption for reduction of emissions of greenhouse gas. Environ Chem Lett 17(2):1031-1038

Jiang Y, Tan P, Qi SC, Liu XQ, Yan JH, Fan F, Sun LB (2019) Metalorganic frameworks with target-specific active sites switched by photoresponsive motifs: efficient adsorbents for tailorable $\mathrm{CO} 2$ capture. Angew Chem Int Edn 58(20):6600-6604. ISSN 14337851. https://doi.org/10.1002/anie.201900141

Jung JM, Lee J, Kim J, Kim KH, Kim HW, Jeon YJ, Kwon EE (2016) Enhanced thermal destruction of toxic microalgal biomass by using CO2. Sci Total Environ 566-567:575-583. https://doi. org/10.1016/j.scitotenv.2016.05.161

Kárászová M, Zach B, Petrusová Z, Červenka V, Bobák M, Šyc M, Izák P (2020) Post-combustion carbon capture by membrane separation, review. Sep Purif Technol 238:116448. ISSN 1383-5866. https://doi.org/10.1016/j.seppur.2019.116448

Karnwiboon K, Krajangpit W, Supap T, Muchan P, Saiwan C, Idem R, Koiwanit J (2019) Solvent extraction based reclaiming technique for the removal of heat stable salts (HSS) and neutral degradation products from amines used during the capture of carbon dioxide (CO2) from industrial flue gases. Sep Purif Technol 228:115744. ISSN 1383-5866. https://doi.org/10.1016/j.seppur.2019.115744

Khan AA, Halder GN, Saha AK (2016) Experimental investigation of sorption characteristics of capturing carbon dioxide into piperazine activated aqueous 2-amino-2-methyl-1-propanol solution in a packed column. Int J Greenh Gas Control 44:217-226. ISSN 1750-5836. https://doi.org/10.1016/j.ijggc.2015.11.020

Kim S, Lee J (2020) Pyrolysis of food waste over a Pt catalyst in CO2 atmosphere. J Hazard Mater 393:122449. https://doi. org/10.1016/j.jhazmat.2020.122449

Kim Y, Lim JA, Jeong SK, Yoon YI, Bae ST, Nam SC (2013) Comparison of carbon dioxide absorption in aqueous MEA, DEA, TEA, and AMP solutions. Bull Korean Chem Soc 34(3):783-787. ISSN 0253-2964

Kim YE, Moon SJ, Yoon YI, Jeong SK, Park KT, Bae ST, Nam SC (2014) Heat of absorption and absorption capacity of CO2 in aqueous solutions of amine containing multiple amino groups. Sep Purif Technol 122:112-118. ISSN 1383-5866. https://doi. org/10.1016/j.seppur.2013.10.030

Kim J, Lee J, Kim KH, Ok Yong Sik, Jeon YJ, Kwon EE (2017) Pyrolysis of wastes generated through saccharification of oak tree by using CO2 as reaction medium. Appl Therm Eng 110:335-345. https://doi.org/10.1016/j.applthermaleng.2016.08.200

Klaus S, Lehenmeier MW, Anderson CE, Rieger B (2011) Recent advances in $\mathrm{CO} 2 /$ epoxide copolymerization-new strategies and cooperative mechanisms. Coord Chem Rev 255(13):1460-1479. https://doi.org/10.1016/j.ccr.2010.12.002

Ko YG, Lee HJ, Oh HC, Choi US (2013) Amines immobilized doublewalled silica nanotubes for CO2 capture. J Hazard Mater 250251:53-60. ISSN 0304-3894. https://doi.org/10.1016/j.jhazm at.2013.01.035

Kobaku SPR, Kota AK, Lee DH, Mabry JM, Tuteja A (2012) Patterned superomniphobic-superomniphilic surfaces: templates for siteselective self-assembly. Angew Chem 124(40):10256-10260. ISSN 00448249. https://doi.org/10.1002/ange.201202823

Kong XZ, Saar MO (2013) Numerical study of the effects of permeability heterogeneity on density-driven convective mixing during CO2 dissolution storage. Int J Greenh Gas Control 19:160-173. ISSN 17505836. https://doi.org/10.1016/j.ijggc.2013.08.020

König DH, Freiberg M, Dietrich RU, Wörner A (2015) Techno-economic study of the storage of fluctuating renewable energy in liquid hydrocarbons. Fuel 159:289-297. https://doi.org/10.1016/j. fuel.2015.06.085

Koohestanian E, Sadeghi J, Mohebbi-Kalhori D, Shahraki F, Samimi A (2018) A novel process for $\mathrm{CO} 2$ capture from the flue gases to produce urea and ammonia. Energy 144:279-285. https://doi. org/10.1016/j.energy.2017.12.034

Kopp A, Class H, Helmig R (2009) Investigations on $\mathrm{CO}_{2}$ storage capacity in saline aquifers-part 2: estimation of storage capacity coefficients. Int J Greenh Gas Control 3(3):277-287. ISSN 17505836. https://doi.org/10.1016/j.ijggc.2008.10.001 
Kosheleva RI, Mitropoulos AC, Kyzas GZ (2019) Synthesis of activated carbon from food waste. Environ Chem Lett 17(1):429-438

Kotowicz J, Balicki A (2014) Enhancing the overall efficiency of a lignite-fired oxyfuel power plant with CFB boiler and membrane-based air separation unit. Energy Convers Manag 80:20-31. ISSN 0196-8904. https://doi.org/10.1016/j.encon man.2013.12.069

Koytsoumpa EI, Bergins C, Kakaras E (2018) The CO2 economy: review of $\mathrm{CO} 2$ capture and reuse technologies. J Supercrit Fluids 132:3-16. ISSN 0896-8446. https://doi.org/10.1016/j.supfl u.2017.07.029

Krishnamurthy KR (2017) Slipstream pilot-scale demonstration of a novel amine-based post-combustion technology for carbon dioxide capture from coal-fired power plant flue gas. Technical report

Krishnan A, Gopinath KP, Dai-Viet NV, Malolan R, Nagarajan VM, Arun J (2020) Ionic liquids, deep eutectic solvents and liquid polymers as green solvents in carbon capture technologies: a review. Environ Chem Lett 2020:1-24

Krull FF, Fritzmann C, Melin T (2008) Liquid membranes for gas/vapor separations. J Membr Sci 325(2):509-519. ISSN 0376-7388

Kumar R, Jayaramulu K, Maji TP, Rao CNR (2013) Hybrid nanocomposites of ZIF-8 with graphene oxide exhibiting tunable morphology, significant $\mathrm{CO} 2$ uptake and other novel properties. Chem Commun 49(43):4947-4949. ISSN 1359-7345. https://doi. org/10.1039/C3CC00136A

Kumar P, Faujdar E, Singh RK, Paul S, Kukrety A, Chhibber VK, Ray SS (2018) High co2 absorption of o-carboxymethylchitosan synthesised from chitosan. Environ Chem Lett 16(3):1025-1031

Larson ED (2006) A review of life-cycle analysis studies on liquid biofuel systems for the transport sector. Energy Sustain Dev 10(2):109-126. https://doi.org/10.1016/S0973-0826(08)60536-0

Lazard (2018) Levelized cost of energy and levelized cost of storage. Technical report

Lee CB, Lee SW, Park JS, Lee DW, Hwang KR, Ryi SK, Kim SH (2013) Long-term CO2 capture tests of Pd-based composite membranes with module configuration. Int J Hydrogen Energy 38(19):7896-7903. ISSN 0360-3199

Lee SR, Lee J, Lee T, Tsang YF, Jeong KH, Oh JI, Kwon EE (2017a) Strategic use of $\mathrm{CO} 2$ for co-pyrolysis of swine manure and coal for energy recovery and waste disposal. J CO2 Util 22:110-116. 10.1016/j.jcou.2017.09.018

Lee J, Oh JI, Ok YS, Kwon EE (2017b) Study on susceptibility of CO2assisted pyrolysis of various biomass to CO2. Energy 137:510517. https://doi.org/10.1016/j.energy.2017.01.155

Lee J, Yang X, Cho SH, Kim JK, Lee SS, Tsang DSW, Ok YS, Kwon EE (2017c) Pyrolysis process of agricultural waste using CO2 for waste management, energy recovery, and biochar fabrication. Appl Energy 185:214-222. https://doi.org/10.1016/j.apene rgy.2016.10.092

Lee T, Lee J, Ok YS, Oh JI, Lee SR, Rinklebe JR, Kwon EE (2017d) Utilizing $\mathrm{CO} 2$ to suppress the generation of harmful chemicals from thermal degradation of polyvinyl chloride. J Clea Prod 162:1465-1471. https://doi.org/10.1016/j.jclepro.2017.06.181

Lee J, Tsang YF, Kim S, Ok YS, Kwon EE (2017e) Energy density enhancement via pyrolysis of paper mill sludge using $\mathrm{CO} 2 . \mathrm{J}$ CO2 Util 17:305-311. 10.1016/j.jcou.2017.01.001

Lee DJ, Jeong KH, Lee DH, Lee SH, Jung MW, Jang YN, Jo GG, Kwag JH, Yi H, Park YK, Kwon EE (2019) Catalytic pyrolysis of swine manure using CO2 and steel slag. Environ Int 133:105204. https ://doi.org/10.1016/j.envint.2019.105204

Lee JH, Im K, Han S, Yoo SJ, Kim J, Kim JH (2020) Bimodal-porous hollow $\mathrm{MgO}$ sphere embedded mixed matrix membranes for CO2 capture. Sep Purif Technol 250:117065. ISSN 1383-5866. https://doi.org/10.1016/j.seppur.2020.117065
Lemmon EW, McLinden MO, Friend DG (2018) Thermophysical properties of fluid systems. In Linstrom PJ, Mallard WG (eds) NIST standard reference database number 69 and NIST chemistry WebBook. National Institute of Standards and Technology, Gaithersburg MD, 20899. https://doi.org/10.18434/T4D303

Li H, Eddaoudi M, O'Keeffe M, Yaghi OM (1999) Design and synthesis of an exceptionally stable and highly porous metal-organic framework. Nature, 402(6759):276-279. ISSN 1476-4687. https ://doi.org/10.1038/46248

Li JR, Ma Y, Colin McCarthy M, Sculley J, Yu J, Jeong HK, Balbuena PB, Zhou HC (2011a) Carbon dioxide capture-related gas adsorption and separation in metal-organic frameworks. Coord Chem Rev 255(15):1791-1823. ISSN 0010-8545. https://doi. org/10.1016/j.ccr.2011.02.012

Li H, Wilhelmsen O, Lv Y, Wang W, Yan J (2011b) Viscosities, thermal conductivities and diffusion coefficients of $\mathrm{CO} 2 \mathrm{mix}-$ tures: review of experimental data and theoretical models. ISSN 17505836

Li G, Xiao P, Xu D, Webley PA (2011c) Dual mode roll-up effect in multicomponent non-isothermal adsorption processes with multilayered bed packing. Chem Eng Sci, 66(9):1825-1834. ISSN 0009-2509. https://doi.org/10.1016/j.ces.2011.01.023

Li JR, Sculley J, Zhou HC (2012a) Metal-organic frameworks for separations. Chem Rev 112(2):869-932. ISSN 0009-2665. https://doi. org/10.1021/cr200190s

Li X, Boek E, Maitland GC, Martin Trusler JP (2012b) Interfacial tension of (Brines $+\mathrm{CO} 2):(0.864 \mathrm{NaCl}+0.136 \mathrm{KCl})$ at temperatures between (298 and 448) K, pressures between ( 2 and 50) $\mathrm{MPa}$, and total molalities of (1 to 5) mol $\mathrm{kg}-1$. J Chem Eng Data 57(4):1078-1088. ISSN 15205134. https://doi.org/10.1021/ je201062r

Li B, Zhang Z, Li Y, Yao K, Zhu Y, Deng Z, Yang F, Zhou X, Li G, Wu H, Nijem N, Chabal YJ, Lai Z, Han Y, Shi Z, Feng S, Li J (2012c) Enhanced binding affinity, remarkable selectivity, and high capacity of $\mathrm{CO} 2$ by dual functionalization of a rht-type metal-organic framework. Angew Chem Int Edn 51(6):14121415. ISSN 1433-7851. https://doi.org/10.1002/anie.201105966

Li W, Yang H, Jiang X, Liu Q (2016) Highly selective CO2 adsorption of $\mathrm{ZnO}$ based $\mathrm{N}$-doped reduced graphene oxide porous nanomaterial. Appl Surf Sci 360:143-147. ISSN 0169-4332. https://doi. org/10.1016/j.apsusc.2015.10.212

Li H, Yan D, Zhang Z, Lichtfouse E (2019a) Prediction of co2 absorption by physical solvents using a chemoinformatics-based machine learning model. Environ Chem Lett 17(3):1397-1404

Li J, Michalkiewicz B, Min J, Ma C, Chen X, Gong J, Mijowska E, Tang T (2019b) Selective preparation of biomass-derived porous carbon with controllable pore sizes toward highly efficient $\mathrm{CO} 2$ capture. Chem Eng J 360:250-259. ISSN 1385-8947. https://doi. org/10.1016/j.cej.2018.11.204

Lin LY, Bai H (2010) Continuous generation of mesoporous silica particles via the use of sodium metasilicate precursor and their potential for $\mathrm{CO} 2$ capture. Microporous Mesoporous Mater 136(1):25-32. ISSN 1387-1811. https://doi.org/10.1016/j.micro meso.2010.07.012

Lin YF, Wang WW, Chang Cy (2018) Environmentally sustainable, fluorine-free and waterproof breathable PDMS/PS nanofibrous membranes for carbon dioxide capture. J Mater Chem A 6(20):9489-9497. ISSN 2050-7488. https://doi.org/10.1039/ C8TA00275D

Liu JL, Lin RB (2013) Structural properties and reactivities of aminomodified silica fume solid sorbents for low-temperature $\mathrm{CO} 2$ capture. Powder Technol 241:188-195. ISSN 0032-5910. https ://doi.org/10.1016/j.powtec.2013.03.022

Liu Y, Wang ZU, Zhou HC (2012) Recent advances in carbon dioxide capture with metal-organic frameworks. Greenh Gases Sci 
Technol 2(4):239-259. ISSN 2152-3878. https://doi.org/10.1002/ ghg. 1296

Liu L, Jin S, Ko K, Kim K, Ahn IS, Lee CH (2020) Alkyl-functionalization of (3-Aminopropyl)triethoxysilane-grafted zeolite beta for carbon dioxide capture in temperature swing adsorption. Chem Eng J 382:122834. ISSN 1385-8947. https://doi.org/10.1016/j. cej.2019.122834

Lozano-Castelló D, Cazorla-Amorós D, Linares-Solano A, Quinn DF (2002) Activated carbon monoliths for methane storage: influence of binder. Carbon 40(15):2817-2825. ISSN 0008-6223. https://doi.org/10.1016/S0008-6223(02)00194-X

Luo K, Zhang C, Zhu S, Bai Y, Li F (2016) Tar formation during coal pyrolysis under $\mathrm{N} 2$ and $\mathrm{CO} 2$ atmospheres at elevated pressures. J Anal Appl Pyrol 118:130-135. https://doi.org/10.1016/j. jaap.2016.01.009

Lux S, Baldauf-Sommerbauer G, Siebenhofer M (2018) Hydrogenation of inorganic metal carbonates: a review on its potential for carbon dioxide utilization and emission reduction. ChemSusChem 11(19):3357-3375. ISSN 1864-5631. https://doi.org/10.1002/ cssc. 201801356

Ma S, Chen G, Zhu S, Wen J, Gao R, Ma L, Chai J (2016) Experimental study of mixed additive of $\mathrm{Ni}(\mathrm{II})$ and piperazine on ammonia escape in $\mathrm{CO} 2$ capture using ammonia solution. Appl Energy 169:597-606. ISSN 0306-2619. https://doi.org/10.1016/j.apene rgy.2016.02.070

Mahapatra K, Ramteke DS, Paliwal LJ (2012) Production of activated carbon from sludge of food processing industry under controlled pyrolysis and its application for methylene blue removal. J Anal Appl Pyrol 95:79-86. ISSN 0165-2370. https://doi.org/10.1016/j. jaap.2012.01.009

Malik A, Lenzen M, Ralph PJ, Tamburic B (2015) Hybrid life-cycle assessment of algal biofuel production. Bioresour Technol 184:436-443. https://doi.org/10.1016/j.biortech.2014.10.132

Martinez MJ, Hesse MA (2016) Two-phase convective CO2 dissolution in saline aquifers. Water Resour Res 52(1):585-599. ISSN 0043-1397. https://doi.org/10.1002/2015WR017085

Masel R, Liu Z, Zhao D, Chen Q, Lutz D, Nereng L (2016) CO2 conversion to chemicals with emphasis on using renewable energy/resources to drive the conversion. In: RSC green chemistry, vol 2016, Royal Society of Chemistry, pp 215-257. ISBN 9781782620396. https://doi.org/10.1039/9781782622444-00215

Mason JA, McDonald TM, Bae TH, Bachman JE, Sumida K, Dutton JJ, Kaye SS, Long JR (2015) Application of a high-throughput analyzer in evaluating solid adsorbents for post-combustion carbon capture via multicomponent adsorption of $\mathrm{CO} 2$, N2, and $\mathrm{H} 2 \mathrm{O}$. J Am Chem Soc 137(14):4787-4803. ISSN 0002-7863. https:// doi.org/10.1021/jacs.5b00838

McDonald JL, Sykora RE, Hixon P, Mirjafari A, Davis JH (2014) Impact of water on co2 capture by amino acid ionic liquids. Environ Chem Lett 12(1):201-208

Mekonnen TH, Mussone PG, Choi P, Bressler DC (2014) Adhesives from waste protein biomass for oriented strand board composites: development and performance. Macromol Mater Eng 299(8):1003-1012. https://doi.org/10.1002/mame.201300402

Meng LY, Park SJ (2012) Effect of exfoliation temperature on carbon dioxide capture of graphene nanoplates. J Colloid Interface Sci 386(1):285-290. ISSN 0021-9797. https://doi.org/10.1016/j. jcis.2012.07.025

Michael K, Golab A, Shulakova V, Ennis-King J, Allinson G, Sharma $\mathrm{S}$, Aiken T (2010) Geological storage of CO2 in saline aquifersa review of the experience from existing storage operations. Int $\mathrm{J}$ Greenh Gas Control 4(4):659-667. ISSN 17505836. https://doi. org/10.1016/j.ijggc.2009.12.011

Millward AR, Yaghi OM (2005) Metal-organic frameworks with exceptionally high capacity for storage of carbon dioxide at room temperature. J Am Chem Soc 127(51):17998-17999. ISSN 00027863. https://doi.org/10.1021/ja0570032

Minju N, Nair BN, Peer Mohamed A, Ananthakumar S (2017) Surface engineered silica mesospheres-a promising adsorbent for $\mathrm{CO} 2$ capture. Sep Purif Technol 181:192-200. ISSN 1383-5866. https ://doi.org/10.1016/j.seppur.2017.03.038

Miranda-Barbosa E, Sigfússon B, Carlsson J, Tzimas E (2017) Advantages from combining CCS with geothermal energy. Energy Procedia 114:6666-6676. ISSN 1876-6102. https://doi. org/10.1016/j.egypro.2017.03.1794

Mishra AK, Ramaprabhu s (2012) Nanostructured polyaniline decorated graphene sheets for reversible $\mathrm{CO} 2$ capture. J Mater Chem 22(9):3708-3712. ISSN 0959-9428. https://doi.org/10.1039/ C2JM15385H

Mishra AK, Ramaprabhu S (2014) Enhanced CO2 capture in Fe3O4-graphene nanocomposite by physicochemical adsorption. J Appl Phys 116(6):64306. ISSN 0021-8979. https://doi. org/10.1063/1.4892458

Mo L, Zhang F, Deng M (2015) Effects of carbonation treatment on the properties of hydrated fly ash-MgO-Portland cement blends. Constr Build Mater 96:147-154. https://doi.org/10.1016/j.conbu ildmat.2015.07.193

Molino A, Chianese S, Musmarra D (2016) Biomass gasification technology: the state of the art overview. J Energy Chem 25(1):10 25. https://doi.org/10.1016/j.jechem.2015.11.005

Mondal U, Yadav GD (2019) Perspective of dimethyl ether as fuel: part I. Catalysis. J CO2 Util 32:299-320. 10.1016/j.jcou.2019.02.003

Morad MM, El-Maghawry HAMM, Wasfy KI (2017) A developed solar-powered desalination system for enhancing fresh water productivity. Solar Energy 146:20-29. https://doi.org/10.1016/j. solener.2017.02.002

Muller N, Qi R, Mackie E, Pruess K, Blunt MJ (2009) CO2 injection impairment due to halite precipitation. In: Energy procedia, vol 1, Elsevier, pp 3507-3514. https://doi.org/10.1016/j.egypr o.2009.02.143

Murcia Valderrama MA, van Putten RJ, Gruter GJM (2019) The potential of oxalic-and glycolic acid based polyesters (review). Towards $\mathrm{CO} 2$ as a feedstock (carbon capture and utilizationCCU). Eur Polym J 119:445-468. https://doi.org/10.1016/j.eurpo lymj.2019.07.036

Nakamura T, Senior CL (2005) Recovery and sequestration of CO2 from stationary combustion systems by photosynthesis of microalgae. Technical report

Nasri NS, Hamza UD, Ismail SN, Ahmed MM, Mohsin R (2014) Assessment of porous carbons derived from sustainable palm solid waste for carbon dioxide capture. J Clean Prod 71:148-157. ISSN 0959-6526. https://doi.org/10.1016/j.jclepro.2013.11.053

Nazlina Mohd Yasin H, Maeda T, Hu A, Cp Yu, Wood TK (2015) CO2 sequestration by methanogens in activated sludge for methane production. Appl Energy 142:426-434. https://doi.org/10.1016/j. apenergy.2014.12.069

NETL (2015) Carbon storage atlas, 5th edn. Technical report, National Energy Technology Laboratory

Niven RK (2005) Ethanol in gasoline: environmental impacts and sustainability review article. Renew Sustain Energy Rev 9(6):535555. https://doi.org/10.1016/j.rser.2004.06.003

Ochedi FO, Yu J, Yu H, Liu Y, Hussain A (2020) Carbon dioxide capture using liquid absorption methods: a review. Environ Chem Lett 2020:1-33

Olah GA, Goeppert A, Surya Prakash GK (2009) Chemical recycling of carbon dioxide to methanol and dimethyl ether: from greenhouse gas to renewable, environmentally carbon neutral fuels and synthetic hydrocarbons. J Organ Chem 74(2):487-498. https:// doi.org/10.1021/jo801260f

Omoregbe O, Mustapha AN, Steinberger-Wilckens R, El-Kharouf A, Onyeaka H (2020) Carbon capture technologies for climate 
change mitigation: a bibliometric analysis of the scientific discourse during 1998-2018. Energy Rep 6:1200-1212. ISSN 23524847. https://doi.org/10.1016/j.egyr.2020.05.003

Osman AI, Abu-Dahrieh JK, Laffir F, Curtin T, Thompson JM, Rooney DW (2016) A bimetallic catalyst on a dual component support for low temperature total methane oxidation. Appl Catal B Environ 187:408-418. ISSN 0926-3373. https://doi.org/10.1016/j.apcat b.2016.01.017

Osman AI, Abu-Dahrieh JK, Cherkasov N, Fernandez-Garcia J, Walker D, Walton RI, Rooney DW, Rebrov E (2018a) A highly active and synergistic $\mathrm{Pt} / \mathrm{Mo} 2 \mathrm{C} / \mathrm{Al} 2 \mathrm{O} 3$ catalyst for water-gas shift reaction. Mol Catal 455:38-47. ISSN 2468-8231. https://doi. org/10.1016/j.mcat.2018.05.025

Osman AI, Abu-Dahrieh JK, McLaren M, Laffir E, Rooney DW (2018b) Characterisation of robust combustion catalyst from aluminium foil waste. ChemistrySelect 3(5):1545-1550. ISSN 2365-6549. https://doi.org/10.1002/slct.201702660

Osman AI, Blewitt J, Abu-Dahrieh JK, Farrell C, Al-Muhtaseb AH, Harrison J, Rooney DW (2019) Production and characterisation of activated carbon and carbon nanotubes from potato peel waste and their application in heavy metal removal. Environ Sci Pollut Res 26(36):37228-37241. ISSN 16147499. https://doi. org/10.1007/s11356-019-06594-w

Osman AI, Deka TJ, Baruah DC, Rooney DW (2020a) Critical challenges in biohydrogen production processes from the organic feedstocks. Biomass Convers Biorefinery. ISSN 2190-6823. https ://doi.org/10.1007/s13399-020-00965-x

Osman AI, Farrell C, Al-Muhtaseb AH, Harrison J, Rooney DW (2020b) The production and application of carbon nanomaterials from high alkali silicate herbaceous biomass. Sci Rep 10(1):2563. ISSN 20452322. https://doi.org/10.1038/s4159 8-020-59481-7

Osman AI, O'Connor E, McSpadden G, Abu-Dahrieh JK, Farrell C, Al-Muhtaseb AH, Harrison J, Rooney DW (2020c) Upcycling brewer's spent grain waste into activated carbon and carbon nanotubes for energy and other applications via two-stage activation. J Chem Technol Biotechnol 95(1):183-195. ISSN 02682575. https://doi.org/10.1002/jctb.6220

Otto A, Grube T, Schiebahn S, Stolten D (2015) Closing the loop: aptured $\mathrm{CO} 2$ as a feedstock in the chemical industry. Energy Environ Sci 8(11):3283-3297. ISSN 17545706. https://doi. org/10.1039/c5ee02591e

Park M, Sub Kwak B, Jo SW, Kang M (2015) Effective CH4 production from $\mathrm{CO} 2$ photoreduction using $\mathrm{TiO} 2 / \mathrm{xmol} \% \mathrm{Cu}-\mathrm{TiO} 2$ doublelayered films. Energy Convers Manag 103:431-438. https://doi. org/10.1016/j.enconman.2015.06.029

Park J, Lim Suh B, Kim J (2020) Computational design of a photoresponsive metal-organic framework for post combustion carbon capture. J Phys Chem C 124(24):13162-13167. ISSN 1932-7447. https://doi.org/10.1021/acs.jpcc.0c01878

Parvez AM, Mujtaba IM, Wu T (2016) Energy, exergy and environmental analyses of conventional, steam and $\mathrm{CO} 2$-enhanced rice straw gasification. Energy 94:579-588. https://doi.org/10.1016/j. energy.2015.11.022

Pfister M, Belaissaoui B, Favre E (2017) Membrane gas separation processes from wet postcombustion flue gases for carbon capture and use: a critical reassessment. Ind Eng Chem Res 56(2):591602. ISSN 0888-5885. https://doi.org/10.1021/acs.iecr.6b03969

Piermartini P, Boeltken T, Selinsek M, Pfeifer P (2017) Influence of channel geometry on Fischer-Tropsch synthesis in microstructured reactors. Chem Eng J 313:328-335. https://doi. org/10.1016/j.cej.2016.12.076

Pietzcker RC, Longden T, Chen W, Fu S, Kriegler E, Kyle P, Luderer $\mathrm{G}$ (2014) Long-term transport energy demand and climate policy. Energy 64:95-108. https://doi.org/10.1016/j.energy.2013.08.059
Pinto F, André R, Miranda M, Neves D, Varela F, Santos J (2016) Effect of gasification agent on co-gasification of rice production wastes mixtures. Fuel 180:407-416. https://doi.org/10.1016/j. fuel.2016.04.048

Plaza MG, González AS, Pevida C, Pis JJ, Rubiera F (2012) Valorisation of spent coffee grounds as $\mathrm{CO} 2$ adsorbents for postcombustion capture applications. Appl Energy 99:272-279. ISSN 03062619. https://doi.org/10.1016/j.apenergy.2012.05.028

Poliakoff M, Leitner W, Streng ES (2015) The twelve principles of CO2 chemistry. Faraday Discuss 183(0):9-17. ISSN 13645498. https ://doi.org/10.1039/c5fd90078f

Portillo E, Alonso-Fari nas B, Vega F, Cano M, Navarrete B (2019) Alternatives for oxygen-selective membrane systems and their integration into the oxy-fuel combustion process: a review. Sep Purif Technol 229:115708. ISSN 1383-5866. https://doi. org/10.1016/j.seppur.2019.115708

Pourebrahimi S, Kazemeini M, Babakhani EG, Taheri A (2015) Removal of the $\mathrm{CO} 2$ from flue gas utilizing hybrid composite adsorbent MIL-53(Al)/GNP metal-organic framework. Microporous Mesoporous Mate 218:144-152. ISSN 1387-1811. https:// doi.org/10.1016/j.micromeso.2015.07.013

Pour N, Webley PA, Cook PJ (2017) A sustainability framework for bioenergy with carbon capture and storage (BECCS) technologies. Energy Procedia 114:6044-6056. ISSN 1876-6102. https ://doi.org/10.1016/j.egypro.2017.03.1741

Pour N, Webley PA, Cook PJ (2018) Potential for using municipal solid waste as a resource for bioenergy with carbon capture and storage (BECCS). Int J Greenh Gas Control 68:1-15. ISSN 1750-5836. https://doi.org/10.1016/j.ijggc.2017.11.007

Prasetya N, Himma NF, Sutrisna PD, Wenten IG, Ladewig BP (2019) A review on emerging organic-containing microporous material membranes for carbon capture and separation. Chem Eng J. ISSN 1385-8947

Prashantha Kumar HG, Xavior MA (2014) Graphene reinforced metal matrix composite (GRMMC): a review. Procedia Eng 97:1033-1040. ISSN 1877-7058. https://doi.org/10.1016/j.proen g.2014.12.381

Puligundla P, Jung J, Ko S (2012) Carbon dioxide sensors for intelligent food packaging applications. Food Control 25(1):328-333. https://doi.org/10.1016/j.foodcont.2011.10.043

Qazvini OT, Telfer SG (2020) A robust metal-organic framework for post-combustion carbon dioxide capture. J Mater Chem A 8(24):12028-12034. ISSN 2050-7488. https://doi.org/10.1039/ D0TA04121A

Qin C, Yin J, Ran J, Zhang L, Feng B (2014) Effect of support material on the performance of $\mathrm{K} 2 \mathrm{CO} 3$-based pellets for cyclic $\mathrm{CO} 2$ capture. Appl Energy 136:280-288. ISSN 0306-2619. https:// doi.org/10.1016/j.apenergy.2014.09.043

Quadrelli EA, Centi G, Duplan JL, Perathoner S (2011) Carbon dioxide recycling: emerging large-scale technologies with industrial potential. ChemSusChem 4(9):1194-1215. https://doi. org/10.1002/cssc. 201100473

Rafiee A, Khalilpour KR, Milani D, Panahi M (2018) Trends in CO2 conversion and utilization: a review from process systems perspective. J Environ Chem Eng 6(5):5771-5794. https://doi. org/10.1016/j.jece.2018.08.065

Randolph JB, Saar MO (2011) Combining geothermal energy capture with geologic carbon dioxide sequestration. Geophys Res Lett 38(10):L10401. ISSN 00948276. https://doi.org/10.1029/2011G L047265

Rashidi NA, Yusup S, Borhan A, Loong LH (2014) Experimental and modelling studies of carbon dioxide adsorption by porous biomass derived activated carbon. Clean Technol Environ Policy 16(7):1353-1361. ISSN 1618-9558. https://doi.org/10.1007/ s10098-014-0788-6 
Rezaei E, Catalan LJJ (2010) Evaluation of CO2 utilization for methanol production via tri-reforming of methane. J CO2 Util 42:101272. 10.1016/j.jcou.2020.101272

Rochelle GT (2009) Amine scrubbing for $\mathrm{CO}_{2}$ capture. Science 325(5948):1652-1654. https://doi.org/10.1126/science.1176731

Román S, González JF, González-García CM, Zamora F (2008) Control of pore development during $\mathrm{CO} 2$ and steam activation of olive stones. Fuel Process Technol 89(8):715-720. ISSN 03783820. https://doi.org/10.1016/j.fuproc.2007.12.015

Russo ME, Olivieri G, Marzocchella A, Salatino P, Caramuscio P, Cavaleiro C (2013) Post-combustion carbon capture mediated by carbonic anhydrase. Sep Purif Technol 107:331-339. ISSN 1383-5866. https://doi.org/10.1016/j.seppur.2012.06.022

Salvi AP, Vaidya PD, Kenig EY (2014) Kinetics of carbon dioxide removal by ethylenediamine and diethylenetriamine in aqueous solutions. Can J Chem Eng 92(12):2021-2028. ISSN 0008-4034. https://doi.org/10.1002/cjce.22064

Santamaría M, Azqueta D (2015) Promoting biofuels use in Spain: a cost-benefit analysis. Renew Sustain Energy Rev 50:1415-1424. https://doi.org/10.1016/j.rser.2015.04.192

Sanz-Pérez ES, Arencibia A, Sanz R, Calleja G (2015) An investigation of the textural properties of mesostructured silicabased adsorbents for predicting $\mathrm{CO} 2$ adsorption capacity. RSC Adv 5(125):103147-103154. ISSN 2046-2069. https://doi. org/10.1039/C5RA19105J

Sanz-Pérez ES, Arencibia A, Calleja G, Sanz R (2018) Tuning the textural properties of HMS mesoporous silica. Functionalization towards $\mathrm{CO} 2$ adsorption. Microporous Mesoporous Mater 260:235-244. ISSN 1387-1811. https://doi.org/10.1016/j.micro meso.2017.10.038

Saravanan K, Ham H, Tsubaki N, Bae JW (2017) Recent progress for direct synthesis of dimethyl ether from syngas on the heterogeneous bifunctional hybrid catalysts. Appl Catal B Environ 217:494-522. https://doi.org/10.1016/j.apcatb.2017.05.085

Schlissel D (2018) Holy Grail of carbon capture continues to elude coal industry. Technical report

Scrivener KL, Kirkpatrick RJ (2008) Innovation in use and research on cementitious material. Cem Concr Res 38(2):128-136. https ://doi.org/10.1016/j.cemconres.2007.09.025

Selley RC, Sonnenberg SA (2015) Sedimentary basins and petroleum systems. In: Elements of petroleum geology, Elsevier, pp 377 426. https://doi.org/10.1016/b978-0-12-386031-6.00008-4

Semelsberger TA, Borup RL, Greene HL (2006) Dimethyl ether (DME) as an alternative fuel. J Power Sour 156(2):497-511. https://doi. org/10.1016/j.jpowsour.2005.05.082

Sevilla M, Fuertes AB (2011) Sustainable porous carbons with a superior performance for CO2 capture. Energy Environ Sci 4(5):1765-1771. ISSN 1754-5692. https://doi.org/10.1039/ COEE00784F

Sevilla M, Falco C, Titirici MM, Fuertes AB (2012) High-performance $\mathrm{CO} 2$ sorbents from algae. RSC Adv 2(33):12792-12797. ISSN 2046-2069. https://doi.org/10.1039/C2RA22552B

Shin D, Kang S (2018) Numerical analysis of an ion transport membrane system for oxy-fuel combustion. Appl Energy 230:875-888. ISSN 0306-2619. https://doi.org/10.1016/j.apene rgy.2018.09.016

Shi B, Wu E, Wu W, Kuo PC (2018) Multi-objective optimization and exergoeconomic assessment of a new chemical-looping air separation system. Energy Convers Manag 157:575-586. ISSN 0196-8904. https://doi.org/10.1016/j.enconman.2017.12.030

Singh A, Olsen SI (2011) A critical review of biochemical conversion, sustainability and life cycle assessment of algal biofuels. Appl Energy 88(10):3548-3555. https://doi.org/10.1016/j.apene rgy.2010.12.012
Singh A, Stéphenne K (2014) Shell cansolv co2 capture technology: achievement from first commercial plant. Energy Procedia 63:1678-1685

Singh G, Syafiqah Ismail I, Bilen C, Shanbhag D, Sathish CI, Ramadass K, Vinu A (2019) A facile synthesis of activated porous carbon spheres from d-glucose using a non-corrosive activating agent for efficient carbon dioxide capture. Appl Energy 255:113831. . ISSN 0306-2619. https://doi.org/10.1016/j.apene rgy.2019.113831

Singh G, Lee J, Karakoti A, Bahadur R, Yi J, Zhao D, AlBahily K, Vinu A (2020) Emerging trends in porous materials for CO2 capture and conversion. Chem Soc Rev 49(13):4360-4404. ISSN 0306-0012. https://doi.org/10.1039/D0CS00075B

Song CF, Kitamura Y, Li SH (2012) Evaluation of Stirling cooler system for cryogenic CO2 capture. Appl Energy 98:491-501. ISSN 0306-2619. https://doi.org/10.1016/j.apenergy.2012.04.013

Song Z, Dong Q, Xu WL, Zhou F, Liang X, Yu M (2018) Molecular layer deposition-modified $5 \mathrm{~A}$ zeolite for highly efficient $\mathrm{CO} 2$ capture. ACS Appl Mater Interfaces 10(1):769-775. ISSN 19448244. https://doi.org/10.1021/acsami.7b16574

Song C, Liu Q, Qi Y, Chen G, Song Y, Kansha Y, Kitamura Y (2019a) Absorption-microalgae hybrid CO2 capture and biotransformation strategy-a review. Int J Greenh Gas Control 88:109-117. ISSN 1750-5836. https://doi.org/10.1016/j.ijggc.2019.06.002

Song C, Liu J, Qiu Y, Xie M, Sun J, Qi Y, Li S, Kitamura Y (2019b) Bio-regeneration of different rich $\mathrm{CO} 2$ absorption solvent via microalgae cultivation. Bioresour Technol 290:121781. ISSN 0960-8524. https://doi.org/10.1016/j.biortech.2019.121781

Span R, Wagner W (1996) A new equation of state for carbon dioxide covering the fluid region from the triple-point temperature to $1100 \mathrm{~K}$ at pressures up to $800 \mathrm{MPa}$. J Phys Chem Ref Data 25(6):1509-1596. ISSN 0047-2689. https://doi. org/10.1063/1.555991

Sreedhar I, Nahar T, Venugopal A, Srinivas B (2017a) Carbon capture by absorption-path covered and ahead. Renew Sustain Energy Rev 76:1080-1107. ISSN 1364-0321. https://doi.org/10.1016/j. rser.2017.03.109

Sreedhar I, Vaidhiswaran R, Kamani BM, Venugopal A (2017b) Process and engineering trends in membrane based carbon capture. Renew Sustain Energy Rev 68:659-684. ISSN 1364-0321. https ://doi.org/10.1016/j.rser.2016.10.025

Srivastava D, Wei C, Cho K (2003) Nanomechanics of carbon nanotubes and composites. Appl Mech Rev 56(2):215-230. ISSN 0003-6900

Srivastava RK, Shetti NP, Reddy KR, Aminabhavi TM (2020) Biofuels, biodiesel and biohydrogen production using bioprocesses: a review. Environ Chem Lett 2020:1-24

Stanly S, Jelmy EJ, Nair CPR, John H (2019) Carbon dioxide adsorption studies on modified montmorillonite clay/reduced graphene oxide hybrids at low pressure. J Environ Chem Eng 7(5):103344. ISSN 2213-3437. https://doi.org/10.1016/j.jece.2019.103344

Stéphenne K (2014) Start-up of world's first commercial post-combustion coal fired CCS project: contribution of shell Cansolv to SaskPower boundary dam ICCS project. Energy Procedia 63:6106-6110. ISSN 1876-6102. https://doi.org/10.1016/j.egypr o.2014.11.642

Strömberg L, Lindgren G, Jacoby J, Giering R, Anheden M, Burchhardt U, Altmann H, Kluger F, Stamatelopoulos GN (2009) Update on Vattenfall's 30 MWth oxyfuel pilot plant in Schwarze Pumpe. Energy Procedia 1(1):581-589. ISSN 1876-6102. https://doi. org/10.1016/j.egypro.2009.01.077

Su F, Lu C, Chen HS (2011) Adsorption, desorption, and thermodynamic studies of $\mathrm{CO} 2$ with high-amine-loaded multiwalled carbon nanotubes. Langmuir 27(13):8090-8098. ISSN 0743-7463. https://doi.org/10.1021/la201745y 
Sun H, Wang Y, Xu S, Osman AI, Stenning G, Han J, Sun S, Rooney D, Williams PT, Wang F, Wu C (2020) Understanding the interaction between active sites and sorbents during the integrated carbon capture and utilization process. Fuel 286:119308. ISSN 0016-2361. https://doi.org/10.1016/j.fuel.2020.119308

Tarkowski R, Uliasz-Misiak B (2019) Prospects for the use of carbon dioxide in enhanced geothermal systems in Poland. J Clean Prod 229:1189-1197. ISSN 0959-6526. https://doi.org/10.1016/j.jclep ro.2019.05.036

Tavakkoli S, Lokare OR, Vidic RD, Khanna V (2017) A technoeconomic assessment of membrane distillation for treatment of Marcellus shale produced water. Desalination 416:24-34. https ://doi.org/10.1016/j.desal.2017.04.014

Theo WL, Shiun Lim J, Hashim H, Mustaffa AA Ho WS (2016) Review of pre-combustion capture and ionic liquid in carbon capture and storage. Appl Energy 183:1633-1663. ISSN 03062619. https://doi.org/10.1016/j.apenergy.2016.09.103

Troschl C, Meixner K, Fritz I, Leitner K, Ap Romero, Kovalcik A, Sedlacek P, Drosg B (2018) Pilot-scale production of poly- $\beta$ -hydroxybutyrate with the cyanobacterium Synechocytis sp. CCALA192 in a non-sterile tubular photobioreactor. Algal Res 34:116-125. https://doi.org/10.1016/j.algal.2018.07.011

Tu Z, Guo M, Sun Poon S, Shi C (2016) Effects of limestone powder on $\mathrm{CaCO} 3$ precipitation in $\mathrm{CO} 2$ cured cement pastes. Cem Concr Compos 72:9-16. https://doi.org/10.1016/j.cemconcomp .2016.05.019

Tuteja A, Choi W, Ma M, Mabry JM, Mazzella SA, Rutledge GC, McKinley GH, Cohen RE (2007) Designing superoleophobic surfaces. Science 318(5856):1618-1622. ISSN 0036-8075. https ://doi.org/10.1126/science.1148326

US USGS (2001) Geological survey world petroleum assessment 2000-description and results, dds-60. United States Geological Survey 2001

Vafajoo L, Afshar SHA, Firouzbakht B (2009) Developing a mathematical model for the complete kinetic cycle of direct synthesis of DME from Syngas through the CFD technique

Vakharia V, Salim W, Wu D, Han Y, Chen Y, Zhao L, Winston Ho WS (2018) Scale-up of amine-containing thin-film composite membranes for CO2 capture from flue gas. J Membr Sci 555:379-387. ISSN 0376-7388. https://doi.org/10.1016/j.memsci.2018.03.074

van der Meer LGH (1995) The $\mathrm{CO}_{2}$ storage efficiency of aquifers. Energy Convers Manag 36(6-9):513-518. ISSN 01968904. https ://doi.org/10.1016/0196-8904(95)00056-J

van der Zwaan B, Smekens K (2009) CO2 Capture and storage with leakage in an energy-climate model. Environ Model Assess 14(2):135-148. ISSN 1573-2967. https://doi.org/10.1007/s1066 6-007-9125-3

Varghese AM, Suresh Kumar Reddy K, Singh S, Karanikolos GN (2020) Performance enhancement of CO2 capture adsorbents by UV treatment: the case of self-supported graphene oxide foam. Chem Eng J 386:124022. ISSN 1385-8947. https://doi. org/10.1016/j.cej.2020.124022

Vega F, Baena-Moreno VM, Gallego Fernández LM, Portillo E, Navarrete B, Zhang Z (2020) Current status of CO2 chemical absorption research applied to CCS: towards full deployment at industrial scale. Appl Energy 260:114313. ISSN 0306-2619. https:// doi.org/10.1016/j.apenergy.2019.114313

Wang J, Zhang X, Zhou Y (2011a) Carbon dioxide capture under ambient conditions using 2-chloroethylamine. Environ Chem Lett 9(4):535-537

Wang Y, Guan C, Wang K, Xian Guo C, Li CM (2011b) Nitrogen, hydrogen, carbon dioxide, and water vapor sorption properties of three-dimensional graphene. J Chem Eng Data 56(3):642-645. ISSN 0021-9568. https://doi.org/10.1021/je100840n

Wang Q, Li K, Guo Z, Fang M, Luo Z, Cen K (2018) Effects of $\mathrm{CO} 2$ atmosphere on slow pyrolysis of high-ash lignite. Carbon
Resour Convers 1(1):94-103. https://doi.org/10.1016/j.crcon .2018.04.002

Wang P, Sun J, Guo Y, Zhao C, Li W, Wang G, Lei S, Lu P (2019) Structurally improved, urea-templated, K2CO3-based sorbent pellets for CO2 capture. Chem Eng J 374:20-28. ISSN 13858947. https://doi.org/10.1016/j.cej.2019.05.091

Wang Y, Jia H, Chen P, Fang X, Du T (2020a) Synthesis of La and Ce modified $\mathrm{X}$ zeolite from rice husk ash for carbon dioxide capture. J Mater Res Technol 9(3):4368-4378. ISSN 2238-7854. https:// doi.org/10.1016/j.jmrt.2020.02.061

Wang R, Jiang L, Li Q, Gao G, Zhang S, Wang L (2020b) Energysaving $\mathrm{CO} 2$ capture using sulfolane-regulated biphasic solvent. Energy 211:118667. ISSN 0360-5442. https://doi.org/10.1016/j. energy.2020.118667

Wang Y, Wang H, Zhang TC, Yuan S, Liang B (2020c) N-doped porous carbon derived from rGO-incorporated polyphenylenediamine composites for $\mathrm{CO} 2$ adsorption and supercapacitors. J Power Sour 472:228610. ISSN 0378-7753. https://doi.org/10.1016/j. jpowsour.2020.228610

Wannakao S, Artrith N, Limtrakul J, Kolpak AM (2015) Engineering transition-metal-coated tungsten carbides for efficient and selective electrochemical reduction of $\mathrm{CO} 2$ to methane. ChemSusChem 8(16):2745-2751. https://doi.org/10.1002/cssc.20150 0245

Weber K, Quicker P (2018) Properties of biochar. Fuel 217:240-261. https://doi.org/10.1016/j.fuel.2017.12.054

Wei H, Deng S, Hu B, Chen Z, Wang B, Huang J, Yu G (2012) Granular bamboo-derived activated carbon for high $\mathrm{CO} 2$ adsorption: the dominant role of narrow micropores. ChemSusChem 5(12):2354-2360. ISSN 1864-5631. https://doi.org/10.1002/ cssc. 201200570

Wei W, Lin K-H, Chang J-S (2018) Economic and life-cycle greenhouse gas optimization of microalgae-to-biofuels chains. Bioresour Technol 267:550-559. https://doi.org/10.1016/j.biort ech.2018.07.083

Wei X, Manovic V, Hanak DP (2020) Techno-economic assessment of coal- or biomass-fired oxy-combustion power plants with supercritical carbon dioxide cycle. Energy Convers Manag 221:113143. ISSN 0196-8904. https://doi.org/10.1016/j.encon man.2020.113143

Wienchol P, Szlęk A, Ditaranto M (2020) Waste-to-energy technology integrated with carbon capture-challenges and opportunities. Energy 198:117352. ISSN 0360-5442. https://doi.org/10.1016/j. energy.2020.117352

Wright HMN, Cashman KV, Gottesfeld EH, Roberts JJ (2009) Pore structure of volcanic clasts: measurements of permeability and electrical conductivity. Earth Planet Sci Lett 280(1-4):93-104

Wu X, Wang M, Liao P, Shen J, Li Y (2020) Solvent-based postcombustion $\mathrm{CO} 2$ capture for power plants: a critical review and perspective on dynamic modelling, system identification, process control and flexible operation. Appl Energy 257:113941. ISSN 0306-2619. https://doi.org/10.1016/j.apenergy.2019.113941

Xu C, Hedin N (2014) Microporous adsorbents for CO2 capture-a case for microporous polymers? Mater Today 17(8):397-403. ISSN 1369-7021

Xu M, Chen S, Seo DK, Deng S (2019) Evaluation and optimization of VPSA processes with nanostructured zeolite NaX for postcombustion CO2 capture. Chem Eng J 371:693-705. ISSN 13858947. https://doi.org/10.1016/j.cej.2019.03.275

Yang Q, Li H, Wang D, Zhang X, Guo X, Pu S, Guo R, Chen J (2020) Utilization of chemical wastewater for $\mathrm{CO} 2$ emission reduction: purified terephthalic acid (PTA) wastewater-mediated culture of microalgae for CO2 bio-capture. Appl Energy 276:115502. ISSN 0306-2619. https://doi.org/10.1016/j.apenergy.2020.115502

Yan Q, Lin Y, Kong C, Chen L (2013) Remarkable CO2/CH4 selectivity and $\mathrm{CO} 2$ adsorption capacity exhibited by 
polyamine-decorated metal-organic framework adsorbents. Chem Commun 49(61):6873-6875. ISSN 1359-7345. https:// doi.org/10.1039/C3CC43352H

Ye J, Xiao J, Huo X, Gao Y, Hao J, Song M (2020) Effect of CO2 atmosphere on biomass pyrolysis and in-line catalytic reforming. Int J Energy Res 44(11):8936-8950. https://doi.org/10.1002/ er.5602

Yun S, Oh SY, Kim JK (2020) Techno-economic assessment of absorption-based $\mathrm{CO} 2$ capture process based on novel solvent for coalfired power plant. Appl Energy 268:114933. ISSN 0306-2619. https://doi.org/10.1016/j.apenergy.2020.114933

Zhan BJ, Poon CS, Shi CJ (2016) Materials characteristics affecting $\mathrm{CO} 2$ curing of concrete blocks containing recycled aggregates. Cem Concr Compos 67:50-59. https://doi.org/10.1016/j.cemco ncomp.2015.12.003

Zhang J, Singh R, Webley PA (2008) Alkali and alkaline-earth cation exchanged chabazite zeolites for adsorption based $\mathrm{CO} 2$ capture. Microporous Mesoporous Mater 111(1):478-487. ISSN 13871811. https://doi.org/10.1016/j.micromeso.2007.08.022

Zhang X, Fu K, Liang Z, Rongwong W, Yang Z, Idem R, Tontiwachwuthikul P (2014) Experimental studies of regeneration heat duty for $\mathrm{CO} 2$ desorption from diethylenetriamine (DETA) solution in a stripper column packed with Dixon ring random packing. Fuel 136:261-267. ISSN 0016-2361. https://doi.org/10.1016/j. fuel.2014.07.057

Zhang H, Liu R, Lal R (2016) Optimal sequestration of carbon dioxide and phosphorus in soils by gypsum amendment. Environ Chem Lett 14(4):443-448

Zhang N, Pan Z, Zhang Z, Zhang W, Zhang L, Baena-Moreno LM, Lichtfouse E (2020a) Co2 capture from coalbed methane using membranes: a review. Environ Chem Lett 2020:1-18

Zhang Z, Wang T, Blunt MJ, Anthony EJ, Park AHA, Hughes RW, Webley PA, Yan J (2020b) Advances in carbon capture, utilization and storage. Appl Energy 278:115627. ISSN 0306-2619. https://doi.org/10.1016/j.apenergy.2020.115627

Zhao G, Aziz B, Hedin N (2010) Carbon dioxide adsorption on mesoporous silica surfaces containing amine-like motifs. Appl Energy 87(9):2907-2913. ISSN 0306-2619. https://doi. org/10.1016/j.apenergy.2009.06.008
Zhao B, Su Y (2014) Process effect of microalgal-carbon dioxide fixation and biomass production: a review. Renew Sustain Energy Rev 31:121-132. ISSN 1364-0321. https://doi.org/10.1016/j. rser.2013.11.054

Zheng B, Yun R, Bai J, Lu Z, Du L, Li Y (2013) Expanded porous MOF-505 analogue exhibiting large hydrogen storage capacity and selective carbon dioxide adsorption. Inorgan Chem 52(6):2823-2829. ISSN 0020-1669. https://doi.org/10.1021/ ic301598n

Zhou Y, Tol RSJ (2005) Evaluating the costs of desalination and water transport. Water Resour Res. https://doi.org/10.1029/2004W R003749

Zhou D, Liu Q, Cheng QY, Zhao YC, Cui Y, Wang T, Han BH (2012) Graphene-manganese oxide hybrid porous material and its application in carbon dioxide adsorption. Chin Sci Bull 57(23):3059-3064. ISSN 1861-9541. https://doi.org/10.1007/ s11434-012-5158-3

Zhou Y, Wang J, Chen P, Ji C, Kang Q, Lu B, Li K, Liu J, Ruan R (2017) Bio-mitigation of carbon dioxide using microalgal systems: advances and perspectives. Renew Sustain Energy Rev 76:1163-1175. ISSN 1364-0321. https://doi.org/10.1016/j. rser.2017.03.065

Zhou DD, Zhang XW, Mo ZW, Xu YZ, Tian XY, Li Y, Chen XM, Zhang ZP (2019) Adsorptive separation of carbon dioxide: from conventional porous materials to metal-organic frameworks. EnergyChem 1(3):100016. ISSN 2589-7780. https://doi. org/10.1016/j.enchem.2019.100016

Zhou T, Shi H, Ding X, Zhou Y (2021) Thermodynamic modeling and rational design of ionic liquids for pre-combustion carbon capture. Chem Eng Sci 229:116076. ISSN 0009-2509. https:// doi.org/10.1016/j.ces.2020.116076

Zoback MD, Byerlee JD (1976) Effect of high-pressure deformation on permeability of Ottawa sand. AAPG Bull 60(9):1531-1542

Publisher's Note Springer Nature remains neutral with regard to jurisdictional claims in published maps and institutional affiliations. 